\title{
Im Angesicht der Endzeit? Positionen in den Lectiones memorabiles des Johannes Wolff (1600)
}

\author{
Sabine Schmolinsky
}

\begin{abstract}
Als der ehemals pfälzische Rat und nun badische Amtmann, der Iurisconsultus Johannes Wolff die Vorworte zu den beiden voluminösen Bänden seines Lebenswerks, den Lectiones memorabiles, am 1. Februar 1600 abschloss, ${ }^{1}$ hatte nicht nur für ihn als lutherischen Protestanten das letzte Jahr eines an grundlegenden Umwälzungen und Befürchtungen reichen Jahrhunderts begonnen, das er allerdings nur noch bis zu seinem Tod am 23. Mai 1600 miterleben sollte. $^{2}$ Seine Lebenswelt musste ihm seit den 1570 er Jahren vermehrt von
\end{abstract}

1 IOHAN. VVOLFII I. C. \| LECTIONVM MEMO- \| RABILIVM ET RECONDITARVM \|| CENTENARII XVI. \| HABET HIC LECTOR DOCTORVM ECCLE- || siæ, Vatum, Politicorum, Philosophorum, Historicorum, aliorumq; || sapientum \& eruditorum pia, grauia, mira, arcana, \& stupenda; iucun- $\|$ da simul \& vtilia, dicta, scripta, atq; facta; Vaticinia item, vota, omina, \| mysteria, Hieroglyphica, miracula, visiones, antiquitates, monu- $\|$ menta, testimonia, exempla virtutu[m], vitiorum, abusuum; \| typos insuper, picturas, atq; imagines: \| SED ET IPSIVS COELI AC NATVRE HORRENDA SI- \| gna, Ostenta, Monstra, atq; Portenta: His interiuncti sunt quoq; || omnes sacri prophaniq; Ordines: || EX QVIBVS OMNIBVS CVM PRÆTERITI STA- \| tus in Ecclesia, Republica, \& communi vita consideratio; tum im- \| pendentium euentuum, ac in dies magis magisq; ingrauescentium $\|$ malorum præsagitio: sed \& multorum abstrusorum hactenus $\|$ desideratorum reuelatio ob oculos per- $\|$ spicuè ponitur. || Lauinge sumtibus Autoris impressit Leonhardus Rheinmichel || Typogr. Palatinus, anno 1600. VD 16, W 4209-4211. Ein zweiter Druck erschien 1671 bei Henning Grosses Erben in Frankfurt am Main; vgl. VD 17, 23:230241R und 23:230244P (wiederholt 1672; vgl. VD 17, 23:230226R). Vgl. hierzu und zum Index des Johannes Jacobus Linsius gen. Hagendorn von 1608 (wiederholt 1672) S. Schmolinsky, Prophetia in der Bibliothek - die Lectiones memorabiles des Johannes Wolff, in: Zukunftsvoraussagen in der Renaissance, hg. von K. Bergdolt/W. Ludwig, unter Mitwirkung von D. Schäfer (Wolfenbütteler Abhandlungen zur Renaissance-Forschung, 23), Wiesbaden 2005, 89-130, hier 90 f., Anm. 5 mit S. 104, Anm. 47.

2 Zur Vita vgl. W. Ludwig, Vorfahren von Paul Ludwig ermittelt, zusammengestellt und mit einem Nachwort versehen von W. L. (Deutsches Familienarchiv. Ein genealogisches Sammelwerk, 116), Neustadt an der Aisch 1994, 84, Nr. 1522; Ders., Gaspar Bruschius als Historiograph deutscher Klöster und seine Rezeption (Nachrichten der Akademie der Wissenschaften in Göttingen. I. Philologisch-historische Klasse, Jg. 2002, Nr. 1), Göttingen 2002, 1-120, hier 82-83; Hessisches Geschlechterbuch, Bd. 14 (Deutsches Geschlechterbuch, 121), Glücksburg / Ostsee 1956, 483-490 mit 515-517; D. Groh, Lizentiat der Rechte Johannes Wolff. Ein Beitrag zur Biographie eines pfälzischen Diplomaten und Historiographen aus der zweiten Hälfte des 16. Jahrhunderts, Diss. 
Katastrophen, Seuchen, Hungersnöten geprägt erscheinen, ${ }^{3}$ die ihn allerdings persönlich wohl kaum betroffen haben dürften, denn er stand zu jener Zeit als Rat und Gesandter in fürstlichen Diensten, zunächst des lutherischen Herzogs Wolfgang von Zweibrücken-Neuburg (1526-1569), ${ }^{4}$ den er 1569 auf dessen

Frankfurt a. M. 1923, 1-8 und 133; basierend auf Gregor Rollwagen, PANEGYricvs, \| De vita et obitu \|I JOHANNIS WOLFII JC. \| DE TABERNIS MONTANIS: [...] Tubinge, Typis Cellianis. II Anno 1601. (VD 17, 547:626291E; vgl. Groh, ebd., 1, Anm. 2). Zu biographischen Artikeln des 17. und 18. Jahrhunderts über Wolff vgl. Schmolinsky (wie Anm. 1), 96, Anm. 22. Weitere Angaben zu Wolffs Leben und Arbeiten sowie den im Folgenden genannten Namen bei Schmolinsky (wie Anm. 1), 96104. Wolff selbst schrieb seinen Namen „Wolff“ (vgl. Groh, ebd., 1, Anm. 1).

3 Zum Überblick vgl. M. Lanzinner, Konfessionelles Zeitalter 1555-1618, in: Gebhardt. Handbuch der deutschen Geschichte, 10., völlig neu bearb. Aufl., hg. von W. Reinhard, X, Stuttgart 2001, 1-203, hier 126-131; W. Schulze, Deutsche Geschichte im 16. Jahrhundert. 1500-1618 (Neue Historische Bibliothek. edition suhrkamp, N. F., 268), Frankfurt a. M. 1987, hier 49-53, 294. Zu „Desintegrationserscheinungen im wirtschaftlichen, konfessionellen und politischen Bereich“ in der Zeit um 1600 vgl. Dens., Untertanenrevolten, Hexenverfolgungen und „kleine Eiszeit“: Eine Krisenzeit um 1600 ?, in: Venedig und Oberdeutschland in der Renaissance. Beziehungen zwischen Kunst und Wirtschaft, hg. von B. Roeck/K. Bergdolt/A.J. Martin (Studi. Schriftenreihe des Deutschen Studienzentrums in Venedig / Centro Tedesco di Studi Veneziani, 9), Sigmaringen 1993, 289-309 (Diskussion S. 314), Zitat S. 306. Zur Hungerkrise der frühen 1570er Jahre in Oberdeutschland vgl. auf breiter Quellengrundlage W. Behringer, Die Krise von 1570. Ein Beitrag zur Krisengeschichte der Neuzeit, in: Um Himmels Willen. Religion in Katastrophenzeiten, hg. von M. Jakubowski-Tiessen/H. Lehmann, Göttingen 2003, 51-156; dazu Ders., „Ettlich Hundert Herrlicher und Schöner Carmina oder gedicht/ von der langwirigen schweren gewesten Teurung/ grossen Hungersnot/ und allerlay zuvor unerhörten Grausamen Straffen/ und Plagen“. Zwei Krisengedichte, ebd., 294-355. Die Krisen von 1586/1587 und in den 1590er Jahren kamen der von 1571/1572 nahe (ebd., 147-148).

4 Vgl. J. Ney, Wolfgang, Pfalzgraf, Herzog von Zweibrücken und Neuburg, ADB 44 (1898) 76-87; B. Kurze, Pfalzgraf Wolfgang von Neuburg, in: Lebensbilder aus dem Bayerischen Schwaben, hg. von G. Freiherrn von Pölnitz, VI (Schwäbische Forschungsgemeinschaft bei der Kommission für bayerische Landesgeschichte. Veröffentlichungen Reihe 3, 6), München 1958, 292-322; F. Konersmann, Kirchenregiment und Kirchenzucht im frühneuzeitlichen Kleinstaat. Studien zu den herrschaftlichen und gesellschaftlichen Grundlagen des Kirchenregiments der Herzöge von Pfalz-Zweibrücken 1410-1793 (Veröffentlichungen des Vereins für Pfälzische Kirchengeschichte, 19 und Schriftenreihe des Vereins für Rheinische Kirchengeschichte, 121), Speyer 1996, 141 144, passim; P. Warmbrunn, Pfalz-Zweibrücken, Zweibrückische Nebenlinien, in: Die Territorien des Reichs im Zeitalter der Reformation und Konfessionalisierung. Land und Konfession 1500-1650, VI: Nachträge, hg. von A. Schindling/W. Ziegler (Katholisches Leben und Kirchenreform im Zeitalter der Glaubensspaltung, 56), Münster 1996, 170 197, hier 175-180; F. Nadwornicek, Pfalz-Neuburg, in: Die Territorien des Reichs im Zeitalter der Reformation und Konfessionalisierung. Land und Konfession 1500-1650, I: Der Südosten, hg. von A. Schindling/W. Ziegler (Katholisches Leben und Kirchenreform im Zeitalter der Glaubensspaltung, 49), 2., verb. Aufl., Münster 1992, 44-55, hier 49; R.H. Seitz, Reformation und Gegenreformation im Fürstentum Pfalz-Neuburg, 
Frankreichfeldzug zur Unterstützung der Hugenotten im dritten der französischen Religionskriege $(1568-1570)$ begleitet hatte, ${ }^{5}$ und dann des Herzogs Johann I. (1550-1604), Wolfgangs zweitgeborenem Sohn und Nachfolger im

in: 475 Jahre Fürstentum Pfalz-Neuburg. Ausstellung im Schloß Grünau bei Neuburg an der Donau. 20. Juni 1980-19. Oktober 1980, Redaktion: H.H. Stierhof/M. Oppel, München 1980, 43-66, hier 48-53.

5 Zum Krieg vgl. A. Jouanna, Le temps des guerres de religion en France (1559-1598), in: Dies./J. Boucher/D. Biloghi/G. Le Thiec, Histoire et dictionnaire des guerres de religion (Bouquins), Paris 1998, 1-445, hier 173-185, bes. 181; Dies., La France du $\mathrm{XVI}^{\mathrm{e}}$ siècle. 1483-1598 (Collection Premier Cycle), $2^{\mathrm{e}}$ édition corrigée, Paris 1997, 451-457, hier 454; B. Vogler, Die Rolle der pfälzischen Kurfürsten in den französischen Religionskriegen (1559-1592), Blätter für pfälzische Kirchengeschichte und religiöse Volkskunde 37/38 (1970-71) 235-266, hier 242-245. Zum Kriegszug Wolfgangs vgl. M. Lanzinner, Friedenssicherung und politische Einheit des Reiches unter Kaiser Maximilian II. (1564-1576) (Schriftenreihe der Historischen Kommission bei der Bayerischen Akademie der Wissenschaften, 45), Göttingen 1993, 162-194, passim. Zu Wolffs Gesandtschaft zu Königin Elisabeth I. von England vgl. E.I. Kouri, For True Faith or National Interest? Queen Elizabeth I and the Protestant Powers, in: Politics and Society in Reformation Europe. Essays for Sir Geoffrey Elton on his Sixty-Fifth Birthday, hg. von E.I. Kouri/T. Scott, Basingstoke/London 1987, 411-436, hier 420-421. Laut B. Nicollier-de Weck, Hubert Languet $(1518-1581)$. Un réseau politique international de Melanchthon à Guillaume d'Orange, Genève 1995, 194-196, 224-226, bes. 196, Anm. 64, passim, ließe sich die Kampagne Wolfgangs in Burgund im Frühjahr 1569 nach den - nicht gedruckten - sehr ausführlichen brieflichen Berichten des Hubert Languet, Gesandter im Dienst des Kurfürsten von Sachsen, detaillierter als bisher geschehen erfassen. Als älterer Mann verfertigte Wolff eine Abschrift seiner Aufzeichnungen und übersandte sie Pfalzgraf Johann I. (1594); vgl. Groh (wie Anm. 2), 11-12 mit Anm. 1. Mit Groh (ebd., 24, Anm. 1) liegt jedoch kein Kriegstagebuch vor (so noch Kurze [wie Anm. 4], 320), wie die ältere Forschung sie nannte; vgl. z. B. J. Ney, Pfalzgraf Wolfgang Herzog von Zweibrücken und Neuburg (Schriften des Vereins für Reformationsgeschichte, Nr. 106/107 = Jg. 29, Stück 2/3), Leipzig 1912, 84, passim. Den Bericht über seine Rückführung des Leichnams Wolfgangs in den Lectiones memorabiles entnimmt Wolff jedoch einer Chronik seines Kollegen Simon Schard I.C. (vgl. unten S. 410 mit Anm. 123); vgl. Wolff (wie Anm. 1), II, 857, ad a. 1569. Zum Tod und zur ersten Beisetzung Wolfgangs in Angoulême im Juni 1569 vgl. Groh (wie Anm. 2), 31 33; zur Umbettung nach Cognac S. 54; zur Überführung von La Rochelle über See bis Lübeck und dann in die Pfalz im Sommer 1571 S. 52-57. Die dabei gegen Leichenschändung getroffenen Vorsichtsmaßnahmen sind vor der Folie der katholischerseits 1560-1572 ausgeübten, blutigen Gewalt gegen hugenottische Körper zu lesen, die D. Crouzet, Imaginaire du corps et violence aux temps des troubles de religion, in: Le corps à la Renaissance. Actes du XXX colloque de Tours 1987, hg. von J. Céard/M.M. Fontaine/J.-Cl. Margolin, Paris 1990, 115-127, als infolge eschatologischer Obsessionen ausgeführte Markierung am Körper des vorgeblich noch im Jüngsten Gericht gegen Gott revoltierenden Häretikers deutet; entfaltet in: Ders., Les guerriers de Dieu. La violence au temps des troubles de religion (vers 1525 - vers 1610) (Époques), I-II, Seyssel 1990. Sie dürften auch im Kontext des entehrenden Umgangs mit dem Leichnam des bei der Schlacht bei Jarnac am 13. März 1569 erschossenen Louis de Bourbon, prince de Condé $\left({ }^{*} 1530\right)$ stehen; vgl. hier nur Jouanna, Le temps (s. oben), 182. 
Fürstentum Pfalz-Zweibrücken, ${ }^{6}$ für den er diplomatische Missionen ausführte. ${ }^{7}$ Nachdem ihm, der 1568 nach Beendigung seines Studiums der Rechte schon einmal ein halbes Jahr lang am Reichskammergericht in Speyer gearbeitet hatte, 1571 misslungen war, dort die ersehnte Stelle eines Beisitzers zu bekommen, trat er 1573 in markgräflich-badische Dienste und wurde 1574 Amtmann in Mundelsheim, mit dessen adeligem Freigut und Schloss er belehnt wurde. ${ }^{8}$ Wann er sich welcherlei Schwierigkeiten in der Phase der reformierten Religionspolitik des Markgrafen Ernst Friedrich von Baden-Durlach (reg. 15841604) ausgesetzt gesehen haben könnte, lässt sich bislang nicht genau sagen. ${ }^{9}$

6 Vgl. Warmbrunn (wie Anm. 4), 180: Der erstgeborene, ebenfalls streng lutherische Philipp Ludwig (1547-1614) erhielt Pfalz-Neuburg; als einziger der fünf Söhne Wolfgangs wandte sich Johann dem Calvinismus zu (1580/1588); vgl. dazu Warmbrunn (wie Anm. 4), 180-182; Konersmann (wie Anm. 4), 144; I. Dingel, Concordia controversa. Die öffentlichen Diskussionen um das lutherische Konkordienwerk am Ende des 16. Jahrhunderts (Quellen und Forschungen zur Reformationsgeschichte, 63), Gütersloh 1996, 105-106, 451. Vgl. V. Press, Johann I., Pfalzgraf bei Rhein, Herzog von Zweibrücken, NDB X (1974) 513-514. Vgl. auch B. Vogler, Die Ausbildung des Konfessionsbewusstseins in den pfälzischen Territorien zwischen 1555 und 1619, in: Festgabe für Ernst Walter Zeeden zum 60. Geburtstag am 14. Mai 1976, hg. von H. Rabe/H. Molitor/H.-Chr. Rublack (Reformationsgeschichtliche Studien und Texte, Supplementbd. 2), Münster 1976, 281-288; basierend auf: Ders., Vie religieuse en pays rhénan dans la seconde moitié du XVI ${ }^{\mathrm{e}}$ siècle $(1556-1619)$. Thèse présentée devant l'Université de Paris IV le 17 juin 1972, I-II, Lille 1974; zu Wolfgang und Johann I. siehe Bd. I, XLII-XLIV.

7 Groh (wie Anm. 2), 37-58. Wolff gehört zum Typus der gelehrten Diplomaten im 16. Jahrhundert, die sich auf der Basis eines Studiums der Artes liberales und der Rechte bei ihren diplomatischen Aufgaben wie ihren gelehrten Interessen in Netzwerken mit ihresgleichen austauschten; vgl. an einem prominenteren Beispiel R. Kohlndorfer, Häretiker, Astronom und kaiserlicher Gesandter: Andreas Dudith (1533-1589). Ein Beispiel für Lebenswelt und Arbeitsweise eines europäischen Diplomaten im 16. Jahrhundert, in: Wege in die Frühe Neuzeit. Werkstattberichte, [...], hg. von A. Brendecke/ W. Burgdorf (Münchner Kontaktstudium Geschichte, 4), Neuried 2001, 133-154, hier 147 (Wolff [wie Anm. 1], II, 820, ad a. 1562, referiert kurz über Dudiths Auftreten auf dem Konzil von Trient). Zur Diskussion von ,Späthumanismus' als Epochenbegriff für u. a. Wolffs Lebenszeit vgl. M. Friedrich, Zwischen ,Späthumanismus' und ,Standeskultur'. Neuere Forschungen zur intellektuellen und sozialen Situation von Gelehrten um 1600, in: ebd., 61-91.

8 Groh (wie Anm. 2), 60-63; Ludwig (wie Anm. 2), Vorfahren.

91583 bekundete Wolff Amtsmüdigkeit (vgl. unten Anm. 10). Einer viel späteren Randnotiz des Martin Crusius in seinem Tagebuch (vgl. unten Anm. 30) zufolge hat Wolff Unbill vom Markgrafen erlitten: „Ioann. Wolfius Licent. Iuris, Hailpronnae habitat, pulsus a Marchione Durlac. et frustrà [...]“ (1. Januar 1598; Diarium II, 1, Anm. zu Z. 10; vgl. unten Anm. 59). Vgl. V. Leppin, Der Kampf des Markgrafen Ernst Friedrich von Baden um sein Bekenntnis und der Widerstand aus Pforzheim, in: Reformierte Spuren in Baden, hg. von U. Wennemuth (Veröffentlichungen des Vereins für Kirchengeschichte in der Evangelischen Landeskirche in Baden, 57), Karlsruhe 2001, 52-67, hier 52-60; V. Press, Baden und badische Kondominate, in: Die Territorien des 
1594 verließ er den höfischen Dienst und erwarb das Bürgerrecht von Heilbronn, der Stadt seiner dritten Frau Barbara Rollwag, die er 1592 geheiratet hatte. ${ }^{10}$

In diesen Jahrzehnten konnte er die zunehmend pessimistischeren Voraussagen der jährlichen Practicae und Prognostiken verfolgen, ${ }^{11}$ und er wurde Zeitgenosse der Wechselwirkungen zwischen besonderer publizistischer Aufmerksamkeit und endzeitlichen Ängsten, die die große Konjunktion im Sternbild Widder des feurigen Trigons aus Widder, Löwe und Schütze im Jahr 1588 begleiteten, um nur das prominenteste, weil so seltene astronomische Ereignis jener Jahre zu nennen. ${ }^{12} \mathrm{Zu}$ dieser Zeit war Wolff jedoch schon lange

Reichs im Zeitalter der Reformation und Konfessionalisierung. Land und Konfession 1500-1650, V: Der Südwesten, hg. von A. Schindling/W. Ziegler (Katholisches Leben und Kirchenreform im Zeitalter der Glaubensspaltung, 53), Münster 1993, 124-166, hier 134-135, 139-140. Das Amt Mundelsheim wurde 1595 von - dem lutherischen Herzog Friedrich I. von Württemberg erworben; vgl. H. Ehmer, Württemberg, in: Die Territorien (s. oben), 168-192, hier 187; F. Merkel, Geschichte des evangelischen Bekenntnisses in Baden von der Reformation bis zur Union (Veröffentlichungen des Vereins für Kirchengeschichte in der evang. Landeskirche Badens, 20), Karlsruhe 1960, 101. Wolff als Amtsträger erwähnt bei W. Baumann, Ernst Friedrich von Baden-Durlach. Die Bedeutung der Religion für Leben und Politik eines süddeutschen Fürsten im Zeitalter der Gegenreformation (Veröffentlichungen der Kommission für geschichtliche Landeskunde in Baden-Württemberg, Reihe B, 20), Stuttgart 1962, 66.

10 Groh (wie Anm. 2), 89; Ludwig (wie Anm. 2), Vorfahren. Ich danke dem Leiter des Stadtarchivs Heilbronn, Herrn Dr. Christhard Schrenk, für die freundliche Überlassung des Doppels folgenden masch.schr. Aufsatzes: M. von Rauch, Der historische Schriftsteller Johann Wolff und seine Beziehungen zu Heilbronn [undat., kurz nach 1903]: Den Ratsprotokollen zufolge hatte Wolff 1583 schon einmal - „,nunmehr der Dienst müd““ - dem Rat vorgebracht, sich in Heilbronn anzukaufen, und seine Dienste erboten, war aber von seinem Vorhaben wieder abgekommen. Auch nach 1594 scheint er sich meist auf seinem Freigut in Mundelsheim aufgehalten zu haben (ebd., 1-2). Heilbronn gehörte - endgültig seit 1543 - zu den lutherischen Reichsstädten; vgl. W. Enderle, Ulm und die evangelischen Reichsstädte im Südwesten, in: Die Territorien, V (wie Anm. 9), 194-212, hier 208.

11 R.B. Barnes, Hope and Despair in Sixteenth-Century German Almanacs, in: Die Reformation in Deutschland und Europa: Interpretationen und Debatten. Beiträge zur gemeinsamen Konferenz der Society for Reformation Research und des Vereins für Reformationsgeschichte, 25.-30. September 1990, im Deutschen Historischen Institut, Washington, D.C., hg. von H.R. Guggisberg/G.G. Krodel (ARG, Sonderbd.), Gütersloh 1993, 440-461, hier 454-459.

12 Vgl. R.B. Barnes, Der herabstürzende Himmel: Kosmos und Apokalypse unter Luthers Erben um 1600, in: Jahrhundertwenden. Endzeit- und Zukunftsvorstellungen vom 15. bis zum 20. Jahrhundert, hg. von M. Jakubowski-Tiessen/H. Lehmann/J. Schilling/R. Staats (Veröffentlichungen des Max-Planck-Instituts für Geschichte, 155), Göttingen 1999, 129-145, hier 132-135. Zu Sachverhalt und zeitgenössischer Diskussion vgl. V. Leppin, Antichrist und Jüngster Tag. Das Profil apokalyptischer Flugschriftenpublizistik im deutschen Luthertum 1548-1618 (Quellen und Forschungen zur Reformationsgeschichte, 69), Gütersloh 1999, 139-149 mit 65-67; B. Mahlmann-Bauer, Die Bulle 
genug passionierter Konsument historisch-theologisch-philosophischer Schriften, um einen guten Überblick auch im weiten Feld endzeitbezogener Texte und deren Interpretationen zu haben.

Johannes Wolff, geboren am 10. August 1537 in Bergzabern als Sohn des Amtmanns Wolfgang Wolff, gehörte der dritten lutherischen Generation ${ }^{13}$ an, für die die Bikonfessionalität des Reichs sowie binnenkonfessionelle Differenzierungen vorgefundene Tatsachen waren. Er hatte eine gute Ausbildung auf humanistischem Fundament genossen, indem er 1552-1557 von Petrus Dasypodius und Johann Sturm an dessen protestantischem Gymnasium in Straßburg in den studia humanitatis unterrichtet worden war und 1557-1560 bei Philipp Melanchthon in Wittenberg Theologie und 1560-1564 bei Jakob Scheck in Tübingen Philosophie studiert hatte. ${ }^{14} 1564-1568$ absolvierte er ein Jurastudium in Frankreich bei den berühmten Juristen Jacques Cujas, Roussard, Antoine Leconte und Hugues Doneau an den Universitäten in Bourges, dem Zentrum des französischen juristischen Humanismus, ${ }^{15}$ sowie Angers, Besançon

contra astrologiam iudiciariam von Sixtus V., das astrologische Schrifttum protestantischer Autoren und die Astrologiekritik der Jesuiten. Thesen über einen vermuteten Zusammenhang, in: Zukunftsvoraussagen (wie Anm. 1), 143-222, hier 182-186. Vgl. auch H. Smolinsky, Deutungen der Zeit im Streit der Konfessionen: Kontroverstheologie, Apokalyptik und Astrologie im 16. Jahrhundert. Vorgetragen am 21. Juli 2000 (Schriften der Philosophisch-Historischen Klasse der Heidelberger Akademie der Wissenschaften, 20), Heidelberg 2000.

13 D. h. zwischen 1526 und 1550 geboren nach der Einteilung von L. Schorn-Schütte, Obrigkeitskritik und Widerstandsrecht. Die politica christiana als Legitimitätsgrundlage, in: Aspekte der politischen Kommunikation im Europa des 16. und 17. Jahrhunderts. Politische Theologie - Res publica-Verständnis - konsensgestützte Herrschaft, hg. von Ders. (HZ. Beihefte [Neue Folge], 39), München 2004, 195-232, hier 212 Anm. 61; bzw. zwischen 1525 und 1549 Geborene: Dies., Kommunikation über Herrschaft: Obrigkeitskritik im 16. Jahrhundert, in: Ideen als gesellschaftliche Gestaltungskraft im Europa der Neuzeit. Beiträge für eine erneuerte Geistesgeschichte, hg. von L. Raphael/ H.-E. Tenorth (Ordnungssysteme, 20), München 2006, 71-108, hier 80, Anm. 27.

14 Vgl. Groh (wie Anm. 2), 2-5. Im März/April 1557 verfasste Dasypodius ein von Sturm mitunterzeichnetes Empfehlungsschreiben für Wolff an die Wittenberger Professoren und namentlich Melanchthon, demzufolge Wolff fünf Jahre lang teils im Straßburger Collegium Wilhelmitanum, teils bei einem Verwandten gelebt hatte; vgl. MBW VIII, 8173 (mit Hinweis auf Wolffs Immatrikulation am 7. Mai 1557 in Wittenberg). Am 25. 11. 1558 empfahl Melanchthon Wolff an Herzog Wolfgang von Pfalz-Zweibrücken und andere; vgl. ebd., 8787. Das Schreiben enthält einen Abriss der Ausbildung Wolffs; vgl. J. Haussleiter, Vier Briefe aus der Reformationszeit, ZKG 15 (1895) 418-427, hier 425-427.

15 Vgl. V. Heise, Der calvinistische Einfluss auf das humanistische Rechtsdenken. Exemplarisch dargestellt an den „Commentarii de iure civili“" von Hugo Donellus (15271591) (Osnabrücker Schriften zur Rechtsgeschichte, 8), Göttingen 2004, 65-103, bes. 72; Chr. Strohm, Religion und Recht bei Hugo Donellus. Beobachtungen zur Eigenart religiöser Bezüge in der frühen calvinistischen Jurisprudenz, in: Reformation und Recht. Festgabe für Gottfried Seebaß zum 65. Geburtstag, hg. von I. Dingel/V. 
und Dôle. In Dôle wurde er am 7. Februar 1568 zum Lizentiaten der Rechte promoviert. ${ }^{16}$ Mit dem juristischen Doktorgrad besaß er die geeignete und benötigte Ausgangsqualifikation für eine Karriere als bürgerlicher Rat, ${ }^{17}$ wie er sie im Kontext lutherischer Konfessionalität durchlief. ${ }^{18}$

Leppin/Chr. Strohm, Gütersloh 2002, 176-223. Zum Rang der Universität Bourges vgl. D.R. Kelley, Law, in: The Cambridge History of Political Thought 1450-1700, hg. von J.H. Burns with the assistance of M. Goldie, Cambridge/New York/Port Chester u. a. 1991, 66-94, hier 79. Vgl. allgemein H.E. Troje, Die Literatur des gemeinen Rechts unter dem Einfluss des Humanismus, in: Handbuch der Quellen und Literatur der neueren europäischen Privatrechtsgeschichte, hg. von H. Coing, II: Neuere Zeit (1500-1800). Das Zeitalter des gemeinen Rechts, Teilbd. 1: Wissenschaft, München 1977, 615-795. Nachdem 1562 im Kontext von Religionsunruhen die Deutschen an der Universität Bourges die Stadt hatten verlassen müssen, kamen erst nach dem Frieden von Amboise 1563 wieder protestantische Studenten nach Bourges; vgl. W. Dotzauer, Deutsche in westeuropäischen Hochschul- und Handelsstädten, vornehmlich in Frankreich, bis zum Ende des alten Reiches. Nation, Bruderschaft, Landsmannschaft, in: Festschrift Ludwig Petry. Teil 2 (Geschichtliche Landeskunde, Bd. V, Teil 2), Wiesbaden 1969, 89-159, hier 140-141. Zu Wolffs juristischen Lehrern vgl. Dens., Deutsche Studenten an der Universität Bourges. Album et liber amicorum, Meisenheim am Glan 1971, 33-47; in den hier veröffentlichten Listen erscheint Wolffs Name nicht. Vgl. auch Dens., Deutsches Studium und deutsche Studenten an europäischen Hochschulen (Frankreich, Italien) und die nachfolgende Tätigkeit in Stadt, Kirche und Territorium in Deutschland, in: Stadt und Universität im Mittelalter und in der früheren Neuzeit. 13. Arbeitstagung in Tübingen 8.-10.11.1974, hg. von E. Maschke/J. Sydow (Stadt in der Geschichte, 3), Sigmaringen 1977, 112-141, hier 115-116; Dotzauers Ergebnisse nimmt peripher auf J. Verger, Etudiants et gradués allemands dans les universités françaises du XIV ${ }^{e}$ au XVI ${ }^{e}$ siècle, in: Gelehrte im Reich. Zur Sozial- und Wirkungsgeschichte akademischer Eliten des 14. bis 16. Jahrhunderts, hg. von R.Chr. Schwinges (Zeitschrift für historische Forschung, Beiheft 18), Berlin 1996, 23-40, hier 35. Laut N. Garnier, La nation allemande à l'Université de Bourges, Revue bourguignonne 18 (1908) 5-67, hier 9, sind die Immatrikulationsmatrikeln nicht erhalten. Zur auch quantifizierenden Untersuchung von Jurastudenten und -studien im frühneuzeitlichen Frankreich vgl. D. Julia/J. Revel, Les étudiants et leurs études dans la France moderne, in: Les Universités européennes du XVI ${ }^{\mathrm{e}}$ au $\mathrm{XVIII}^{\mathrm{e}}$ siècle. Histoire sociale des populations étudiantes, II: France, hg. von Dens. (Recherches d'histoire et de sciences sociales, 18), Paris 1989, 25-486, hier 107-189 mit 397-432. Wolff spricht von etwa 300 deutschen Studenten in Bourges; vgl. Groh (wie Anm. 2), 5-6.

$16 \mathrm{Zu}$ Studium und Abschluss vgl. Groh (wie Anm. 2), 5-8; Rollwagen (wie Anm. 2), f. $13^{\mathrm{v}}-14^{\mathrm{r}}$ : Bei dem dort genannten Franciscus Russardus könnte es sich um den Rechtsgelehrten Louis Roussard († 1567), Professor in Bourges, handeln, von dem 1567 in Antwerpen das ,Ivs Civile Manvscriptorvm Librorvm Ope [...] Consilio tamen et auctoritate Fran. Dvareni, I.C. [...]' erschien; der Vorname des François Douaren (1509-1559) wäre dann zu Roussard geraten. Vgl. Zedler XXXII (1742) Sp. 1893: Russard (Ludwig). Zur Universität Dôle vgl. Dotzauer, Deutsche in westeuropäischen Hochschulstädten (wie Anm. 15), 155-158.

$17 \mathrm{Zu}$ parallelen Biographien von Räten am Heidelberger Hof des pfälzischen Kurfürsten Friedrich III. (reg. 1559-1576) vgl. V. Press, Calvinismus und Territorialstaat. Regierung und Zentralbehörden der Kurpfalz 1559-1619 (Kieler Historische Studien, 7), 
Wolff trat veröffentlichend zunächst als Herausgeber geschichtstheoretischer $^{19}$ und chronikalischer ${ }^{20}$ Schriften hervor; weiterhin übersetzte er jagdkundliche französische Werke der 1560/70er Jahre ${ }^{21}$ und schuf aus zwei französischen und einer italienischen Falkenkunde ein ,New Falcknereybuch (1584). ${ }^{22}$ Seiner eigenen Darstellung zufolge muss ihn ein historisch-theologischer Lese- und Sammeleifer von frühen Zeiten an begleitet haben, denn er erwähnt in der ausführlichen Widmungsvorrede des ersten Bandes der Lectiones memorabiles an die lutherischen Herzöge Barnim X. von Pommern-Stettin (XII.,

Stuttgart 1970, 241-242, 262; die Berufung bürgerlicher, humanistisch gebildeter, graduierter juristischer Räte hatte zuerst Friedrich II. (reg. 1544-1556) betrieben (vgl. ebd., 194-196).

18 Johanns I. von Pfalz-Zweibrücken Übertritt zum Calvinismus erfolgte erst 1588; vgl. oben Anm. 6.

19 Io. Bodini Methodus historica, duodecim eiusdem argumenti Scriptorum, tam veterum quàm recentiorum, Commentariis adaucta: quorum elenchum Præfationi subiecimus, Basileae ex Petri Pernae Officina. 1576. Cum Priuilegio. VD 16, B 6274. Vgl. Bibliographie critique des éditions anciennes de Jean Bodin, hg. von R. Crahay/M.-Th. Isaac/ M.-Th. Lenger avec la collaboration de R. Plisnier (Académie Royale de Belgique. Classe des Lettres. Collection in- $8^{\circ}, 2^{\mathrm{e}}$ série. Tome LXX), Brüssel 1992, 26-28. Um fünf Autoren vermehrte Ausgabe: Artis historicae penus Octodecim Scriptorum tam veterum quàm recentiorum monumentis $\&$ inter eos Io. præcipuè Bodini libris Methodi historicæ sex instructa. Autores sequens pagina indicabit. BAsILEæ Ex Officina Petri Pernæ 1579 Cum privilegio. VD 16, W 4208. Vgl. Crahay/Isaac/Lenger, 28-31; das in Bd. I als Schlussschrift in Bd. II angekündigte Werk des Antonius Riccobonus wurde in einen eigenen, dritten Band ausgegliedert (ebd., 31 und 26). Zur Rolle der Ausgaben Wolffs für die ars historica vgl. M.-D. Couzinet, Histoire et méthode à la Renaissance. Une lecture de la Methodus ad facilem historiarum cognitionem de Jean Bodin. Préface de C. Vasoli (Philologie et Mercure), Paris 1996, 35-36, 39-40, 46.

20 ALBERTI || KRANTZIJ || RERVM GERMANICA- || rum historici clariss. Regnorum A- || quilonarium, Daniæ, Sueciæ, || Noruagiæ, Chronica. \| Quibus gentium origo vetustißima, \& Ostrogothorum, Wisi- || gothorum, Longobardorum atq; Normannorum, antiquitus inde $\|$ profectorum, res in Italia, Hispania, Gallia \& Sicilia gestæ, præter || domesticam historiam, narrantur. || Accessit, supplementi cuiusdam instar, Dithmarsici belli || historia, Christiano Cilicio Cimbro autore. || Item Jacobi Ziegleri Schondia, id est regionum \& populorum Septentrionalium, || ad Krantzianam historiam perutilis descriptio. || Cum præfatione ad Illustrissimum Principem LVDOVICVM Ducem \| Wirtenbergensem, Ioan. Wolfij I. C. || Addito Indice locupletissimo. || FRANCOFVRTI AD MOENVM \|| APVD AND. WECHELVM. || M. D. LXXV. Albert Krantz, Metropolis, 1576; vgl. VD 16, K 2251. 1577 als ,Rerum Gallicarum Annales' das ,Compendium de origine et gestis Francorum' (editio princeps Paris 1495) des Pariser Humanisten und Trinitariergenerals Robert Gaguin (1433-1501); vgl. VD 16, G 44. Zu Wolffs historiographischen Arbeiten vgl. Schmolinsky (wie Anm. 1), 98-101.

21 Die beiden Übersetzungen Wolffs wurden 1590 in Straßburg durch Bernhart Jobin als ,New Jaegerbuch [...]' gedruckt; vgl. VD 16, D 2871 und C 4012. Vgl. Schmolinsky (wie Anm. 1), 101 und 103.

22 Es ist nur handschriftlich erhalten; vgl. Schmolinsky (wie Anm. 1), 103 mit Anm. 42. 
1549 - 1603) und Philipp Julius von Pommern-Wolgast (1584-1625), ${ }^{23}$ dass es seine Reisen und monatelangen Gesandtschaften an die Höfe des Kaisers, der Könige von Frankreich, Navarra, England und Polen und vieler Fürsten gewesen seien, die ihm fortgesetzte Studien in Bibliotheken und Büchern der Höfe, Klöster, Kollegien, Universitäten, Städte und privater Gelehrter ermöglicht hätten; ferner habe er sich Schriften kaufen lassen. Lesend und exzerpierend hatte er sich ein Archiv erschaffen und aus ihm sein Werk erstellt. ${ }^{24}$ Wie er zwischenzeitig seine Materialien strukturiert, organisiert und verwaltet hat, ist nicht bekannt. ${ }^{25}$

23 Wolff war während seines Studiums in Frankreich mit den jungen pommerschen Herzogssöhnen Ernst Ludwig (1545-1592) und Barnim gereist; dankbar erinnert er sich am Ende der Epistola dedicatoria der empfangenen Unterstützung: Wolff (wie Anm. 1), I, f. )()()$\left([6]^{\mathrm{r}-\mathrm{v}}\right.$; vgl. Schmolinsky (wie Anm. 1), 97 (fehlerhaft bezüglich Philipps I.). Zu diesen und den anderen Söhnen Philipps I. (1515-1560), Herzogs von PommernWolgast, vgl. M. Wehrmann, Die Söhne des Herzogs Philipp I. von Pommern auf der Universität zu Greifswald, Baltische Studien, N. F. 10 (1906) 33-66; ferner R. Schmidt, Ernst Ludwig, Herzog von Pommern-Wolgast, NDB IV (1959) 619-620; A. Häckermann, Bogislav XIII., Johann Friedrich, Barnim X., Casimir VII., Herzöge von Pommern, ADB III (1876) 55-56. Vgl. Groh (wie Anm. 2), 6. Für den 1600 bereits verstorbenen Ernst Ludwig setzt Wolff dessen Sohn Philipp Julius als Widmungsträger ein. Vgl. zu den pommerschen Herzögen R. Schmidt, Pommern, Cammin, in: Die Territorien des Reichs im Zeitalter der Reformation und Konfessionalisierung. Land und Konfession 1500-1650, II: Der Nordosten, hg. von A. Schindling/W. Ziegler (Katholisches Leben und Kirchenreform im Zeitalter der Glaubensspaltung, 50), 3. Aufl., Münster 1993, 182-205, hier 183.

24 Wolff (wie Anm. 1), I, f. $)()()\left(2^{\mathrm{v}}-3^{\mathrm{r}}\right.$, hier f. $)()()\left(2^{\mathrm{v}}\right.$ : „Nam sicubi in curijs \& aulis Imperatoris, \& Regum Galliæ, Nauarræ, Angliæ \& Poloniæ, vt etiam principum passim; \& conuentibus Imperij, ob expedienda negotia, sæpè per menses aliquot commorandum fuit, ne inane periret tempus, interea omnigenas Imperatoris, Regum, Monasteriorum, Collegiorum, Vniversitatum, Ciuitatum, \& doctorum virorum bibliothecas, librosque perlustraui. Et multos, quos habere non potui, non sine sumtibus ex longinquo \& molesto itinere missis literis comparare non destiti, solusque $\&$ vnus, ac sine adminiculo cuiusquam hominis perlegi, \& ex eis hoc Opus congessi." Vgl. unten Anm. 54.

25 Allenfalls mag eine Anspielung auf eine vor der Bearbeitung zum Druck anders geartete Ablage der Exzerpte enthalten sein in: „Motus ergò amicorum precibus, \& inseruiendi veritati religionis studio, ad limam \& regulariorem seriem reuocaui lectionum harum farraginem. \& ad prælum (nam quis vetet, apposito lumen de lumine summi) adornaui.“ (Wolff [wie Anm. 1], I, f. ) ()()$\left(3^{\mathrm{r}}\right)$. Zur Gelehrtentechnik der ars excerpendi vgl. É. Décultot, Introduction. L'art de l'extrait: définition, évolution, enjeux, in: Lire, copier, écrire. Les bibliothèques manuscrites et leurs usages au XVIII ${ }^{\mathrm{e}}$ siècle, hg. von Ders. (De l'Allemagne), Paris 2003, 7-28. Wolff (ebd., f. ) ()()$\left(2^{v}\right)$ stellt ausdrücklich fest, dass er seine Bücher „solus[...] \& vnus, ac sine adminiculo cuiusquam hominis perlegi, \& ex eis hoc Opus congessi“, aber er erwähnt auch (ebd., f. )()()(3 $\left.{ }^{r}\right)$ einen „amanuensis“, allerdings nur, um an ihm die bekehrende Wirkung der geballten Argumentationen zu belegen: Der junge - mit nicht mehr als seinem Vornamen Martin eingeführte - Mann, der an der Schule der Jesuiten in Fulda ausgebildet worden war, entwickelte sich während der Arbeiten des Schreibens vom scharfzüngigen Verfechter des Papsttums zu einem 


\section{Die Lectiones memorabiles - Merkmale einer Sammlung}

Welcher Art die Fragen sind, auf die die in den Lectiones memorabiles ausgebreiteten Zitate, Exzerpte und Regesten diskursiv reagieren sollen, kann hier nicht im Einzelnen untersucht werden. Als Buchtyp stellt das Werk eine Sammlung dar, die schon durch ihren Umfang ${ }^{26}$ den Anspruch eines Kompendiums erhebt. Wolff selbst benennt sie additiv beschreibend: „dicta, scripta, atq; facta; Vaticinia item, vota, omina, mysteria, Hieroglyphica, miracula, visiones, antiquitates, monumenta, testimonia, exempla virtutu[m], vitiorum, abusuum“ finde der Leser, deren Urheber „Doctor[es] Ecclesiæ, Vat[es], Politic[i], Philosoph[i], Historic[i], ali[i]q; sapient[es] \& erudit[i]" seien, ferner unheilvolle himmlische und natürliche Zeichen: „sed et ipsius coeli ac naturæ horrenda Signa, Ostenta, Monstra, atq; Portenta“. ${ }^{27}$ Applizierbar sei dieses Material auf Vergangenheit und Zukunft, auf Erwägungen über den früheren Zustand von Kirche, Staat und gemeinem Leben wie auf die Vorahnung drohender Ereignisse und sich von Tag zu Tag immer mehr verschlimmernder Übel, aber auch vieles Erwünschte, bisher Verborgene werde enthüllt. ${ }^{28}$

Näherhin hat Wolff seiner Sammlung als Argumentationslinie eine spezifische Variante des reformatorischen Verderbtheitsdiskurses hinsichtlich der Papstkirche zugrunde gelegt. Für jedermann erkennbar seien die Mängel der

gemäßigten Leser der Bibel, der sich im Angesicht seines frühen Todes der protestantischen Lehre zuwandte. Rollwagen (wie Anm. 2), f. $24^{\mathrm{r}}$, erwähnt von Wolff bezahlte Sekretäre und Drucker: „[...] omnem parui in hoc impensam pecuniam æstimauit, amanuenses plures pluribus annis in hoc aluit, typographos conduxit, quibus etiam mercedem suam promptè ac liberaliter exsoluit, [...]." Vgl. unten Anm. 30.

26 Im Erstdruck von 1600 (siehe Anm. 1) umfassen die beiden Bände zusammengenommen 2142 Folioseiten bei einem Satzspiegel von $27,5 \times 15 \mathrm{~cm}$ mit meist 64 Zeilen. Inserierte Bilder beanspruchen fast immer nur den halben Satzspiegel.

27 So im Titel beider Bände; vgl. oben Anm. 1. Wolff interessieren zudem alle geistlichen und weltlichen Orden („omnes sacri prophaniq; Ordines“).

$28 \mathrm{Vgl}$. oben Anm. 1: „[...] cum præteriti status in Ecclesia, Republica, \& communi vita consideratio; tum impendentium euentuum, ac in dies magis magisq; ingrauescentium malorum præsagitio: sed \& multorum abstrusorum hactenus desideratorum reuelatio ob oculos perspicuè ponitur." Zur Apokalyptik des späteren 16. und frühen 17. Jahrhunderts vgl. R.B. Barnes, Prophecy and Gnosis. Apocalypticism in the Wake of the Lutheran Reformation, Stanford, California 1988; zur Bedeutung der astrologischen Prophetie für die lutherische Konfessionskultur, eröffnet durch Philipp Melanchthons naturphilosophisches Interesse an Astrologie, vgl. Dens., Astrology and the Confessions in the Empire, c. 1550-1620, in: Confessionalization in Europe, 1555-1700. Essays in Honor and Memory of Bodo Nischan, hg. von J.M. Headley/H.J. Hillerbrand/A.J. Papalas, Aldershot 2004, 131-153. Zur Rolle monströser Missbildungen in der Publizistik des spätreformatorischen Deutschlands vgl. Ph.M. Soergel, Die Wahrnehmung der Endzeit in monströsen Anfängen, in: Im Zeichen der Krise. Religiosität im Europa des 17. Jahrhunderts, hg. von H. Lehmann/A.-Ch. Trepp (Veröffentlichungen des MaxPlanck-Instituts für Geschichte, 152), Göttingen 1999, 33-51. 
Kirche, die nicht nur solche der Personen, sondern - so insinuiert Wolff - auch solche der Lehre seien. Als widerlegbar erscheint das Argument, die eigene Kirche besitze ihren Ursprung in Christi und der Apostel Zeiten und habe sich sodann in ordentlicher Abfolge ohne Irrtümer und Verderbnis ausgebreitet, ohne dass dies bestritten worden sei. Gerade letzteres hätten seit der Zeit der Apostel bis in Wolffs Gegenwart sehr viele "Catholici viri“ geleugnet und bekanntlich den abscheulichen Zustand der Kirche mit frommem Eifer stets beklagt sowie deren Reformation von ganzem Herzen ersehnt. Den Zeugnissen dieser Personen gilt Wolffs Werk, ${ }^{29}$ das in dieser Hinsicht den Charakter eines Speichers für konfessionspolemisch nutzbare historische Quellen annimmt. ${ }^{30}$

29 Wolff (wie Anm. 1), I, f. ) (2v : „Qui enim in Ecclesia sint defectus, quis non videt? \& tamen pleriq; hoc diuerticulo omnem reprehensionem effugere, \& elidere conantes, dicunt, esse quidem defectus, sed tantùm personarum; doctrinæ nullum: $\&$ simili modo nihil aliud quàm Ecclesiam suam; \& hoc subinde crepant, eam à Christi \& Apostoloru[m] temporibus originem trahere, ac deinde ordinaria successione, veluti per traducem, propagatam, sine errore ac corruptione: nec quenquam ante hæc (vti nunc) extitisse, qui se opposuerit. Quod tamen negârunt ab Apostolorum tempore vsq; ad hodiernum diem plures Catholici viri, quos constat defoedatam Ecclesiæ conditionem pio zelo seriò semper deplorasse, reformatione $[\mathrm{m}] \mathrm{q}$; toto pectore exoptasse; de quibus nunc paucis tantùm, plurimis infrà toto Opere tractabitur. "Wolff, ebd., f. ) $\left(2^{\mathrm{v}}-4^{\mathrm{v}}\right.$, fügt eine nach Jahreszahlen geordnete Liste erster Belege an, deren erster die apostolische Nachfolge der römischen Kirche hervorhebt: „179. Nam Irenæus dicit: Ecclesiam Romanam præ aliis suspiciendam, quatenus Apostolorum doctrinam seruet.“

30 In der Kurzcharakteristik eines Zeitgenossen, wie des Gräzisten und Tübinger Universitätsprofessors Martin Crusius (1526-1607) handelt es sich um ein „op[us] Vaticiniorum“ „contra Papatum“. Crusius' Tagebucheinträge über Wolff werfen zugleich ein Licht auf die Art der Arbeitsprozesse an den Lectiones memorabiles. 21. Januar 1596: „Studion, et Hans wolf, in opere Vaticiniorum conficiendo pergunt. Sculptor Laederlinus sculpit quotidie imagines, ad id pertinentes. Ist kain haimligkait." (Diarium I, 10,25-27. Wolffs - als solcher ungenannter - Kompagnon Simon Studion beschäftigte sich laut Crusius mit Prognostiken; vgl. Diarium I, 127,17-18; 323,32-33; 415,910; II, 135,8-9; vgl. unten Anm. 129. Joachim Laederlin / Lederle war Formschneider in Tübingen; vgl. Diarium IV, 113). 23. Januar 1596: „[...] allatae erant literae Licentiati Juris D. Joannis Wolfii: qui cum Studione conficit illud opus. Petit, ut carmen

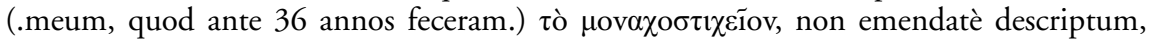
corrigam: quasi velit id operi suo inserere, ceu in antiquo M. Scr. codice Graeco repertum, etc. [...] Defenderam 1564. quadam epistola [...]. Rescribam ergo D. Wolfio, ne pro antiquitate in opus suum referat. 1. ne Papistae refutent, lectâ illa mea epistula. Tunc toti operi eius aspergeretur labes, ut suspectum fieret. 2. Nullo modo debet veritas Religionis nostrae defendi figmentis." (Diarium I, 14,9-21). 30. Januar 1596: Notizen zum Transport des Briefes durch Boten nach Mundelsheim (Diarium I, 21,35-38). 24. April 1596: „Literas accepi à D. Ioanne Wolfio. Scribit, se perlegisse partem priorem Annalium meorum (.ex quibus quaerit de lapide sepulcrali, in quo scriptum sit Luterus, quid sibi hoc velit.) et versari iam in altera parte. Steuchum et Gassarum petit: sed non habeo. Putat, suum et Stud. opus, ad autumnum habiturum Typographum. " (Diarium I, 74,31-35; vgl. III, 176,23-28: Crusius notiert Wolffs Übernahme einer Übersetzung von ihm sowie die Zitate aus seinen Annales Suevici; vgl. Wolff [wie Anm. 1], II, 944- 
Als Gliederungsform seiner Auswahl erinnerungswürdiger und entlegener Lesefrüchte hat Wolff „centenarii“ gewählt, ohne dieses zu seiner Zeit bereits etablierte komputistische Prinzip weiter zu kommentieren. ${ }^{31}$ Innerhalb der Zentenarien sind die narrationes in chronologischer Folge Entstehungsjahren der zugrunde gelegten Schriften oder Daten der Autoren und Autorinnen bzw. der Ereignisse zugeordnet. ${ }^{32}$ Auf die Erschließung seines Werks legte Wolff besonderen Wert, indem er „noua methodo“ am Ende jedes Jahrhunderts ebenfalls chronologisch angelegte Listen der Namen von Kaisern, Päpsten, Konzilien, Orden und Gelehrten beifügte. ${ }^{33}$ Wenngleich derlei Ordnungsprinzipien im

946; vgl. ebd., I, 81: Zitat aus Augustinus Steuchus, De perenni Philosophia; ebd., I, 80, 233: Zitate aus Achilles Gassarus, Chronicon). 26. April 1596: „Rescripsi D. Ioanni Wolfio humaniter: me non habere libros, nec ab aliis haberi, quos petat. Me nihil scire praeterea de nomine Luterus, etc.“ (Diarium I, 76,34-35). Simon Studion aus Urach war zumindest um 1586 Schulleiter in Marbach (vgl. VD 16, S 9788-9790; vgl. unten Anm. 129). Crusius sollte Wolff ein „[...] Germanicè excusum contra Iesuitas (.de ipsorum astutiis, auaritia, crudelitate, etc.)“ ins Lateinische übersetzen: „Sed ego per alium curabo vertendum. Ille properat suum magnum, contra Papatum, opus absoluere, et edere." (Diarium I, 207,3-7 am 4. Oktober 1596; zu Wolffs Mahnung vgl. 213,910 am 16. Oktober). Am 25. November brachte Erhard Cellius seine Übersetzung und einen Brief von Crusius nach Mundelsheim (Diarium I, 244,6-8; vgl. Wolff [wie Anm. 1], II, 1044-1056, hier 1044: „1597. Prodijt hoc tempore sequens admonitio, Theutonicæ linguæ scripta idiomate, ad laudatam Germaniæ nationem, de occultis Iesuitarum virtutibus, [...] \& à docto viro, Erhardo Cellio, Tubingâ nuper ad me, in Latinam ab ipso translata linguam, missa."). Vgl. oben Anm. 9 und unten Anm. 59 zu Schwierigkeiten Wolffs.

31 Vgl. oben Anm. 1. Zur historischen Einordnung vgl. M. Hartmann, Humanismus und Kirchenkritik: Matthias Flacius Illyricus als Erforscher des Mittelalters (Beiträge zur Geschichte und Quellenkunde des Mittelalters, 19), Stuttgart 2001, 70-71 mit Anm. 124; A. Brendecke, Die Jahrhundertwenden. Eine Geschichte ihrer Wahrnehmung und Wirkung, Frankfurt a. M./New York 1999, 89-90.

32 Eine Ausnahme bildet die Sätzesammlung aus vielen verschiedenen Autoren über das Papsttum am Ende des ersten Bandes: „De Paparum in Colo, Inferno, \& in Terris maiestate \& potentia.“, in: Wolff (wie Anm. 1), I, 990-1005, ad a. [1500].

33 Wolff (wie Anm. 1), I, f. )()()( $3^{\mathrm{v}}$ : „Et præcipuè ne deesset Index Operis; noua methodo, quia distributum est in Centenarios annorum, Catalogum subiunxi singulis seculis omnium Imperatorum \& Pontificum Romanorum; ordinum Ecclesiasticorum, \& plerorumq; aliâs hominum, eruditionis \& similium virtutum laude tunc claroru[m]: sic enim tempus $\&$ nomen autoris cùm factorum tum historiaru[m] facilimè reperiri potest." Zuvor finden sich weitere Erläuterungen Wolffs zum Aufbau seines Werks. Acht Jahre nach seinem Tode publizierte Johann Jakob Hagendorn, gen. Linsius, einen Index absolutissimus: IN || IOHANNIS VVOLFII || IVRISCONSVLTI ET CONSILIARII || PALATINI, SVMMÆ ERVDITIONIS || VIRI, TOMOS DVOS, SIVE CEN- || TENARIOS XVI. || LECTIONVM MEMORABI- || LIVM ET RECONDITARVM \| SVPERIORIBVS ANNIS || EDITOS \| INDEX ABSOLVTISS. || METHODICE, QVANTVM ALPHABE- \| TI ORDO PERMITTIT, OMNIA IN TOTO \| opere præclara \& relatu digna, sub singulis principalioribus \& $\|$ velut substantialibus vocabulis; per distinctiones, Præ- $\|$ dicata, Concreta, Abstracta \&c. complectens, vti || latiùs 
Verhältnis zu zeitgenössisch existierenden Theorien und Praxen der systematischen Präsentation von gelehrtem Wissen ${ }^{34}$ vergleichsweise einfach sind und Wolff nicht durchwegs Sorgfalt auf die Verzeichnung der benützten Drucke und Handschriften verwendete, so unterstützte er doch durch diese Maßnahmen den Verwendungszweck der Lectiones memorabiles als historisches Hand- und Textbuch. ${ }^{35}$

Dessen auffälligstes Merkmal ist die Verteilung des Stoffes: Den fünfzehn Jahrhunderten seit Christi Geburt im ersten Band von 1048 Seiten steht ein

ex Præfatione ad Lectorem \| apparet. \| AVTHORE || M. IOHANNE IACOBO LINSIO, \| COGNOMINE HAGENDORN. [...] || LAvingæ \|| Excudebat M. Iacobus VVinter, Anno || M. DC. VIII. Wieder erschienen 1672 bei Henning Grosses Erben in Frankfurt am Main; vgl. VD 17, 23:230248U. Vgl. O. Bucher, Bibliographie der Lauinger Drucke 1472-1619 mit einer Geschichte der Lauinger Drucker und Druckereien von R.H. Seitz, Archiv für Geschichte des Buchwesens 8 (1967) 1461-1598, hier 1569, Nr. 422.

34 Zur Wissenssystematisierung in Enzyklopädien vgl. U.J. Schneider, Bücher als Wissensmaschinen (Einleitung), in: Seine Welt wissen. Enzyklopädien in der Frühen Neuzeit, hg. von Dems., Darmstadt 2006, 9-20; Ders., H. Zedelmaier, Wissensapparate. Die Enzyklopädistik der Frühen Neuzeit, in: Macht des Wissens. Die Entstehung der modernen Wissensgesellschaft, hg. von R. van Dülmen/S. Rauschenbach, Köln/Weimar/ Wien 2004, 349-363; H. Zedelmaier, Bibliotheca universalis und Bibliotheca selecta. Das Problem der Ordnung des gelehrten Wissens in der frühen Neuzeit (Beihefte zum Archiv für Kulturgeschichte, 33), Köln/Weimar/Wien 1992; zu den prominenten Beispielen Theodor Zwinger und Konrad Gessner auch U. Friedrich, Grenzen des Ordo im enzyklopädischen Schrifttum des 16. Jahrhunderts, in: Die Enzyklopädie im Wandel vom Hochmittelalter bis zur Frühen Neuzeit. Akten des Kolloquiums des Projekts D im Sonderforschungsbereich 231 (29.11.-1.12.1996), hg. von Chr. Meier (Münstersche Mittelalter-Schriften, 78), München 2002, 391-408. Zum philosophisch-theologischen Rahmen von Enzyklopädistik W. Schmidt-Biggemann, Enzyklopädie und Philosophia perennis, in: Enzyklopädien der Frühen Neuzeit. Beiträge zu ihrer Erforschung, hg. von F.M. Eybl/W. Harms/H.-H. Krummacher/W. Welzig, Tübingen 1995, 1-18. Der potentielle Rezipierendenkreis der Lectiones memorabiles ist vielgestaltig und offen, so dass das Werk „nutzungsorientierte[n] Enzyklopädietypen“ - und auch der „allgemeine[n]“ kaum zugeordnet werden kann, wie sie Christel Meier aufstellt: Enzyklopädischer Ordo und sozialer Gebrauchsraum. Modelle der Funktionalität einer universalen Literaturform, in: Die Enzyklopädie (s. oben), 511-532.

35 Im Anschluss an die Geschichte eines jungen Jesuitenschülers, der sich im Zuge seiner Arbeiten als Sekretär bei ihm vom Luthertum hatte überzeugen lassen, führt Wolff diese pragmatischen Zwecke seines Werks an: Wolff (wie Anm. 1), I, f. ) ()()$\left(3^{\mathrm{r}}\right.$ : „Ex hoc \& alijs quilibet augurari potest, multos rectiùs sensuros esse, si meliora $\&$ rectiora docerentur: præsertim cùm nec centesimo cuiq; suppetat copia librorum, vel tantum temporis, aut à gerendarum siue publicarum siue domesticarum rerum curâ orium; \& occasio emendi, acquirendi, perlegendi \& expiscandi tot tantosq; authores." Vgl. unten Anm. 57. Das pragmatische Argument der Menge bewegt z. B. auch die Verfasser von Lutherflorilegien; vgl. E. Koch, Lutherflorilegien zwischen 1550 und 1600. Zum Lutherbild der ersten nachreformatorischen Generation, Theologische Versuche 16 (1986) 105-117, hier $105-106$. 
zweiter Band mit 1094 Seiten zum 16. Jahrhundert gegenüber. ${ }^{36}$ Sie ist Wolffs lutherischer Konfessionszugehörigkeit geschuldet, hatte doch letzteres als das die anderen bei weitem überragende Jahrhundert die göttliche Erweckung des Mannes gesehen, der die falschen Traditionen der Kirche aufgedeckt und das so lange durch Schwert, Feuer und Blut unterdrückte wahre Licht des Evangeliums wieder zum Leuchten gebracht hatte und vor dem Reichstag öffentlich dafür eingestanden war, wie Wolff einleitend zum zweiten Band in der Epistola nuncupatoria an den ihm seit seiner Zeit in Frankreich bekannten Freund Joachim von Schulenburg ausführt. ${ }^{37}$ Die Buch- und Schriftenproduktion

36 Ähnlich verteilt Jakob Gilbert, Pfarrer in Beetzendorf bei Salzwedel, den Zeitraum der 16 Zenturien seit Christi Geburt; vgl. Th. Kaufmann, Römisches und evangelisches Jubeljahr 1600. Konfessionskulturelle Deutungsalternativen der Zeit im Jahrhundert der Reformation, in: Millennium. Deutungen zum christlichen Mythos der Jahrtausendwende. Mit Beiträgen von Chr. Bochinger/J. Frey/E. Hauschildt/Th. Kaufmann/H. Timm (Kaiser Taschenbücher, 171), Gütersloh 1999, 73-136, hier 131, Anm. 214 mit S. 115, Anm. 159. Vgl. M. Marten, Über Predigten Jakob Gilberts. Praktische Bibelkunde und erbauliches Lesen, Magisterarbeit Hamburg 2001, 30-31, über Verbindungslinien zu Luthers ,Supputatio ' und Carions Chronik. Gilbert findet sich nicht in den Lectiones memorabiles.

37 Wolff (wie Anm. 1), II, f. ) $\left(2^{\mathrm{r}}\right.$ : „Nobilitate generis, virtute et doctrina præstanti viro, Domino Ioachimo a Schulenburg \&c. Domino \& fautori suo gratiosissimo S.“; näherhin f. $)()\left(2^{\mathrm{r}},\right)()\left([4]^{\mathrm{r}-\mathrm{v}}\right.$. Ebd., f. $)\left(2^{\mathrm{v}}\right.$ : „Licet autem vnicus saltem annorum centenarius supersit, tamen cæteris nullo modo posthaberi debet: sed certè vel vnico hoc maximè præcellere, quòd in eo vera Euangelij lux, multis annis, quæstu \& dominandi libidine (heu deplorandum) oppressa, \& à piis viris diu ardenter $\&$ efflictim desiderata, tandem Dei gratia iterum fulgere cœpit. || Nam cùm diutius conniuere Deus ad miseriam hanc non posset (doluit enim Dominus super miseriis populi sui, Iud. 10.) suscitauit talem, qui, virtute $\&$ auxilio Spiritus sancti, Ecclesiæ falsas traditiones detexit, \& sic verbum veritatis, tot annos, gladio igne $\&$ sanguine suppressum, in lucem vendicauit, \& quod cæci priuatim fieri impediebant (concionibus graui interdicto prohibitis) id Dei impulsu \& dispositione, publicè in amplissimo Imperii conuentu; coram toto mundo, Regibus, Principibus, \& ipsis Pontificiis præsentibus atque audientibus, ipsimet exequi debuerunt. Ex quo deinde in toto mundi spacio illa confessio in diuersas, Latinam, Italicam, Gallicam, Hispanicam, Græcam, \& Sclauonicam quoque, linguas conuersa, cunctis populis diuulgata innotuit." Wolff ruft hier nicht den eschatologisch-prophetischen Luther auf, der insbesondere in den 1570er Jahren wieder aktualisiert worden war; vgl. W. Sommer, Luther - Prophet der Deutschen und der Endzeit. Zur Aufnahme der Prophezeiungen Luthers in der Theologie des älteren deutschen Luthertums, in: Zeitenwende - Zeitenende. Beiträge zur Apokalyptik und Eschatologie, hg. von Dems. (Theologische Akzente, 2), Stuttgart/Berlin/Köln 1997, 109-128; wiederabgedruckt in: Ders., Politik, Theologie und Frömmigkeit im Luthertum der Frühen Neuzeit. Ausgewählte Aufsätze (Forschungen zur Kirchen- und Dogmengeschichte, 74), Göttingen 1999, 155-176. Den Topos vom Licht des Evangeliums führen z. B. auch die Verfasser von Lutherflorilegien als einen Grund ihres Tuns an; vgl. Koch (wie Anm. 35), 107. „Ioachimus a Schulenburg" könnte mit Joachim VI (Nr. 347) Schulenburg zu identifizieren sein; vgl. D.W. Graf von der Schulenburg/H. Wätjen, Geschichte des Geschlechts von der Schulenburg 1237 bis 1983, Wolfsburg 1984, 114, vgl. 84 . 
,seines' Jahrhunderts ist jedoch weit mehr präsent, als nur im zweiten Band ausgewertet worden zu sein, denn auch bei Einträgen im ersten Band finden sich immer wieder Hinweise auf Wolff zeitgenössische Fundorte und Diskussionszusammenhänge, oft auch durch den Zusatz „vt apud eum“ mit dem Haupteintrag zum Autor verbunden.

Wolff war um die Erläuterung der historischen Kontexte seiner Autoren und Autorinnen bemüht ${ }^{38}$ und nutzte dafür wie für allgemeine Mitteilungen die chronikalischen Werke seiner Zeit. ${ }^{39}$ Seine Vorgehensweise kennzeichnete er als eine kondensierende, galt es doch eine Menge von fast 3000 Autoren, auch Autorinnen, in nicht mehr als zwei Bänden zu Wort kommen zu lassen. ${ }^{40}$ Allerdings inserierte er gegebenenfalls, insbesondere im zweiten Band, ganze

38 Wolff (wie Anm. 1), I, f. )()()( $3^{\mathrm{v}}$ : „Imperatorum \& Paparum nomina sub calcem narrationum adhibita sunt, non ideò, quòd annum facti aut narrati respiciant; sed vt simul cum tempore, quo quisque Author claruit, etiam eiusdem temporis Imperatores \& Papas in promtu sub oculis habeat Studiosus Lector."

39 Wolff (wie Anm. 1), I, f. ) ()()( $3^{\mathrm{v}}$ : „Communia ex historijs, Balæo, Nigrino, Sleidano, \& similibus, [...].“ Zu John Bale (1495-1563) vgl. aus literaturwissenschaftlicher Perspektive einführend P. Happé, John Bale (Twayne's English Authors Series, 520), New York 1996; Schriftenverzeichnis von Bale in: Bibliotheca Carmelitana, notis criticis et dissertationibus illustrata, hg. von [P. Cosmas de Villiers], I, Orléans 1752, Sp. 753759, hier 754-758 [Nachdruck: Rom 1927]. Zu Georg Nigrinus (Schwartz, 1530 1602) vgl. A. Link, Nigrinus, Georg, ADB XXIII (1886) 695-698. Zu dem Juristen und Historiographen Johannes Sleidan (eig. Philippi, 1506-1556) vgl. S. Rau, Geschichte und Konfession. Städtische Geschichtsschreibung und Erinnerungskultur im Zeitalter von Reformation und Konfessionalisierung in Bremen, Breslau, Hamburg und Köln (Hamburger Veröffentlichungen zur Geschichte Mittel- und Osteuropas, 9), Hamburg/München 2002, 106-108, passim: in seiner Zeit in Paris (etwa 1533-1542) hatte Sleidan Quellen vor allem zur Geschichte des Papsttums gesammelt (ebd., 108). $\mathrm{Zu}$ Sleidans Zeitgeschichte De statu religionis et rei publicae Carolo Quinto Caesare Commentariorum Libri XXV vgl. St. Benz, Zwischen Tradition und Kritik. Katholische Geschichtsschreibung im barocken Heiligen Römischen Reich (Historische Studien, 473), Husum 2003, 57-58, passim. Zu seinem universalgeschichtlichen Lehrbuch De quatuor summis imperiis libri tres (1556) vgl. E.Cl. Scherer, Geschichte und Kirchengeschichte an den deutschen Universitäten. Ihre Anfänge im Zeitalter des Humanismus und ihre Ausbildung zu selbständigen Disziplinen, Freiburg i. Br. 1927, Nachdr. Hildesheim/New York 1975, 46-48, passim; Liste der mehr als 80 Auflagen, Bearbeitungen und Übersetzungen S. 476-480, Nr. 61.

40 Wolff (wie Anm. 1), I, f. ) ()()$\left(3^{\mathrm{v}}:\right.$, „[...] cùm in reuidendo animaduerterem, opus in aliquot volumina præter opinionis spem excreuisse, nolui, plures eius esse partes, quàm duas; \& ideo à plerisq; autoribus subtraxi multa (aliò differendi animo) admodum, vt plurimorum obiter $\&$ titulotenus tantùm sit in his duobus libris facta mentio: spero autem, pauca, $\&$ breuia nonnunquam ea sufficientia fore, $\&$ eò inseruitura, vt quarum rerum saltem gustus quidam datur hîc, illarum illectamento postea ad ipsos recurrendi autores, ad capiendum \& hauriendum inde pleniora vberiùs, ansam industrius Lector arripiat: nam plura apponere, numerus sanè trium ferè millium autorum, ex quibus congestum est hoc Opus, admittere noluit.“ 
Schriften, wenn sie nicht vorhanden - also offensichtlich ungedruckt - oder sehr selten waren. ${ }^{41}$ Trotz der Zitatzeichen, Idem am Beginn eines Absatzes sowie manchmal Hac N. am Ende eines Blocks von Exzerpten, ${ }^{42}$ lassen sich Wolffs Anteile nicht durchwegs deutlich eingrenzen. Zudem ist in jedem Fall aufs neue zu klären, mit wessen Argument verbunden Wolff ein namentlich nicht gekennzeichnetes als scheinbar eigenes setzt.

Aufgrund ihrer Struktur wie ihrer inhaltlichen Ausrichtung könnten die Lectiones memorabiles als ein Werk im Gefolge der Ecclesiastica historia Magdeburgica $^{43}$ oder als ein erweiterter und stärker noch historisierter Catalogus tes-

41 Wolff (wie Anm. 1), I, f. )()()( $3^{\mathrm{v}}$ : „Quædam scripta integra inserui, quia vel non extant, vel etiamsi extent, valdè sunt rara; necdum in omnium manus peruenerunt: tum etiam ne omninò interciderent: iuxta Poëtam enim, Non minor est virtus, quàm quarere, parta tueri." Vgl. Ludwig, Gaspar Bruschius (wie Anm. 2), 5, 82-102, zu umfänglichen, bei Wolff abgedruckten Exzerpten aus einem anderweitig nicht bekannten, kirchen- und klostergeschichtlichen Manuskript des Bruschius. Vgl. unten Anm. 69.

42 Wolff legte Wert auf Wörtlichkeit, zum einen wegen eines auch in altertümlich wirkender, dunkler Rede womöglich enthaltenen Bedeutungsüberschusses, zum anderen um Kritikern den Wind aus den Segeln zu nehmen: Wolff (wie Anm. 1), I, f. )()()( $3^{\mathrm{v}}$ : „In allegandis autem authoribus, malui ipsorum verbis, quàm meis vti eò, quòd dulciùs ex ipso fonte bibantur aque. Nam tametsi multi obscurè, quidam (veterum more) stylo non admodum concinno loquuntur; tamen habet hoc iucundi priscorum quorundam obsoleta dictio, ac suo quodam modo rudiùs comta oratio, vt ex ea plus intelligamus, quàm dicitur, plus significetur, quàm effertur. || Deinde etiam authorum verba, addito cuiuslibet nomine; $\&$ anno, quo claruit; retinui, ob viperas $\&$ morsus zoilorum, ne possent cauillari, corruptum, mutatum, in sensus alienos peruersum aliquid, aut deprauatum esse, aut me, instar corniculæ Aesopicæ, velle me exornare plumis alienis, \& venditare peregrina pro meis, antiqua pro nouis. Igitur si velint, autoribus ipsis (mea enim, quod apertè dico, non sunt) dentem infigant, non mihi, [...]."

43 VD 16, E 218-238. Vgl. H. Scheible, Die Entstehung der Magdeburger Zenturien. Ein Beitrag zur Geschichte der historiographischen Methode (Schriften des Vereins für Reformationsgeschichte, Nr. 183, Jg. 72), Gütersloh 1966; G.B. Lyon, Baudoin, Flacius, and the Plan for the Magdeburg Centuries, Journal of the History of Ideas 64 (2003) 253-272; O.K. Olson, Matthias Flacius and the Survival of Luther's Reform (Wolfenbütteler Abhandlungen zur Renaissanceforschung, 20), Wiesbaden 2002, 256-279; Hartmann (wie Anm. 31), 198-204, passim; A. Grafton, Where was Salomon's House? Ecclesiastical History and the Intellectual Origins of Bacon's New Atlantis, in: Die europäische Gelehrtenrepublik im Zeitalter des Konfessionalismus. The European Republic of Letters in the Age of Confessionalism, hg. von H. Jaumann (Wolfenbütteler Forschungen, 96), Wiesbaden 2001, 21-38, hier 26-33; M. Wallraff, Die Rezeption der spätantiken Kirchengeschichtswerke im 16. Jahrhundert, in: Auctoritas patrum II. Neue Beiträge zur Rezeption der Kirchenväter im 15. und 16. Jahrhundert. New Contributions on the reception of the Church Fathers in the 15th and 16th Centuries, hg. von L. Grane/A. Schindler/M. Wriedt (Veröffentlichungen des Instituts für Europäische Geschichte Mainz. Abteilung abendländische Religionsgeschichte, 44), Mainz 1998, 223-255, hier 242-247; ferner auch H. Hotson, The Historiographical Origins of Calvinist Millenarianism, in: Protestant History and Identity in Sixteenth-Century 
tium veritatis erscheinen. In der Tat verarbeitete Wolff Exzerpte aus dem Catalogus des Matthias Flacius Illyricus $(1520-1572)^{44}$ kommentarlos, zählte dieser doch offensichtlich zu similibus, ${ }^{45}$ und er nutzte das Werk der Magde-

Europe, II: The Later Reformation, hg. von B. Gordon, Aldershot/Brookfield, USA/ Singapore, u.a. 1996 (repr. 1998), 159-181.

44 VD 16, F 1293-1294. Vgl. W. Schmidt-Biggemann, Flacius Illyricus' „Catalogus testium veritatis" als kontroverstheologische Polemik, in: Reformer als Ketzer. Heterodoxe Bewegungen von Vorreformatoren, hg. von G. Frank/F. Niewöhner. Unter Mitarbeit von S. Lalla (Melanchthon-Schriften der Stadt Bretten, 8), Stuttgart/Bad Cannstatt 2004, 263-291; I. Backus, Historical Method and Confessional Identity in the Era of the Reformation (1378-1615) (Studies in Medieval and Reformation Thought, 94), Leiden/Boston 2003, 343-350; Hartmann (wie Anm. 31), 141-146 (vgl. 213); Olson (wie Anm. 43), 233-251. Papsttumskritik als zentralen Aspekt hebt hervor H. Scheible, Der Catalogus testium veritatis. Flacius als Schüler Melanchthons, Blätter für pfälzische Kirchengeschichte und religiöse Volkskunde 63 (1996) 343-357. Vgl. ferner Th. Haye, Der Catalogus testium veritatis des Matthias Flacius Illyricus - eine Einführung in die Literatur des Mittelalters?, ARG 83 (1992) 31-48. Wolff dürfte mindestens auch eine Handschrift des Catalogus zu Händen gewesen sein, denn Crusius (vgl. oben Anm. 30) bemerkt am 16. Juli 1597: „Item Licentiato Iur. Ioanni Wolfio (.qui nunc etiam Hailprunnae est.) scribens, meos Testes verit. Illyrici repeto. Gratulor de opere absoluto.“ (Diarium I, 365,30-32); am 4. Juni 1600: „Audio, [...] Hailprunnae mortuum esse Ioan. Wolfium, Iur. Licentiatum: cuius opus excudatur Lavingae. Non reddidit mihi codicem Illyrici de testibus veritatis, quem ante plures annos ei commodaueram." (Diarium III, 91,17 und 19-21; vielleicht bezieht sich darauf auch Crusius' Notiz vom 11. Juni 1599, Diarium II, 294,9-10). Zu Flacius vgl. Th. Kaufmann, Matthias Flacius Illyricus. Lutherischer Theologe und Magdeburger Publizist, in: Mitteldeutsche Lebensbilder. Menschen im Zeitalter der Reformation, hg. von W. Freitag, Köln/Weimar/ Wien 2004, 177-199.

45 Vgl. oben Anm. 39. Als Beispiele seien genannt Wolff (wie Anm. 1), I, 360: „1150. Arnoldus Brixiensis. HIc suâ ætate (hoc est Conrado Imperatore) Papæ, \& Ecclesiasticorum tyrannidem, \& luxum grauiter reprehendit, [...]“; ebd., 656-657: „1150. Ex Visionibus virginis Elizabethe Germana. || ELizabeth virgo Germana floruit circa annum 1150. \& fuit Diuæ Hildegardis familiaris. [...]", mit Datierungen und Textpassagen übernommen aus: Catalogus testi- || VM VERITATIS, QVI \| ante nostram ætatem recla- || marunt Papæ. || Opus uaria rerum, hoc presertim tempore || scitu dignißimarum, cognitione refertum, || ac lectu cum primis utile atq; || necessarium. || Cum Præfatione MATHIÆ FLA- || CII Illyrici, qua Operis huius \& || ratio \& usus exponitur. || 3. Reg.I9. Rom.II || Reliqua mihi ipsi feci septem millia uirorum, qui || non incuruarunt genu imagi- || ni Baal. || BASILEÆ PER IOAN- \|| nem Oporinum. [1556], 645, 656-657. Vgl. M. Roddewig, Flacius, Vergerius, Foxe, Wolfius, Mornay und der erste deutsche Übersetzungsversuch aus dem Paradiso vom Jahr 1573, Deutsches Dante-Jahrbuch 44/45 (1967) 100-149, hier 104, 132-137, passim, über die Quellen (u.a. Flacius' Catalogus), aus denen Wolff seine Bemerkungen über Dante und Zitate aus dessen Schriften bezieht; dazu Olson (wie Anm. 43), 248-251; P.G. Schmidt, Elias of Thriplow - A ThirteenthCentury Anglo-Latin Poet, in: Papers of the Liverpool Latin Seminar. Third Volume 1981, hg. von F. Cairns (Classical and Medieval Texts, Papers and Monographs, 7), Liverpool 1981, 363-370, hier 368, zu Bemerkungen Wolffs über einen wenig bekannten englischen Autor vielleicht aus der zweiten Hälfte des 13. Jahrhunderts, die auf Flacius' Catalogus beruhen; D. Kurze, Johann von Wünschelburg, ${ }^{2}$ VL IV (1983) 818 - 
burger Zenturiatoren als Quelle. Dessen hervorstechendes Merkmal, die Gliederung nach loci innerhalb jeder Zenturie, ${ }^{46}$ findet sich jedoch nicht bei Wolff.

Am augenfälligsten in den Lectiones memorabiles ist die Präsenz prophetischer Materialien aller Art. ${ }^{47}$ Namhaft gemacht hat dies für joachimisch-joachitische Texte Marjorie Reeves, die hier nicht nur Pseudo-Joachim von Fiore reichlich zitiert fand, sondern darüber hinaus feststellte: „Wolf's collection of prophecies is so extensive that it forms a major source for the study of this type of material. “48 Nun zielen nicht alle signa und vaticinia, die Wolff anführt, unmittelbar auf endzeitliche Ereignisse, ${ }^{49}$ aber insbesondere im zweiten, dem 16. Jahrhundert gewidmeten Band gewinnen sie an Brisanz, denn ihr Sammler hat gegebenenfalls Daten mitzuteilen. Zudem kann Wolff ein eigenes Interesse an dieser Art von Zukunftsschau nicht abgesprochen werden, zumindest sofern es sich um Texte ,seines' Reformators handelt. Er habe, so berichtet er zum Jahr 1560, aus Büchern und Schriften Luthers viele Vatizinien gesammelt und sie in sein Werk einzufügen beabsichtigt, bis ein gedrucktes Büchlein Georg Walthers

822, zu Daten und Textauszügen, die Wolff aus Flacius übernommen hat, wie dies zuerst F. Lauchert, Materialien zur Geschichte der Kaiserprophetie im Mittelalter, HJb 19 (1898) 844-872, hier 844-845, im Hinblick auf Johann von Wünschelburg (um 1385-nach 1456) bemerkt hatte.

$46 \mathrm{Zu}$ den 16 loci vgl. Scheible (wie Anm. 43), 9-10, passim.

47 In einer 1650 gehaltenen und publizierten „Friedens-Danck-Predigt“ zitiert der Straßburger Theologe Johann Conrad Dannhauer eine sonst nicht bekannte Prophezeiung Luthers aus Wolffs Lectiones memorabiles; vgl. Th. Kaufmann, Dreißigjähriger Krieg und Westfälischer Friede. Kirchengeschichtliche Studien zur lutherischen Konfessionskultur (Beiträge zur historischen Theologie, 104), Tübingen 1998, 130-134, hier 133-134 mit Anm. 343. Vgl. A. Hamilton, The Apocryphal Apocalypse. The Reception of the Second Book of Esdras (4 Ezra) from the Renaissance to the Enlightenment (Oxford Warburg Studies), Oxford 1999, 147: „Wolf [...], had studied under Melanchthon, and his work is an illustration [...] also of the immense interest in non-canonical prophecy which Melanchthon's friends and followers had inherited."

48 M. Reeves, The Influence of Prophecy in the Later Middle Ages. A Study in Joachimism, Oxford 1969 (new edition Notre Dame/London 1993), 487-488, Zitat S. 488 f., Anm. 11. Als „die Zeichen der Zeit [...] im Jahre 1600 in zwei gewaltigen Folianten [...] kompendiös und in einmaliger Geschlossenheit zusammengestellt" las jüngst Thomas Kaufmann in einer endzeitlich getönten, kirchengeschichtlichen Perspektive Wolffs Werk; vgl. Dens., 1600 - Deutungen der Jahrhundertwende im deutschen Luthertum, in: Jahrhundertwenden (wie Anm. 12), 73-128, hier 85-86, vgl. 89, 93.

49 Abgesehen von den zahlreichen prophetischen Hinweisen auf eine Reform der Kirche, die Wolff in der (Kirchen-)Geschichte findet, seien einige Prophezeiungen auf Martin Luther genannt; z. B. Wolff (wie Anm. 1), I, 393, ad a. 1170 (da der hier zitierte Paracelsus ein wundersames Bildzeichen Friedrich Barbarossa zuweist); ebd., 669 im Liber de magnis tribulationibus des Telesphorus von Cosenza (vgl. Reeves, [wie Anm. 48], 524, passim), worauf Wolff schon in seiner Epistola dedicatoria in Bd. I, f. $)()\left(2^{\mathrm{r}-\mathrm{v}}\right.$, zu sprechen gekommen war; II, 78, ad a. 1517 („Memorabile“). 
in seine Hände gelangt sei, in dem dieser viele von ihnen bereits veröffentlicht und ihn also von seinem Vorhaben abzusehen gezwungen habe. ${ }^{50}$

Wolffs Sammeln und Schreiben fand in einem Zeitraum statt, der als Phase einer sich verdichtenden „Endzeitmentalität“ im Luthertum gilt. ${ }^{51}$ Dies ist etwa an Flugschriften, Predigten, Praktiken und Prognostiken, Traktaten vielfältig nachgewiesen worden. ${ }^{52}$ Mit Luther im Papsttum den Antichrist offenbart zu sehen, stellte einen entscheidenden Eingriff in die Chronologie der Endzeitereignisse $\mathrm{dar}^{53}{ }^{53}$ ohne dass damit notwendig Zeitpunkte erkennbar werden mussten, die zu wissen unverändert in Gottes Ratschluss lag. Es fragt sich also, welche Verschränkungen die von Wolff als jahrhundertealt belegten Diskurse

50 Wolff (wie Anm. 1), II, 804: „1560. Georgius VValther. || EX tomis \& scriptis Lutheri multa ego vaticinia collegeram, $\&$ huic operi inserere animus fuerat: interea verò quidam libellus huius Georgij VValtheri typis excusus in manus meas peruenit, in quo ipse multa de ijs iam publicauit: ideoque me proposito desistere compulit." Vgl. Koch (wie Anm. 35), 105, 108-109, 114; seiner Bibliographie zufolge war Walthers 1559 in Wittenberg erschienene Sammlung Prophezeiungen D. Martini Lutheri nicht die erste ihrer Art. Die Verfassernamen der wenigen früheren erscheinen jedoch nicht in Wolffs Register zum zweiten Band der Lectiones memorabiles. Vgl. Barnes, Prophecy (wie Anm. 28), 60-62; I. Dingel, Strukturen der Lutherrezeption am Beispiel einer Lutherzitatensammlung von Joachim Westphal, in: Kommunikationsstrukturen im europäischen Luthertum der Frühen Neuzeit, hg. von W. Sommer (Die Lutherische Kirche Geschichte und Gestalten, 23), Gütersloh 2005, 32-50, hier 46 zu prophetischen Sammlungen.

51 Kaufmann (wie Anm. 36), 85-86.

52 Vgl. Leppin (wie Anm. 12); Kaufmann (wie Anm. 36 und 48); Barnes (wie Anm. 11, 12 und 28); E. Koch, Bibelauslegung und Endzeiterwartung in der frühen Neuzeit, in: Endzeitvorstellungen, hg. von B. Haupt (Studia humaniora, 33), Düsseldorf 2001, 313329, hier 313-317. Vgl. zu eschatologischen Ängsten im weiteren Rahmen von 1348 bis 1660 J. Delumeau, La Peur en Occident (XIV - XVIII ${ }^{\mathrm{e}}$ siècles). Une cité assiégée, Paris 1978, 197-231.

53 Vgl. Leppin (wie Anm. 12), 108, 209: End- und Widerchrist müssen nicht identisch sein. Zur Entwicklung von Luthers Antichristkonzept vgl. ebd., 214-220: Luthers Verständnis des Antichrist ist kein biographisches, sondern ein kriterienhaftes, an II Th 2,3-4 orientiertes. Dies ermöglicht ihm dessen Identifikation mit dem Papsttum nach Gregor I. († 604); vgl. dazu H. Preuß, Die Vorstellungen vom Antichrist im späteren Mittelalter, bei Luther und in der konfessionellen Polemik. Ein Beitrag zur Theologie Luthers und zur Geschichte der christlichen Frömmigkeit, Leipzig 1906, 83-182, hier 157-161; vgl. 202-206 zu den Antichristauffassungen lutherischer Theologen. Umfassend zur lutherischen Argumentation nach der Chronologie der Text- und Bildquellen vgl. I. Richardsen-Friedrich, Antichrist-Polemik in der Zeit der Reformation und der Glaubenskämpfe bis Anfang des 17. Jahrhunderts. Argumentation, Form und Funktion (Europäische Hochschulschriften, Reihe I: Deutsche Sprache und Literatur, 1855), Frankfurt a. M./Berlin/Bern u.a. 2003, 78-133; zur Rezeption 134-149, passim, bes. 139-141 zu Luther als Offenbarer des Antichrist. Hierzu kurz mit Schwerpunkten im englischen Protestantismus R.K. Emmerson, Antichrist in the Middle Ages. A Study of Medieval Apocalypticism, Art, and Literature, Manchester 1981, 206-223 mit $301-$ 308. 
der Reformbedürftigkeit und des Reformbedürfnisses mit welchen Vorstellungen über Endzeitlichkeit in den Lectiones memorabiles eingehen. Wer sind ihre Akteure in den von Wolff für kompilierenswert und veröffentlichungswürdig gehaltenen Zeugnissen? Welche Spezifika des Werks sollten seine Zeitgenossen und -genossinnen angesichts eines reich besetzten Markts an ähnlich ausgerichteten Druckerzeugnissen zu Kauf und Lektüre animieren?

\section{Argumentationslinien in den Lectiones memorabiles}

Als Movens seines Tuns nennt Wolff nicht nur die Beobachtung der Glaubenszweifel und -wechsel gebildeter und gelehrter Männer, die ihn ins Grübeln über sein Seelenheil versetzt und ihn veranlasst habe, sich mit frommen Männern auszutauschen. Darüber unbefriedigt habe er die Bibel, dann die Kirchenväter und andere historiae nach der Wahrheit zu durchforsten begonnen ${ }^{54}$ und sich unter Hintanstellung seiner dienstlichen Aufgaben bald nur noch der sammelnden Erforschung der Klagen über vergangene und gegenwärtige Missbräuche in Kirche und Gemeinwesen gewidmet. ${ }^{55}$ Sondern er verweist auch auf Resonanzen im öffentlichen Raum der fürstlichen und gelehrten Männer in Kirche und Politik, die er offensichtlich kommunikativ zu erzeugen gewusst hatte. ${ }^{56}$ Schließlich habe er sich zu einer Publikation seiner lectiones „publicæ saluti \& vtilitati“ sowie „inseruiendi veritati religionis studio" bewegen lassen. ${ }^{57}$

54 Wolff (wie Anm. 1), I, f. )()()(2v : „Cùm ante hæc tempora, etiam magnæ eruditionis \& sapientiæ viros in causâ religionis vacillare, \& nunc mutare, nunc verò abnegare priorem fidem suam, in qua nati, baptizati, \& educati fuerant, viderem: cœpi \& ego de animæ mex salute esse solicitus, \& cum doctis pijsque viris de hac re sæpius conferre. $\|[\ldots]\|$ Veruntamen ego non acquiescendum ratus huiusmodi rationi; \& precatus Deum cum Dauide, vt auertat oculos meos à vanitate, ne similis fierem descendentibus in lacum: sed vt confiteri ipsi Domino possem in Ecclesiâ magnâ, \& in populo graui laudare eum: diligenter primùm ex sacris literis, deinde. S. Patribus, aliisq; historijs, quas vndiquaque comparare $\&$ reperire poteram, de rei veritate disquirere cœpi. Ad quam rem non parùm commodabant mihi peregrinationes, frequentes illustrium ac celebriorum terræ locorum visitationes, \& legationes." Es folgt der Bericht über Wolffs Bibliotheksbesuche und Lektüren (s. oben Anm. 24).

55 Wolff (wie Anm. 1), I, f. ) ()()$\left(2^{\mathrm{v}}-3^{\mathrm{r}}\right.$ : „Gustu igitur dulcedinis ex veritate percepto, tandem ad inquirendum altiùs eam $\&$ rimandum, relictis omnibus penè negotiis politicis $\&$ aulicis, vnicè huic me dedicaui, \& solicitè statum Ecclesiæ antiquæ $\&$ hodiernæ (etiam vltra illud præscriptum Horatij, nonum preme in annum) non absq; magnis laboribus, $\&$ sumtibus indagaui. Quibus dum sedulò incumberem, \& tot tantasq; querimonias \& detestationes omnifariorum abusuum, tam in Republica, quàm præcipuè in Ecclesia, patrum, \& aliorum grauissimorum authorum penè infinitorum offenderem, cœpi memoriæ causâ colligere \& coaceruare huiusmodi testimonia $\&$ authoritates, soli mihi, vt instar solatij, speculi, normæ \& indicis essent in hac causa.“ 
Wie die Reaktionen seiner Zeitgenossen sich tatsächlich gestalteten, bliebe zu erforschen. Solange etwa aus Briefwechseln oder persönlichen Aufzeichnungen nicht mehr über die Haltungen der Freunde, Gesprächspartner oder Korrespondenten Wolffs zu den Lectiones memorabiles bekannt ist, lassen sich nur Einzelbeobachtungen beibringen. So ließ der Rat der lutherischen Stadt Heilbronn dem neuen Bürger Wolff, als dieser sich etliche Bücher aus der Ratsbücherei ausleihen wollte, mitteilen, dass er „,durch solch Buch wider das Papsttum, sonderlich mit dem hiesigen Dato, einem ehrbaren Rat keinen Anhang machen "“ solle. $^{58}$ Seinen württembergischen Landesherrn scheint Wolff vergeblich um finanzielle Unterstützung seines Unternehmens angegangen zu sein. ${ }^{59}$ Die Widmungsträger des ersten Bandes, die pommerschen Herzöge

56 Wolff (wie Anm. 1), I, f. )()()(3 (im Anschluss an das Zitat in Anm. 55): „Cùm verò postmodùm inter viros principes ac doctos, \& Ecclesiasticos \& Politicos, sermo fieret de hisce rebus, \& explicarem nonnunquam ego, quæ huius vel alterius authoris esset mens \& sententia, ita vt ex me intelligerent, non exiguam copiam ex varijs scriptoribus me domi consignatam habere: nonnulli etiam ipsi vidissent promtuarium huiusmodi lectionum; hunc quasi thesaurum apud vnum hominem delitescere, nolentes, sed vrgentes diu multumq;, \& tandem importunè nonnihil, me hæc etiam alijs editione publicâ communicare voluerunt; dicentes: dubium non esse, quin, si multi, qui in Papatu viuunt, cognitum \& exploratum haberent, quid esset veritas; \& quòd nonnulla mera essent hominum figmenta, totq; vitiis $\&$ abusibus pleraque referta; multaque vel quæstus causâ, vel dominandi libidine excogitata; seriò ipsimet miseram suam sortem essent deploraturi, si docerentur, quâ esset incedendum, ne veritate fidei aberrantes, seipsos salute defraudarent." Mehr und besser zu wissen, könnte möglicherweise in besonderem Maß zu Wolffs persönlicher Umsetzung des Habitus eines gelehrten Juristen gehört haben; vgl. die Reiseerinnerung von 1567, die er 1600 als memorialen Schlusspunkt gegen Ende seiner Widmung des ersten Bandes an die pommerschen Herzöge positioniert: Sie besteht darin, den eigenen, damals schon nicht zurückgehaltenen Tadel fremden Nichtwissens - angesichts des königlichen Mausoleums in der Kathedrale von Bayonne - ins Gedächtnis zu rufen („[...] ego me non continere potui, quin hanc ignorantiam illis exprobrarem." Ebd., f. $)()()\left([6]^{\mathrm{r}-\mathrm{v}}\right)$.

57 Wolff (wie Anm. 1), I, f. ) ()()$\left(3^{\mathrm{r}}\right.$ (im Anschluss an das Zitat in Anm. 56): „Et huius sanè fatale rei experimentum cùm in proprijs viderim ædibus, motus eo, non potui non publicæ saluti \& vtilitati inseruire. [Es folgt die Geschichte vom sich bekehrenden Sekretär, vgl. oben Anm. 35; im Anschluss an den dort zitierten Text:] Motus ergò amicorum precibus, \& inseruiendi veritati religionis studio, ad limam \& regulariorem seriem reuocaui lectionum harum farraginem, $\&$ ad prælum (nam quis vetet, apposito lumen de lumine summi) adornaui." Zu utilitas publica im sich ausdifferenzierenden ius publicum vgl. einleitend M. Stolleis, Geschichte des öffentlichen Rechts in Deutschland, I: Reichspublizistik und Policeywissenschaft 1600-1800, München 1988, 76.

58 Vgl. von Rauch (wie Anm. 10), 2, mit Zitat aus dem Ratsprotokoll vom 24. Januar 1595.

59 Dies lässt sich aus einer Randnotiz des Crusius in seinem Tagebuch zum 1. Januar 1598 schließen: „[...] frustrà petit sumptus à Wirtemb. Princ. ad operis sui editionem.“ (Diarium II, 1, Anm. zu Z. 10; im Anschluss an den Text in Anm. 9). Am 20. Mai 1598 vermerkt Crusius mit einem „NB!“ am Rande, Christoph Nenning habe ihm berichtet, 
Barnim und Philipp Julius, unterstützten Wolffs Erben nach dessen vor dem Druck erfolgtem Tod, indem sie das Werk von ihrem Kanzleiboten nach Lauingen zum Druck bringen ließen und Geld gaben. Zudem erhielt „Wolffs Freundschaft" 15 Goldgulden, als am 25. September 1600 die zwei Bände dem Rat präsentiert wurden. ${ }^{60}$ Der Absatz scheint jedoch zögerlich vonstatten gegangen zu sein, denn die Witwe Barbara Rollwag bat später - „wohl vergeblich“ - den Rat, ihr 20 Exemplare abzukaufen. ${ }^{61}$ Im 1601 gedruckten Panegyricus auf Wolff feierte Gregorius Rollwagen die Lectiones memorabiles als Haupt- und Lebenswerk des Verstorbenen, ${ }^{62}$ und in den sich anschließenden Carmina Funebria - angeführt von einem carmen des Wolff besonders verbundenen Paulus Melissus Francus und beendet von einem griechischen, zudem lateinisch wiedergegebenen carmen des Martin Crusius - werden sie mehrfach rühmend thematisiert. ${ }^{63}$ Offensichtlich blieben sie von Interesse, denn 1608 erschien in

das Werk Wolffs solle in Stuttgart gedruckt werden: „Ait idem, D. Ioannis Wolfii opus, Stutgardiae excusum iri." (ebd., 54,26).

60 Vgl. von Rauch (wie Anm. 10), 2, mit Zitat aus dem Ratsprotokoll vom 25. September 1600. Das Werk war zur Buchmesse in Frankfurt angekündigt; vgl. Crusius' Tagebucheintrag zum 25. September 1600: „Ex Indice librorum in his Nundinis Franc. [...] 3). Ioan. Wolfii I. C. lectionum memorabilium et reconditarum Centenarii XVI. Lauingae in folio apud Rheinmichelium." (Diarium III, 167,22 und 29-30). Zu den Kontakten zwischen Crusius und Wolff vgl. oben Anm. 30 sowie unten Anm. 61 und 63.

61 Vgl. von Rauch (wie Anm. 10), 2-3; Zitat S. 2. Crusius (vgl. oben Anm. 30) nennt 7 Gulden als Preis: „Opus magnum VII fl. D. Ioan. Wolfii, Lauingae excusum: lectionum memorab. et reconditarum centenarios 16 à Grupp. mihi commodatum, coepi hinc inde videre. Ibi in parte 2. [...]." (Diarium III, 176,23-25 am 11. Oktober 1600; Georg Gruppenbach, Buchhändler und Buchdrucker in Tübingen, im Tagebuch sehr oft genannt). Zum Vergleich: „Ich hab pro hoc anno, schatzung und steur bezalet $12 \mathrm{fl} .12 \frac{1}{2} \beta$. ut et antehac. perlustrabam (.hodierno die, et hisce diebus.) alterum Tomum Ioan. Wolfii (.qui continet $16^{\mathrm{m}}$ centenarium, vel seculum, Christi.) ligatum. Mea Facultas emit Exemplar unum: et item Senatus, unum: utrique, in suam Bibliothecam." (Diarium III, 195,18-22 am 23. November 1600).

$62 \mathrm{Vgl}$. Rollwagen (wie Anm. 2), f. $9^{\mathrm{v}}-10^{\mathrm{r}}$ (panegyrisch aus dem Werktitel schöpfend); f. $23^{\mathrm{v}}-24^{\mathrm{v}}$ (im Lebenslauf mit Angaben zur Entstehung; vgl. oben Anm. 25); f. $26^{\mathrm{r}-\mathrm{v}}$ (als Nachlass).

63 Rollwagen (wie Anm. 2), f. $27^{\mathrm{r}}-35^{\mathrm{r}}$; zu Paulus Melissus Francus vgl. ebd., f. 25․ Von ihm, dem zu dieser Zeit in Deutschland poetisch einflussreichen Paulus Melissus Schede (1539-1602), stammt auch das Gedicht „In Effigiem Iohannis VVolfir I.C.“ zu einem Porträt Wolffs von 1597, das sich auf den Versoseiten der Frontispize von Bd. 1 und 2 der Lectiones memorabiles sowie des Titelblatts von Rollwagens Panegyrikus befindet. $\mathrm{Zu}$ Schede vgl. E. Schäfer, Paulus Melissus Schedius (1539-1602). Leben in Versen, in: Humanismus im deutschen Südwesten. Biographische Profile. Im Auftrag der Stiftung „Humanismus heute“ des Landes Baden-Württemberg hg. von P.G. Schmidt, Sigmaringen 1993, 239-263; L. Piepho, Paulus Melissus and Jacobus Falckenburgius: Two German Protestant Humanists at the Court of Queen Elizabeth, Sixteenth Century Journal 38 (2007) 97-110, hier 103. Crusius (vgl. oben Anm. 30) notiert am 14. März 1601: „Epigramma Graecolat. ad orationem funebrem D. Ioannis Wolfii scripsi.“ 
Lauingen ein Index absolutissimus des Johann Jakob Hagendorn, gen. Linsius, der sie insbesondere nach Sachen erschloss. ${ }^{64}$ Dass das Werk auch in der katholischen Gelehrtenwelt zur Kenntnis genommen wurde, zeigen beispielsweise die Nachforschungen, die der Jesuit Johannes Busaeus (1547-1611) auf Anfrage von Matthäus Rader SJ (1556-1634) wegen einer darin enthaltenen, den Begründer der jesuitischen Präsenz im deutschsprachigen Raum, Petrus Canisius SJ (1521-1597), diffamierenden Geschichte anstellte. ${ }^{65}$

Wolff entfaltet sein antipäpstliches Hauptargument, den historischen Befund der immer schon vorhanden gewesenen berechtigten Kirchenkritik, entlang mehrerer quellengeleiteter Argumentationslinien. In der Epistola dedicatoria zum ersten Band der Lectiones memorabiles verzeichnet er zunächst, wie erwähnt, die seit der Zeit der spätantiken Kirchenväter des zweiten Jahrhunderts bis in seine Gegenwart nachweisbaren Diagnosen von Verderbnis und Lehrirrtümern in der römischen Kirche, die doch den Primat aufgrund der Apostelnachfolge behaupte. ${ }^{66}$ In einem zweiten, längeren chronologischen Durchgang werden die gleichermaßen auffindbaren Klagen über verkommene Sitten und Ärgernisse in der Kirche, deren Herrschsucht bis zur blutigen Glaubensbefestigung durch die Inquisition sowie die Laster der wenig apostelgleichen Kleriker, insbesondere der Päpste, abgehandelt. ${ }^{67}$

Im Umkehrschluss stellen auch Reformbemühungen Belege im Sinne Wolffs dar. „Reformationes“ würden von einzelnen Herrschern, wie z. B. Kaiser Karl dem Großen († 814) und dessen Sohn Ludwig (I.) dem Frommen († 840) sowie Otto I. († 973) berichtet. Kirchenreform erscheint weiterhin als eine

(Diarium III, 244,32) und am 9. April 1601: „Panegyricum Gregorii Rollwageni, de vita et obitu Ioan. Wolfii Tabernomont. mihi M. Cellius à se excusum mittit." (Diarium III, 259,8-9). Zu Crusius' Praxis zweisprachiger Gedichte vgl. W. Ludwig, Hellas in Deutschland. Darstellungen der Gräzistik im deutschsprachigen Raum aus dem 16. und 17. Jahrhundert (Berichte aus den Sitzungen der Joachim Jungius-Gesellschaft der Wissenschaften e. V., Hamburg, Jg. 16, Heft 1), Hamburg 1998, 55.

64 Vgl. oben Anm. 33.

65 Vgl. den Brief des Johannes Busaeus an Matthäus Rader vom 3. Januar 1611, in: P. Matthäus Rader SJ, Bd. I: 1595-1612, bearb. von H. Zäh/S. Strodel. Eingeleitet und hg. von A. Schmid (Bayerische Gelehrtenkorrespondenz), München 1995, 524-526 (Nr. 259), bes. 525, Anm. 1: Bezugspunkt ist Wolff (wie Anm. 1), II, 707, ad a. 1557. Zu Raders Vita Canisii (Erstdruck 1614) vgl. R. Haub, „Bei Gott, ich erdichte nichts; ich gebe nur der Wahrheit Zeugnis“. Impressionen zum Testament des Petrus Canisius, in: Petrus Canisius SJ (1521-1597). Humanist und Europäer, hg. von R. Berndt (Erudiri Sapientia, 1), Berlin 2000, 313-345, hier 317-319; H.J. Sieben SJ, Von der Kontroverstheologie zur Zusammenarbeit in der Res publica literaria (1546-1643). Jesuitenpatristik von Petrus Canisius bis Fronton du Duc, ebd., 169-201, bes. 187. Diese Hinweise - und manch andere - verdanke ich Jan Marco Sawilla. Die in den Lectiones memorabiles geführte antijesuitische Polemik wäre eigens zu untersuchen.

66 Wolff (wie Anm. 1), I, f. ) $\left(2^{\mathrm{v}}-4^{\mathrm{v}}:\right.$, „[...] de corruptione \& erroribus doctrinæ Ecclesiæ [...]“ (ebd., f. ) $\left(4^{v}\right)$. Vgl. S. 379 mit Anm. 29.

67 Wolff (wie Anm. 1), I, f. ) $\left(4^{\mathrm{v}}-\right)()\left(2^{\mathrm{r}}\right.$. 
Sache der Prophetie joachimisch-joachitischer Prägung, denn nicht nur hatte „Abbas Ioachimus de reformatione futurâ" prophezeit, dass bald jener vom Propheten Jeremia vorhergesagte „ventilator[...] Ecclesiæ sextæ“ kommen und das lang vernachlässigte Evangelium der Wahrheit predigen werde, sondern vor allem hatten Joachim und Telesforus von Cosenza einen zur Reformierung der Kirche berufenen Augustinermönch geweissagt, der sich aus Furcht vor Verfolgung verborgen halten werde, wie es „quidam", so meint Wolff, in Luthers Versteck auf der Wartburg und seiner Berufung nach Wittenberg erfüllt sähen. ${ }^{68}$ Kirchenreform sei das Anliegen des allgemeinen Konzils gewesen, das Kaiser Sigismund voll frommen Reformeifers, aber wenig erfolgreich in Basel veranstaltet habe, und Papst Hadrian VI. (reg. 1522 - 1523) habe durch seine Legaten auf dem Nürnberger Reichstag (1522) die Existenz und Folgen von Missbräuchen an der Kurie anerkennen lassen und deren Reform als Mittel allgemeiner Gesundung versprochen. ${ }^{69}$ Auch hätten zahlreiche weitere Reformvor-

68 Wolff (wie Anm. 1), I, f. ) () (2 ${ }^{\mathrm{r}-\mathrm{v}}$ : „Abbas Ioachimus de reformatione futurâ hoc affirmat super Ieremiæ cap. 8 . \& 13. post B. Gregorij tempora neminem comparuisse, qui populum Dei erudierit, vel rectè ingressus fuerit ad Euangelium veritatis. Et propterea secuturum breui à Ieremia prædictum illum ventilatorem Ecclesiæ sextæ, cui aperiendum sit ostium intelligentiæ, ad prædicandum Euangelium diu omissæ \& amissæ veritatis; contra illum prædicatorem non præualiturum errorem hæreticorum, semet veros confessores dicentium. Super Esaiam part. 2. || Et apertiùs idem Abbas Ioachimus, \& quoque Telesphorus prædixerunt: fore, vt vocetur ad Ecclesiam reformandam monachus Augustinianus, qui ob $\|$ metum persecutorem [!] lateret inclusus, vt sit pastor Ecclesiæ. Quod quidam tunc impletum fuisse dicunt: cùm Lutherus, monachus Augustinianus, proscriptus \& damnatus, latitaret in arce VVartburg, \& ab vniuersitate VVittenbergensi ad ministerium vocaretur. In quo loco adeò mirabiliter conseruatus fuit, vt quemadmodum Diaboli locum sepulti Mosis; sic nec pontificij, etsi Magorum \& Diaboli auxilium implorauerint, locum absconditi Lutheri detegere potuerint. Chytræus in Chron. Arct. \& alij. || Telesphorus de Cusentiâ, \& Petrus de Alliaco tradiderunt, Ecclesiam opus habere magnâ diligentiq; reformatione \& emendatione. [...]. “ $\mathrm{Zu}$ den joachitischen Zitaten und Anspielungen vgl. künftig S. Schmolinsky, Joachim of Fiore through Johannes Wolff. A visit to the archives of Joachism in the Lectiones memorabiles (1600), in: The Influence of Inspiration: The Thought of Joachim of Fiore in Past and Present. Essays Presented to Dr Marjorie E. Reeves on Her Centenary, hg. von J.E. Wannenmacher, Aldershot [im Druck]. Zu Telesforus von Cosenza vgl. R. Rusconi, Il presente e il futuro della Chiesa: unità, scisma e riforma nel profetismo tardomedievale, in: L'attesa della fine dei tempi nel Medioevo, hg. von O. Capitani/J. Miethke (Annali dell'Istituto storico italo-germanico, Quaderno 28), Bologna 1990, 195-220, hier 197 200, 203, sowie die dort genannte Literatur.

69 Wolff (wie Anm. 1), I, f. ) () (2 $2^{\mathrm{v}}-3^{\mathrm{r}}$; ebd., f. ) ()$\left(3^{\mathrm{r}}\right.$ : „Adrianus Sextus Pontifex, legatis suis ad comitia Norimbergensia profecturis dedit in mandatis, vt statibus Imperij suo nomine dicerent, scire Papam, in sanctâ sede aliquot ia[m] annis multa abominanda fuisse, abusus in spiritualibus, excessus in mandatis, \& omnia deniq; in peruersum mutata: nec mirum, si ægritudo à capite in membra, à summis pontificibus ad alios inferiores prælatos descenderit: omnes enim declinare, nec esse, qui faciant bonum, nec esse vsque ad vnum. || Quamobrem necesse esse, vt omnes demus gloriam Deo, \& humiliemus 
schläge klerikaler Provenienz und laikale katholische Äußerungen vorgelegen, die gegebenenfalls einen impliziten Nutzen der lutherischen Sekte eingestanden. ${ }^{70}$ In der Essenz hatten sie lange vor Luthers Geburt dessen Reformation vorhergesagt. ${ }^{71}$

Da nun alle Ermahnungen Gottes, auch die von ihm gesandten Wunderzeichen und Prophetien, ${ }^{72}$ missachtet worden seien, sei offensichtlich, woher so große Übel und Veränderungen in Kirche und Staat resultierten. ${ }^{73}$ Wolff systematisiert mit Hilfe zahlreicher Autor/innen deren Gründe: Gottvergessenheit in der Regierung des Gemeinwesens, missbräuchliche Machtzuwächse der Päpste auf Kosten des Reichs nach einer - vor allem karolingerzeitlichen - Phase geglückter Kirchenherrschaft in Unterordnung unter die Kaiser, Ignoranz und Unverstand Herrschender und insbesondere des Klerus, die Unredlichkeit

animas nostras ei; videatque vnusquisque nostrûm, vnde ceciderit, $\&$ se potiùs quilibet iudicet, quàm à Deo in virgâ furoris sui iudicari velit: qua in re, quod ad nos attinet, pollicebimini, nos omnem operam adhibituros, vt primùm curia hæc, vnde omne hoc malum processit, reformetur; vt, sicut inde corruptio in omnes inferiores emanauit, ita etiam ab eâdem sanitas \& reformatio omnium statuum emanet.“ Ab „scire ..." stammt der Text mit kleineren Abweichungen aus der Instruktion Hadrians VI. (1459-1523), die sein Nuntius Francesco Chieregati (1478-1539) am 3. Januar 1523 auf dem Reichstag zu Nürnberg den Ständen vorlegte; vgl. Deutsche Reichstagsakten unter Kaiser Karl V., III, bearb. von A. Wrede (Deutsche Reichstagsakten. Jüngere Reihe, 3), Gotha 1901 (2. Aufl. photomech. Nachdr., Göttingen 1963), Nr. 74 auf S. 390-399, hier 397; vgl. 385-386: sie entsprach nicht der, die Chieregati am 10. Dezember 1522 verlesen hatte, ohne Einsicht zu gewähren (vgl. Text ebd., 388-389, Anm. 1). Die Fassung des 3. Januar wurde ab 1523 mehrfach gedruckt (vgl. ebd., 391-393), so auch bei Wolff (vgl. ebd., 392-393); vgl. Wolff (wie Anm. 1), II, 195-197.

70 Wolff (wie Anm. 1), I, f. ) () (2 $2^{\mathrm{v}}-3^{\mathrm{r}}$. Wolff hebt besonders Georg Witzel (1501-1573) „peculiari tractatu“ hervor (ebd., f. ) ()$\left(3^{\mathrm{r}-\mathrm{v}}\right)$. Als erster Herausgeber druckt er Witzels 1564 entstandene Schrift über die Kircheneinheit Via regia (ebd., II, 354-393, ad a. 1532); vgl. B. Henze, Aus Liebe zur Kirche Reform. Die Bemühungen Georg Witzels (1501-1573) um die Kircheneinheit (Reformationsgeschichtliche Studien und Texte, 133), Münster 1995, 253-270, zu Wolffs Abdruck und den von ihm abhängigen Drucken des 17. Jahrhunderts S. 259-262 und 403-404: [111,1] und [111,5]; E. Rummel, The Confessionalization of Humanism in Reformation Germany (Oxford Studies in Historical Theology), Oxford 2000, 138-144, hier 141-142, passim. Zu Witzels Modell der frühen Kirche vgl. Backus (wie Anm. 44), 46-51.

71 Wolff (wie Anm. 1), I, f. )()(3v, nach einer Reihe im Hauptteil zu findender Autoren: „Et de aliis pluribus, qui vates multis annis ante Lutherum natum eius reformationem prædixerunt, quoq; ex sequentibus patebit."

72 Wolff (wie Anm. 1), I, f. ) () (3v $-4^{\mathrm{v}}$.

73 Wolff (wie Anm. 1), I, f. ) () (4 $4^{v}$ : „Cùm autem nihil proficerent vel promissa vel minæ Dei, nec possent quicquam patrum, aut quorumcunq; piorum admonitiones aut consilia; ipsa etiam diuinitus missa signa $\&$ ostenta eluderentur, $\&$ in vanum quasi fulgura ex pelui ducerentur ita, vt nec saxis cederet hæc desperata hominum contumacia \& obstinatio, [...], haud meritò quæras, vnde hæc tanta mala \& mutationes (de quibus etiam in altera præfatione dicetur) in Ecclesiâ \& Politiâ.“ 
schlechter Ratgeber. ${ }^{74}$ Gott mehr als die Herrscher respektierende Kleriker seien, insbesondere in geistlichen Dingen, als Fürstenberater nützlich, zumal Politiker nichts über Angelegenheiten der Religion zu befinden hätten. ${ }^{75}$

Den festgestellten Zusammenhang zwischen Vernachlässigung der Religion und Ausbreitung größter Sünden und Übel auch im Staat führt Wolff als eine chronologisch angelegte Zitatencollage über Zustände und Missstände von Herrschaften und Reichen fort, die ab Lactantius (ca. 250-wohl 325) endzeitlichen Charakter annimmt, denn Wolff wählt erklärtermaßen nicht Textausschnitte, die Reichsreformen ansprächen, sondern solche, die das Imperium Romanum als letztes Reich thematisieren. ${ }^{76}$ In präsentischer Zuspitzung ist seine

74 Wolff (wie Anm. 1), I, f. $)()\left(4^{\mathrm{v}}-[6]^{\mathrm{r}}\right.$ : „,[...] quòd olim, cùm Papæ adhuc sub Imperatoribus essent, hi sedulò \& piè gubernabant Ecclesiam, [...]. Sed \&, vt Carolus Magnus, $\&$ Ludouicus eius filius (de quibus etiam suprà) alijq; plures ante \& post illos, referente Adone Episcopo in Chronico, ordinabant viros proprios iustos, pios \& bonos, [...] ita, vt in Ecclesia \& Politiâ omnia optimè se haberent." (ebd., f. ) ()$\left(4^{v}\right)$. Wolff interessierte sich hier besonders für die Auslegung der Rota Ioachimi und plante einen eigenen, wohl nicht mehr zustande gekommenen Traktat: „De quo, \& aliis rotæ ominosæ appictis mysticis infrà quædam, sed plura in proprio tractatu mysteriorum \& hieroglyphicorum, Deo dante.“ (ebd., f. $)()\left([5]^{\mathrm{r}}\right)$. „[...] || Quæ tamen, proh dolor, inscitia multò latiùs serpit etiam in clero hodie, \& perniciosior est Ecclesiæ. [...] || Quarta causa est quorundam vtriusq; status consiliariorum improbitas, [...].“ (ebd.). Nach zahlreichen Beispielen: „Vt igitur breuibus hunc locum absoluamus, pro certo habendum est, Ecclesiasticos \& politicos, qui principi adsunt, vnicam causam esse omnis boni \& mali. [...]“ (ebd., f. )()$\left([5]^{v}\right)$.

75 Wolff (wie Anm. 1), I, f. ) ()$\left([5]^{\mathrm{v}}-[6]^{\mathrm{r}}\right.$ : „Quæstio, num Ecclesiastici consilijs principum interesse debeant, non est huius loci: [...]. Verùm non potest improbari, si non excludantur ij (præsertim vbi de sacris est agendum rebus) qui potiùs Deum respiciant, quàm principum [!] \& sua commoda: \& ad id prosunt, vt reprimant coërceantque eos, [...]. $\|$ Improbandum igitur omninò est, si de sacris iudicare, \& disponere ex suo arbitratu \& ratione soli volunt Politici, cùm nec ipsorum sit hoc officij, nec ea, vtpote quibus nunquam operam dederunt, sciant aut intelligant."

76 Wolff (wie Anm. 1), I, f. )()([6] $]^{\mathrm{r}}$ : „Cùm igitur constet, ex religione neglectâ semper maxima peccata, \& mala etiam in Rempublicam simul transfundi, dici iam posset $\&$ deberet fusiùs de abusibus, vitiisque in Politiâ quoque regnantibus; verùm, quia iam non superest locus perorandi, quomodo essent tollenda, \& Respublica reformanda \& instituenda, remittimus eius rei cupidos ad alios, qui de hac re doctissimè scripsisse putantur." Vgl. ebd., II, f. $)\left(2^{\mathrm{v}}\right.$ : „Qualiter autem in priori libro demonstrari cœptum est, quomodo abusib. defœedatam Ecclesiæ, \& ex hac dependentis Politiæ, communisq; vitæ conditione $[\mathrm{m}]$ semper pij deplorauerint, \& media ad repurganda statuum deliquia oste[n]derint, idq; ipsum cœlu $[\mathrm{m}]$, reru[m]q; natura subinde inhorrueri $[\mathrm{n}] \mathrm{t}$, tali pariter modo hac altera parte ex scriptis vatum pioru[m] \& doctoru[m] virorum ide[m] continuabitur." Vgl. ebd., f. ) (3. Zum einer solchen Argumentation zugrunde liegenden Modell der politica christiana vgl. Schorn-Schütte, Obrigkeitskritik (wie Anm. 13); zum Anteil der gelehrten Juristen seit der Mitte des 16. Jahrhunderts S. 226-227; ferner M. Weiß, „... weltliche hendel werden geistlich." Zur politica christiana des 16. Jahrhunderts, in: Ideen (wie Anm. 13), 109-124. 
Schlussfolgerung eine Frage, nämlich „was endlich zu erwarten sei!“. ${ }^{77}$ Sie setzt ein Zukunftsszenario aus ebenfalls chronologisch angeordneten Zitaten in Gang, die im bekannten straf- und bußtheologisch intendierten Zusammenhang von Sünde und göttlich initiiertem Unheil den Blick zurück auf die verderbte Kirche lenken. Wolff beschließt seine Belege mit einer Äußerung des alten Luther, derzufolge Gott das den Christen gewährte „verbum gratiæ“ wieder entziehen und einem würdigeren und dankbareren Volk übertragen könne, wenn es hartnäckig verschmäht werde. ${ }^{78}$

In der Epistola nuncupatoria zum zweiten, dem Jahrhundert der Reformation gewidmeten Band beschäftigt sich Wolff eingehender mit dem Verhältnis zwischen kirchlichen und weltlichen Mächten. Er diagnostiziert verminderte Kräfte und Einkünfte des Reichs; so viele Federn seien dem Adler vom römischen Klerus ausgerupft und so viele Edelsteine aus der kaiserlichen Krone vom Papst herausgeschlagen worden, dass ein Heilmittel grundlegender Art benötigt werde. Da die Lutheraner sich an keinerlei Recht darüber gewagt hätten, seien die „Romanistae“ dazu zu hören, insbesondere Lorenzo Valla, demzufolge der Kaiser und die anderen Fürsten anzuhalten seien, sich zu bemühen, dass Rom und alles dem Imperium Entfremdete bei Strafe ewiger Verdammnis dem „ordo politicus" zurückgegeben würde. Denn dass die Konstantinische Schenkung erfunden, erlogen und nichtig sei, stehe fest - und Wolff weiß zahlreiche Namen als Zeugen zu nennen -, so dass Valla die Wahrheit schreibe, nicht aber jener Schmarotzer Lupold von Bebenburg. ${ }^{79}$

77 Wolff (wie Anm. 1), I, f. ) $)()\left([1]^{\mathrm{r}}\right.$ : „Cùm igitur satis ex his paucis recensitis constare queat, quæ vitia $\&$ defectus habeat, \& vnde contraxerit Ecclesia, quidque desideretur etiam in Politiâ: quàm item varii Imperiorum, eorumque qui illis præsunt, inde resultent casus, \& mirabiles mutationes, audiamus restat, quia in hac contumaciâ pijs \& salutaribus monitis tam pertinaciter resistere pergimus, quid sit tandem expectandum!"

78 Wolff (wie Anm. 1), I, f. ) ()()( $2^{v}$ : „His adde præsagam hanc Lutheri vocem, quando dolens proiectam mundi peruicaciam, \& verbi diuini contemtum, non longè ante mortem dixit: se vereri, ne nobis; tametsi Euangelij luce purissimâ iam fruamur, ob contemtum \& nauseam illius eueniat, quod Israëlitis. [...] sic \& nobis gentibus iterum potest verbum gratiæ subtrahere, $\&$ in digniorem, $\&$ gratiorem populum transferre, iuxta illud Apostoli dictum Rom. 11. si non permanseris in bonitate, certè excidêris."

79 Wolff (wie Anm. 1), II, f. ) ([5 $]^{\mathrm{r}-\mathrm{v}}$ : „,Videmus interim, adeò attenuatas esse vires \& reditus Imperii, tot euulsas pennas aquilæ à Romano clero, tot excussas ge[m]mas coronæ Cæsareæ à Pontifice, de quo suprà $\&$ in sequentibus, vt omninò opus sit remedio. De hoc cùm Lutherani nihil fari ausint, audiantur ipsi Romanistæ: fuit enim iam dudum agitata hæc quæstio, \& inprimis à Laurentio Valla, dum scribit; teneri Cæsarem \& alios principes, sub pœena æternæ damnationis, operam dent, vt reddantur politico ordini Roma, \& omnia, quæ ab Imperio sunt abalienata. || Constat enim, donationem Constantini fictam, ementitam \& nullam esse; [...]. | Quia autem veritatem scripsit Valla, [...]. Cuius exemplo motus Lupoldus à Babenberg, sacerdos parasitus, ad assequendum Episcopatum Bambergensem, in libro de viribus Regni \& Imperii Romani, contra conscientiam scribit, se nescire, quorum opinio sit verior? Sed ad rem." Die genannten 
Die in der Form einer Gerichtsrede gehaltene Schrift De falso credita et ementita Constantini donatione des Lorenzo Valla (1407-1457), offensichtlich im April/Mai 1440 entstanden, ${ }^{80}$ erscheint im ersten Band der Lectiones memorabiles zu 1411. Wolff führt nur zwei sich auf die gegenwärtige Herrschaftsausübung des Papsttums beziehende Textpassagen aus dem Anfangs- und dem Schlussteil des Werks an. ${ }^{81}$ Wenngleich Vallas Schrift keine direkte Handlungsaufforderung bietet, ${ }^{82}$ so enthält doch das erste Exzerpt einen Satz: „At ego contra existimo iustius licere principibus spoliare te imperio omni quod optines “ ${ }^{83}$ der es als gerechter erwägt, den Fürsten zuzubilligen, das Papsttum seiner weltlichen Herrschaft zu berauben. Legitim sei, sich vom verbrecherischen Vater oder Herrn loszusagen, so führt Valla im zitierten Schlussteil aus, ohne sich - als Christen - derselben blutigen Mittel wie das Papsttum zu bedienen. Legitim sei, aufgrund des päpstlichen Missbrauchs von Macht und Schätzen das „patrimonium ecclesie a Constantino donatum“ den Okkupanten wieder zu entreißen, damit die christliche Religion nicht noch mehr von Schandtaten und Ausschweifungen unterdrückt werde. ${ }^{84}$ Dennoch will Valla Fürsten und Völker nicht zu Zwangsmaßnahmen gegen den Papst aufgerufen haben, sondern zu Ermahnungen an dessen Einsichtsfähigkeit, sich freiwillig in seinen Bereich zurückzuziehen, um nur „vicarius Christi [...] et non etiam Cesaris" zu sein. ${ }^{85}$

Vallas Rede ist in solcher Verkürzung nicht adäquat wiedergegeben, aber dies musste auch nicht Wolffs Bemühen sein, ging es ihm doch, wie ähnlich verfahrenden Interpreten, um das aus der Kondensation resultierende politische Argument, das den protestantischen Juristen zu einer Zeit interessierte, als Valla

Namen in Verbindung mit dem Lupolds lassen vermuten, dass Wolff eine der aus Ulrich Huttens Ausgaben seit 1518 hervorgegangenen kompilierten Ausgaben vorlag; vgl. W. Setz, Lorenzo Vallas Schrift gegen die Konstantinische Schenkung. De falso credita et ementita Constantini donatione. Zur Interpretation und Wirkungsgeschichte (Bibliothek des Deutschen Historischen Instituts in Rom, 44), Tübingen 1975, 95-97, zu Huttens Ausgaben 151-166; Lorenzo Valla, De falso credita et ementita Constantini donatione, hg. von W. Setz (MGH. Quellen zur Geistesgeschichte des Mittelalters, 10), Weimar 1976 (Nachdr. München 1986), 37-41.

80 Valla (wie Anm. 79), 10-13; Setz (wie Anm. 79), 62-63, 190-191.

81 Wolff (wie Anm. 1), I, 746-747; mit Varianten entsprechend Valla (wie Anm. 79), 59,17-61,5 („[...] verum etiam stolidum.“) und 171,7-176,16.

82 Setz (wie Anm. 79), 63.

83 Valla (wie Anm. 79), 60,18-19.

84 Valla (wie Anm. 79), 172,4-11; 173,16-174,4.

85 Valla (wie Anm. 79), 175,18-176,4 und 8-9; Z. 5-6: „Sin recuset, tunc ad alteram orationem multo truculentiorem accingemur.“ Eine solche Schrift hat Valla nicht verfasst. 
längst in den Kreis der lutherischen testes veritatis aufgenommen war. ${ }^{86}$ Die Konstantinische Schenkung bildete für Wolff einen der Aufhänger zur Erörterung des von ihm für zentral gehaltenen Problems des gerechten Maßes in der Verteilung von Rechten und Gerechtigkeiten, wie sie für eine gesunde Respublica vonnöten sei. ${ }^{87}$ Wie seine Beispiele zeigen, zielte dies vor allem auf den weltlichen und geistlichen Besitz von Gütern und die Beteiligung der Kirche an Kriegskosten, insbesondere in Hinsicht auf die Türken. ${ }^{88}$ Zudem existierten zahlreiche Schrecken erregende Vatizinien über bevorstehende Übel - Wolff nennt eine Johannes Hilten zugeschriebene Prophezeiung und eine auf das Reich und die Bedrohung durch die Türken zielende Deutung der Bildprophetie Rota Ioachimi -, so dass fromme, kluge Männer wünschten, dass die zahlreichen Schätze des Reichs besserem Gebrauch zugeführt würden, Legionen aufgestellt und stehende Heere unterhalten würden, die gegen die Feinde des Reichs kämpften, damit die christlichen Fürsten nicht so sehr geschwächt und

86 Vgl. Setz (wie Anm. 79), 44; zu Valla als reformatorischem Wahrheitszeugen S. 166173, 177, 193. In Flacius' Catalogus testium veritatis (wie Anm. 44), 959-960, wird Valla in die Mitte des 15. Jahrhunderts datiert.

87 Wolff (wie Anm. 1), II, f. ) ([6] $]^{\mathrm{r}}$ : „Ex quo eius [= Elizabethæ] sermone certè afflatus diuinus inter alia in eo quoq; conspicitur, dum sub verbis proportionis \& iustæ mensuræ intelligit distributionem illam iustitiæ, sine qua Rempublicam saluam esse non posse, affirmant Plato \& Aristoteles, \& post hos Paulus ab Eytzen \& Hieronymus VVildenbergius. [...]." Wolff zitiert hier umfänglich die Visionärin Elisabeth von Schönau (1129-1164), umfangreicher noch in Bd. I, 362-363, ad a. 1150. Vgl. K. Köster, Elisabeth von Schönau, ${ }^{2}$ VL II (1980) 488-494; A.L. Clark, Elisabeth of Schönau. A Twelfth-Century Visionary (Middle Ages Series), Philadelphia 1992. Wolff scheint eine Schrift zum Thema geplant zu haben: „Quæ autem proportio aut iusta mensura hodie sit inter Imperatorem \& Papam, cuiusuis facilè est cernere, \& propediem de Imperatorum \& Paparum patrimonio prodibit tractatus." (ebd.).

88 Wolff (wie Anm. 1), II, f. ) $\left([6]^{\mathrm{r}}-\right)()\left([1]^{\mathrm{r}}\right.$. Wolff argumentiert hier schließlich reichsrechtlich mit den Beschlüssen des Reichstags von Augsburg im Jahr 1500, denen zufolge die Einkünfte aus Annaten und Vacantien, die ursprünglich für den Türkenkrieg eingerichtet worden seien, von den Päpsten zurückzufordern seien, die sie zwischenzeitig einbehalten hätten (ebd., f. ) ()$\left([1]^{\mathrm{r}}\right)$. Dieses Argument hat seinen berühmtesten Ort in Luthers Schrift An den christlichen Adel deutscher Nation von des christlichen Standes Besserung (1520); vgl. M. Brecht, Luther und die Türken, in: Europa und die Türken in der Renaissance, hg. von B. Guthmüller/W. Kühlmann (Frühe Neuzeit, 54), Tübingen 2000, 9-27, hier 11. Auch über Annaten plante Wolff eine Schrift: „(de quibus propediem, Deo dante, luculenter \& seriatim alibi)“ (II, f. ) ()$\left([1]^{\mathrm{r}}\right)$. Die weltlichem Glanz und weltlicher Herrschaft hingegebene Papstkirche wird als auch systemisch reformbedürftig, hier in kanonistischer Hinsicht, dargestellt: „[...]. Nam quanta confusione, \& contrariis inter se sententiis \& rationibus, Papatus defensores, quasi seipsos inuicem oppugnantes, dissideant, cognoscere licet ex contradictionum doctorum Romanæ Ecclesiæ, libro doctissimi Theologi Ioannis Pappi, Argentorati excuso. Et quantum etiam concilia \& canones sibi aduersentur, propediem proprio tractatu demonstrabitur." (ebd., f. $)\left(4^{r}\right)$ - ein weiterer nicht mehr verwirklichter Plan Wolffs. 
die Sehnen des Reichs nicht von den Gliedern abgeschnitten würden. ${ }^{89}$ Darüber hinaus blieb Wolff ratlos, denn einem solchen Zusammenwirken von militärischer Vorratswirtschaft und Kult, wie es Beispiele der alten Griechen lehrten, sei die Praxis seiner Gegenwart weit unterlegen. ${ }^{90}$

\section{Endzeiten in den Lectiones memorabiles}

In Wolffs polemischer Argumentation spielen das Ende der Zeit und das womöglich nah bevorstehende Jüngste Gericht erst in zweiter Hinsicht eine Rolle. Sie bilden jedoch einen der Fluchtpunkte mancher Einträge in den Lectiones memorabiles, ohne dass Wolff bestrebt gewesen zu sein scheint, die sich beispielsweise in den zeitgenössischen Praktiken und der Flugschriftenpublizistik bietende Fülle an potentiellen Endzeitdaten wiederzugeben. Szenarien und Akteure des endzeitlichen Geschehens, wie den Untergang Roms und des Römischen Reichs sowie den Antichrist, fand er vor allem im umfangreichen Corpus sibyllinischer Weissagungen thematisiert, das ihm von Autoren aller Jahrhunderte bis hin zu Onofrio Panvinio (1530-1568) geboten und kommentiert wurde. ${ }^{91}$

89 Wolff (wie Anm. 1), II, f. ) ()$\left([1]^{\mathrm{v}}\right.$ : „Cùm igitur ex multorum vatum prædictione tanta, tamq; horrenda extent de impendentibus malis vaticinia, de quibus in priorib. \& sequentibus; \& Ioan. Hilten monachus prædixerit, $[\ldots]$; cùm item $[. .$.$] in rota Ioachimi$ [...] his de causis vellent pii \& prudentes viri, multas Imperii gazas in meliores vsus conuerti, constitui legiones militu[m], sustentari exercitus perpetuos, qui contra hostes eius pugnarent, ne adeò debilitarentur principes Christiani, \& nerui Imperii membris præcidere[n]tur." Zu den hier ausgelassenen Textpassagen vgl. unten Anm. 101 und Anm. 106.

90 Wolff (wie Anm. 1), II, f. )()([1] $]^{\mathrm{v}}-2^{\mathrm{r}}$ : „In quo, proh dolor, etiam ab Ethnicis multum superamur: qui, vt Græcoru[m] historiæ docent, collectos thesauros suos in templo Delphico, quos ab initio belli, quod sacru[m] vocabant, [...]. Deus Opt. Max. tandem similiter cæco Papatui oculos Spiritu S. aperiat, vt in viam redeat, $\&$ abiectis mundanis fragilibus, cœlestia perpetua plus, quàm hactenus, spectet. || Talia igitur antecessorum $\&$ maiorum nostrorum fuerunt pia instituta, sapientia consilia, fortiaq; facta. At quib. nos hodie consiliis \& mediis pericula propulsamus?"

91 Wolff (wie Anm. 1), I, 50-89; 82-89, hier 82: „ONVPHRII PANVINII || VERONENSIS, FRATRIS EREMITAE \| AVGVSTINIANI DE SIBYLLIS ET \| CARMINIBVS SIBYLLINIS. || Ad Achillem Maffeum Ciuem Romanum. || LIBER." Vgl. J.-L. Ferrary, Onofrio Panvinio et les Antiquités romaines (Collection de l'École Française de Rome, 214), Rom 1996, 206: De sibyllis et carminibus sibyllinis liber ist ein Anhang zu De ludis saecularibus (gewidmet an Achille Maffei), das ein Teil der 1558 in Venedig erschienenen Fastorum libri $V$ a Romulo rege usque ad Imp. Caes. Carolum V Austrium [...] von Panvinio bildete. Wolff kann die Schrift in einem Heidelberger Nachdruck von

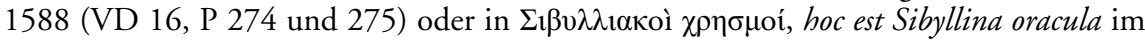
Druck Paris 1599 zur Kenntnis genommen haben. Zur Literatur der Oracula Sibyllina vgl. W. Augustyn, Zur Bildüberlieferung der Sibyllen in Italien zwischen 1450 und 1550, 
Die Daten der Jahrhundertwenden pflegten für apokalyptische Prophezeiungen kaum maßgeblich zu sein, und dies galt auch für die Jahreszahl 1600 als solche in den verschiedenartigen Zeugnissen gesteigerter eschatologischer Erwartungen, deren Erscheinen Wolff in der Annäherung an das neue Jahrhundert beobachten konnte. ${ }^{92}$ Er selbst dürfte diesem Jahreswechsel ebenfalls keine endzeitliche Emphase beigelegt haben, denn dieser bewegte ihn zu nicht mehr als komputistisch getönten Neujahrswünschen „pro felici auspicio huius noui seculi" an seine fürstlichen Gönner und Freunde aus Studienzeiten..$^{93}$ Im Textcorpus der Lectiones memorabiles ließ er Jahrhundertwechsel und auch den Jahrtausendwechsel unkommentiert vorüberziehen. Verdichtungen prophetischer Zeichen oder Ballungen apokalyptischer Warnungen finden sich nicht verzeichnet. $^{94}$

in: Zukunftsvoraussagen (wie Anm. 1), 365-435, hier 373-380. Der den heutigen Argumentationen über das vormoderne Wissen vom Antichrist gern zugrunde gelegte Brieftraktat des Abtes Adso von Montier-en-Der (um 930-992; zur Revision seiner Biographie vgl. Adsonis Dervensis Opera hagiographica, hg. von M. Goullet [CCCM 198], Turnhout 2003, VII-XXVI) De ortu et tempore Antichristi, der in neun Versionen überliefert ist, wurde im 16. Jahrhundert gedruckt in Opera-Ausgaben des Hrabanus Maurus (um 780-856) und des Augustinus (354-430) rezipiert; vgl. Adso Dervensis, De ortu et tempore Antichristi necnon et tractatus qui ab eo dependunt, hg. von D. Verhelst (CCCM 45), Turnhout 1976, 4, 91-94.

92 Vgl. Brendecke (wie Anm. 31), 45-74 zu 1300, 1400 und 1500. Besondere Endzeiterwartungen für 1500 lassen sich kaum belegen; vgl. J. Schilling, Der liebe Jüngste Tag. Endzeiterwartung um 1500, in: Jahrhundertwenden (wie Anm. 12), 15-26; H. Dormeier, Apokalyptische Vorstellungen in der italienischen Kunst um 1500, in: ebd., 2751, hier 27-28 und 50-51: apokalyptische Text- und Bildquellen dürften auf aktuelle Probleme und kaum auf die Jahreszahl 1500 reagiert haben. Zu 1600 vgl. Kaufmann (wie Anm. 36 und 48); Barnes (wie Anm. 12); H. Lehmann, Endzeiterwartung im Luthertum im späten 16. und im frühen 17. Jahrhundert, in: Die lutherische Konfessionalisierung in Deutschland. Wissenschaftliches Symposion des Vereins für Reformationsgeschichte 1988, hg. von H.-Chr. Rublack (Schriften des Vereins für Reformationsgeschichte, 197), Gütersloh 1992, 545-554 (Diskussion S. 555-558). Als ein besonderer Zeuge dessen gilt Daniel Schaller (1550-1630); vgl. H. Lehmann, Weltende 1630: Daniel Schallers Vorhersage von 1595, in: Jahrhundertwenden (wie Anm. 12), 147-161; Kaufmann (wie Anm. 48), 81-84; Ders. (wie Anm. 36), 126; Barnes (wie Anm. 12), 140-141. Vgl. auch Brendecke (wie Anm. 31), 110-118.

93 Wolff (wie Anm. 1), I, f. ) ()()$\left([4]^{v}\right.$ : „Hisce motus igitur \& ego, ne laudatas has consuetudines prætergredi velle viderer, Cels. V V. hanc primam Operis huius noui Lectionum Memorabilium \& Reconditarum Partem totam pro felici auspicio huius noui seculi offerre statui.“ Zum Jahreswechsel zu 1600 vgl. Brendecke (wie Anm. 31), $97-$ 109, bes. 109: der Jahrhundertwechsel wurde selten thematisiert.

94 Allenfalls ließen sich auffällige Naturzeichen geltend machen, die Wolff für die letzten Jahrzehnte des 10. Jahrhunderts aus verschiedenen Chroniken zusammengestellt hat, ohne jedoch einen Bezug zum bevorstehenden Jahr 1000 zu erwähnen; vgl. Wolff (wie Anm. 1), I, 269, 271. 
Dennoch macht auch Wolff ein aus Prophezeiungen resultierendes Gefühl des Bedrohtseins und zeitlicher Unmittelbarkeit geltend, das sich für ihn, wie erwähnt, mit den Johannes Hilten zugeschriebenen Voraussagen sowie dem Verständnis der Rota Ioachimi verband. ${ }^{95}$ Der Minorit Johannes Hilten (um 1425- um 1500) galt unter Lutheranern als ein Prophet Luthers, ${ }^{96}$ und als solchen präsentierte ihn Wolff zu 1502 in den Lectiones memorabiles in einem Bericht, dessen Elemente erklärtermaßen aus dem Artikel „De Votis Monasticis“ der Apologia Confessionis Augustanae des Philipp Melanchthon (1497-1560) stammten. ${ }^{97}$ Darin sollte Hilten für das Jahr 1516 jemanden prophezeit haben,

95 Vgl. oben S. 397-398 mit Anm. 89.

96 Vgl. Leppin (wie Anm. 12), 145-146, mit weiteren Nachweisen bei Melanchthon (die ebd., 146, Anm. 100, wiedergegebene, deutsche Paraphrase des Berichts über Hilten durch Hartmann Braun [1612, recte 1617] dürfte einer Übersetzung aus Flacius' Catalogus oder den Lectiones memorabiles entsprechen [s. unten Anm. 97: „ac tandem [...] non queant."]); weiterer Kontext ist die Zuschreibung einer Weissagung zu 1588 an Hilten (vgl. oben Anm. 12). Vgl. ferner H.-U. Hofmann, Luther und die JohannesApokalypse. Dargestellt im Rahmen der Auslegungsgeschichte des letzten Buches der Bibel und im Zusammenhang der theologischen Entwicklung des Reformators (Beiträge zur Geschichte der biblischen Exegese, 24), Tübingen 1982, 662-672; H.-J. Schönstädt, Antichrist, Weltheilsgeschehen und Gottes Werkzeug. Römische Kirche, Reformation und Luther im Spiegel des Reformationsjubiläums 1617 (Veröffentlichungen des Instituts für Europäische Geschichte Mainz, 88; Abt. für Abendländische Religionsgeschichte), Wiesbaden 1978, 228, 300; Kaufmann (wie Anm. 36), 115, 117-118; Ders. (wie Anm. 48), 98-99; Reeves (wie Anm. 48), 234, Anm. 5; F.W. Bautz, Hilten, Johann, Biographisch-Bibliographisches Kirchenlexikon II (1990) 870-871; V. Leppin, Hilten, Johann, RGG III (2000) 1738.

97 Wolff (wie Anm. 1), II, 4: „1502. Ioannes Hilten monachus Franciscanus, vates. || PHilippus in Apologia, in capite de votis monasticis narrat, fuisse monachum quendam Isennaci in Turingia, nomine Ioann. Hilten, qui ob reprehensos quosdam monasticos abusus, in carcerem coniectus fuerit, ac tandem grauiter laborans, ad se Guardianum conuentum [!] vocauerit, petieritque, sui morbi rationem haberi: $\&$ cùm insuper duriter ab eo obiurgatus esset, dixerit, se quidem nihil admodum contra monachatum docuisse: sed venturum anno 1516. qui sit monachos euersurus, ac cui repugnare planè non queant. Eo autem anno Lutherus docere incepit. || Quæ fuerit porrò eius doctrina, non satis indicat, sed tamen innuit, eum de aliis etiam quibusdam articulis satis rectè sensisse. Imperatore Maximiliano 1. PP. Alexandro 6. V.S. $\|$ Obiit in oppido Isenach in Thuringia, in carcere. Inter multos autem bonos libros, quos scripsit, etiam in Danielem edidit commentaria: \& prædixit varia, quæ euenerunt in vrbe Gotha. Scripsit propria manu, breui futuram esse mutationem doctrinæ religionis: \& doctrinam priorem abrogatum iri." Vgl. Apologia Confessionis Augustanae auctore Phil. Melanthone. B. Apologia altera, in: CR 27, Sp. 419-646, hier 627-628; Apologia Confessionis Augustanae, in: Die Bekenntnisschriften der evangelisch-lutherischen Kirche. Herausgegeben im Gedenkjahr der Augsburgischen Konfession 1930, 6., durchges. Aufl., Göttingen 1967, 139-404, hier 377,30-378,12. Vgl. Chr. Peters, Apologia Confessionis Augustanae. Untersuchungen zur Textgeschichte einer lutherischen Bekenntnisschrift (1530-1584) (Calwer Theologische Monographien. Reihe B: Systematische Theologie und Kirchengeschichte, 15), Stuttgart 1997, 246, zu Hilten betreffenden Redaktion(en) 
der das Mönchtum umstürzen werde. Eine Verbindung zwischen 1516 und dem Beginn des Lutherschen Lehrens wird in der Apologia allerdings nicht explizit hergestellt. Sie findet sich in Flacius' Catalogus testium veritatis, dessen Abschnitt über Hilten Wolff nahezu wörtlich übernommen hat. ${ }^{98}$ Flacius wie Wolff konnten dabei auf weitere Schriften Melanchthons zurückgreifen, in denen dieser mehr oder weniger ausführlich auf Hilten, dessen eigenhändig geschriebenen Danielkommentar und die darin enthaltene Prophezeiung zu 1516 zu sprechen gekommen war. ${ }^{99}$

Melanchthons einschlägige Berichte pflegten jedoch eine weitere Prophetie Hiltens zu enthalten, die auf eine nahe bevorstehende Zukunft zielte, indem sie für (etwa) 1600 die Herrschaft der Türken in Deutschland und Italien voraussagte. ${ }^{100}$ Wolff übernahm sie nicht, wenn es galt, das Jahrhundert des Re-

Melanchthons in der deutschen „Quartausgabe“ vom Oktober 1531; ebd., 440, zu Luthers Randbemerkung in der lateinischen „Quartausgabe“ vom Mai 1531 über eine Erinnerung aus seiner Jugendzeit an eine Erwähnung Hiltens. Wolff hatte Hilten bereits in der langen Reihe von Prophet/innen der Reformation und Luthers genannt, die er gleich bei Beginn seines Werks nach der Datierung und den Vorzeichen der Geburt Christi positioniert hatte; vgl. Wolff (wie Anm. 1), I, 3.

98 Catalogus testi- || VM VERITATIS, QVI || ante nostram ætatem recla- || marunt Papæ. || Opus uaria rerum, hoc presertim tempore $\|$ scitu dignißimarum, cognitione refertum, $\|$ ac lectu cumprimis utile atq; || necessarium. || Cum Præfatione MATHIÆ FLA- || CII Illyrici, qua Operis huius \& || ratio \& usus exponitur. || [...] || BASILEÆ PER IOAN- $\|$ nem Oporinum. || [1556], 1006: Zitat vom Anfang bis „... recte sensisse.“ Vgl. oben Anm. 44. Die Information über Hiltens Tod im Kerker konnte Wolff z. B. in der Postilla Melanthoniana, Die Epiphaniae, in: CR 24, Sp. 219-234, hier 225, finden (Druck 1594; vgl. ebd., Sp. XVII/XVIII-XIX/XX).

99 Vgl. z. B. MBW 6, 6435: Widmungsschreiben des Georg Maior an König Christian III. von Dänemark, verfasst von Melanchthon (5. Mai 1552), in: CR 7, 5112, Sp. 994-998, hier 995-996 (vgl. unten Anm. 101); MBW 6, 6450: Brief Melanchthons an Johannes Mathesius (18. Mai 1552), in: CR 7, 5124, Sp. 1006-1007; MBW 8, 8786: Vorrede Melanchthons zu: J[ohannes] F[unck], Anleitung zum vorstandt im buch das man nennet Apocalypsis, [...], Wittenberg 1559 (25. November 1558; kein Exemplar nachgewiesen); Postilla Melanthoniana, Dominica IIII Adventus, in: CR 24, Sp. 55-71, hier 64 (vgl. oben Anm. 98); Postilla Melanthoniana, Die Ioannis Baptistae, in: CR 25, Sp. 77-103, hier 80-81.

100 Universitätsschrift Melanchthons (18. Februar 1542), in: CR 4, 2450, Sp. 779-781, hier 780-781; MBW 6, 6438: Brief an Matthäus Collinus (7. Mai 1552), in: CR 7, 5114, Sp. 998-999, hier 999; MBW 6, 6450: Brief an Johannes Mathesius (s. Anm. 99), Sp. 1007; MBW 6, 6603: Brief an Matthäus Collinus (16. Oktober 1552), in: CR 7, 5235, Sp. 1106-1107, hier 1107; MBW 7, 6699: Brief an Johannes Bretschneider (September 1550), in: CR 7, 4783, Sp. 652-654, hier 653; MBW 7, 6841: Brief an Herzog Johann Albrecht von Mecklenburg (29. Mai 1553); MBW 7, 6892: Brief an Valentin Korte (10. Juli 1553), in: CR 8, 5429, Sp. 121-122, hier 121; MBW 7, 6952: Brief an Ulrich Mordeisen (27. August 1553), in: CR 8, 5460, Sp. 145; MBW 7, 7308 (mit MBW 6, 6611): Brief an Joachim Moller (18. Oktober 1554), in: CR 7, 5241, Sp. 1111-1112, hier 1112; MBW 7, 7688: Vorrede zu: Christoph Lasius, Das güldene Kleinot vom verlornen Schaf, Wittenberg 1556 (15. Januar 1556), in: CR 8, 
formators mit einer der den Lutheranern bedeutsamsten Prophetien zu eröffnen. Aber er nutzte sie argumentativ in einer personalisierenden Formulierung, die er offensichtlich einem 1552 von Melanchthon verfassten Widmungsschreiben entlehnt hat und die dieser nur einmal im Kontext der Vatizinien Hiltens verwendet hatte. Sie besagte, dass ein höchst schrecklicher Mensch ab 1600 über ganz Europa herrschen werde. ${ }^{101}$ Wiewohl Wolff die - von Melanchthon angenommene - Identifikation mit einem türkischen Tyrannen nicht aussprach, so legte er sie doch durch das Folgende nahe. Allerdings ließ er den von Melanchthon angeführten zweiten Teil der Voraussage über Gog und Magog im Jahre 1606 aus, so dass die Türken in dieser Perspektive Wolffs trotz des ihnen beigelegten Bedrohungspotentials nicht als die Endzeitmacht erschienen, die seit jeher unter dem Namen der beiden Endzeitvölker im kollektiven eschatologischen Bewusstsein verankert war. Auch vermied Wolff dadurch, am Ort einer möglichen persönlichen Meinungsäußerung, in einer Epistola nuncupatoria, ein bestimmtes Jahr als Beginn der letzten Ereignisse vor dem Weltende zu benennen.

Der zweiten erwähnten Prophetie, der Rota Ioachimi, maß Wolff eine so große Erklärungskraft zu, dass er sie auf dem Frontispiz beider Bände der Lectiones memorabiles mittig unterhalb des Titels abbilden ließ, ${ }^{102}$ verwiesen

5914, Sp. 663-666, hier 663; MBW 7, 7777: Empfehlungsschreiben für Simon Iessenius (1. April 1556), vgl. K. Karner, Melanchthoniana aus Ungarn, ARG 55 (1964) 66-70, hier 68-70 (mit Textabdruck); MBW 8, 9185: Vorrede zu: De origine Imperii Turcorum [...], Wittenberg 1560 (1. Januar 1560), in: CR 9, 6904, Sp. 1026-1027, hier 1026; Breves commentarii in Matthaeum, conscripti a Philippo Melanthone, in: CR 14, Sp. 543-1042, Caput XI., Sp. 839-850, hier 841; Postilla Melanthoniana, Dominica IIII Adventus (s. Anm. 98), Sp. 64; Postilla Melanthoniana, Dominica Trinitatis, in: CR 25, Sp. 1-28, hier 14 (aus strategischen Gründen würden die Türken erst Deutschland und dann Italien erobern). Vgl. Wolff (wie Anm. 1), II, 303-304, ad a. 1529, mit anderen, die zu erwartenden Türkenkriege betreffenden Exzerpten aus Schriften Melanchthons.

101 Wolff (wie Anm. 1), II, f. ) ()$\left([1]^{\mathrm{v}}:\right.$ „[...]; \& Ioan. Hilten monachus prædixerit, ab an. 1600. regnaturum homine[m] sæuissimum in vniuersa Europa; [...]" (vgl. oben Anm. 89). Widmungsschreiben (s. Anm. 99), Sp. 996: „Huius Hilteni manu et aliae multae sententiae scriptae sunt. Anno 1600. ait in Europa universa regnaturum esse hominem saevissimum; et mox in pagella altera inquit regnaturos esse Gog et Magog anno 1606. Opinor utranque praedictionem de Turcis loqui. Sed si diversae gentes peregrinae et barbarae significantur, quae simili crudelitate Europam vastabunt et inter sese dimicabunt, plus erit calamitatum. [...]. Est et terribilior explicatio horum vaticiniorum addita ipsius manu de tempore, quam diu Turcica tyrannis Europam reliquam vastatura sit." Vgl. dazu Kaufmann (wie Anm. 48), 100-101, Anm. 106. Zu Melanchthons Identifikation der Türken mit Gog und Magog vgl. C. Göllner, Turcica, III: Die Türkenfrage in der öffentlichen Meinung Europas im 16. Jahrhundert, Bucureşti/BadenBaden 1978, 337-338.

102 Vgl. Abb. 1. Das Titelblatt wird wiederholt in Wolff (wie Anm. 1), II, 938; statt des Titels findet sich ein erklärender, insbesondere Querverweise ins Werk herstellender 


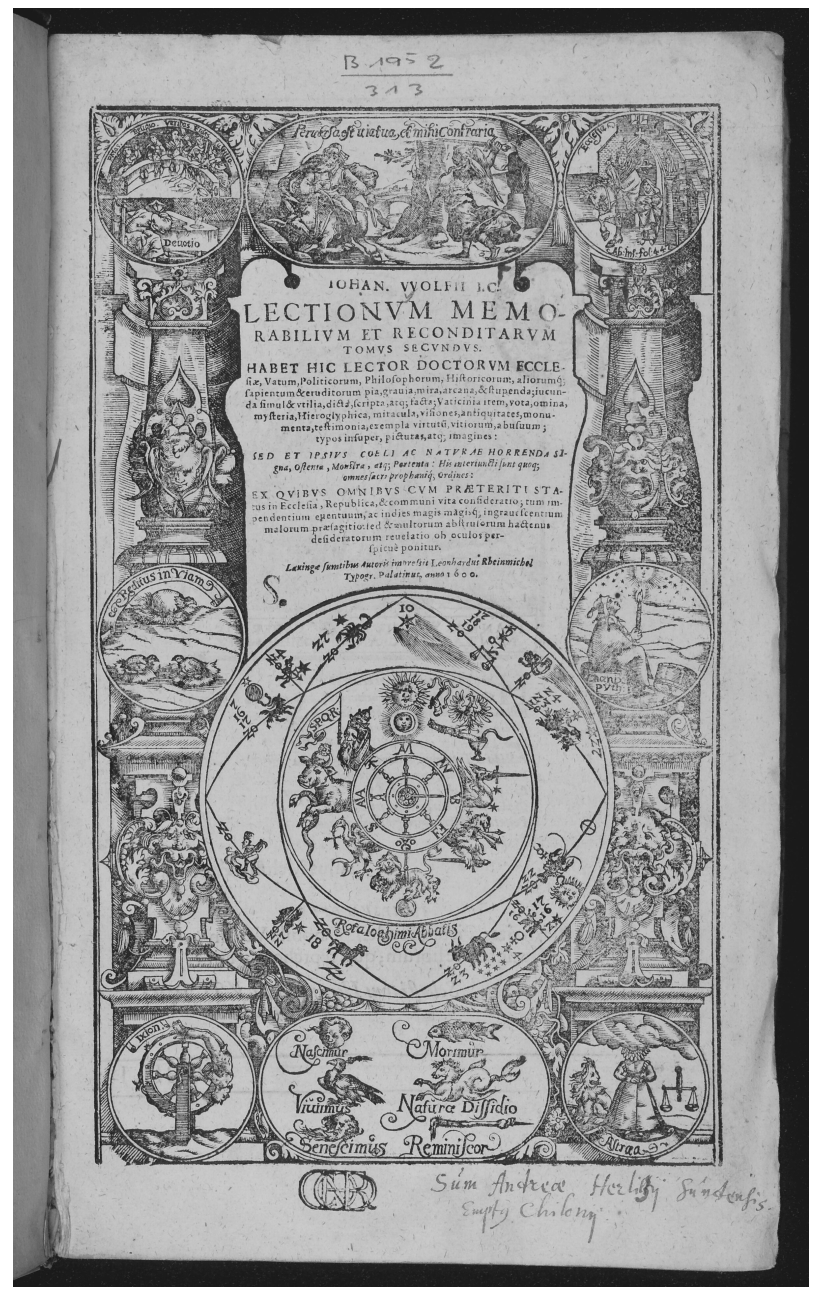

Abb. 1: Johannes Wolff, Lectionum memorabilium et reconditarum centenarii XVI., Bd. 2, Lauingen 1600 , f. $)\left([1]^{\mathrm{r}}\right.$. Mit freundlicher Genehmigung der Staats- und Universitätsbibliothek Hamburg Carl von Ossietzky (Signatur: B 1952 / 313: 2).

doch die acht Speichen des Rades auf Buchstabengruppen und geheimnisvolle Symbole, die üblicherweise als Papstprophezeiungen gedeutet wurden. Daher rückte Wolff im Anschluss an die dreißig Papstvatizinien, die er als erste der

Text; zur Deutung der Elemente der gesamten „pictura“ vgl. ebd., 939-940. In allen drei Fällen erscheint die Rota astronomisch-astrologisch eingebunden in den Zodiacus und Gestirnskonstellationen; vgl. dazu „Vaticinium antiquum, cuius hoc est schema synasterismi cœlestis prodigiosi, additum \& insertum (ne intercideret) his figuris, Ioachimicæq; Rotæ || circumpositum, [...].“(Verse), ebd., 941-942, Zitat S. 941. 
unter dem Namen Joachims von Fiore versammelten Schriften bzw. Exzerpte nach dem Venezianischen Druck des Hieronymus Porrus von 1589 wiedergegeben hatte, ${ }^{103}$ eine Erklärung der Rota ein, die er ebenfalls dort gefunden hatte. In ihr führte der Herausgeber und Kommentator Paschalinus Regiselmus jene Auslegung ad absurdum, die die ersten vier Symbole auf die Päpste Pius IV. (reg. 1559-1565), Pius V. (reg. 1566-1572), Gregor XIII. (reg. 1572-1585) und Sixtus V. (reg. 1585-1590) bezog. Allerdings wollte er der Figur auch nicht jegliches Vermögen, Bewunderung, Staunen oder Anregung zu bewirken, absprechen. ${ }^{104}$

Im zweiten Band kam Wolff noch einmal auf die Rota Ioachimi zurück, um nun eine neue, eine lutherische Auslegung vorzuführen. ${ }^{105}$ Für seine in der

103 Wolff (wie Anm. 1), I, 443-458; Interpretationen von Paschalinus Regiselmus, Paracelsus und Ioannes Adrasder (= Andreas Osiander) ebd., 459-488; Hinweis auf den Druck von 1589 ebd., 443. Vaticinia, || Siue || Prophetiæ || Abbatis || Iодснimi, || \& || Anselmi Episcopi || Marsicani, || Cum imaginibus are in- || cisis, correctione, et pul- \| critudine, plurium manu- $\|$ scriptorum exemplariu $[m] \|$ op $[\mathrm{er}]$ e, et uariaru $[m]$ imaginu $[m]$ || tabulis, et delineationibu[s], || alijs antehac impressis || longe prestantiora. Qviвus Rota, ET Oraculum Turcicum maxime considerationis adiecta sunt. Vna cum Præfatione, et Adnotationibus Paschalini Regiselmi. Venetiss Mdlxxxix cvm Privilegirs Apud Hieronymum Porrum. Unveränd. fotomech. Nachdr. Leipzig 1972. Zur Ausgabe vgl. The Late Medieval Pope Prophecies. The Genus nequam Group, hg. von M.H. Fleming (Medieval and Renaissance Texts and Studies, 204), Tempe, Arizona 1999, 5-6 mit Anm. 22. Zu Regiselmo vgl. Reeves (wie Anm. 48), 458-461; zu radförmigen Papstprophetien in Handschriften und Drucken des späten 16. Jahrhunderts vgl. Dies., Some Popular Prophecies from the Fourteenth to the Seventeenth Centuries, in: Popular Belief and Practice, hg. von G.J. Cuming/D. Baker (Studies in Church History, 8), Cambridge 1972, $107-134$, hier 127-128. Zu Joachim von Fiore in den Lectiones memorabiles vgl. künftig Schmolinsky (wie Anm. 68).

104 Wolff (wie Anm. 1), I, 459 (hier nur Abb. der rota): Rota Abb. Ioachimi, à Pio IV. (vt aiunt) in Solis \& Luna imaginibus incipiens, \& futura de Pontificibus predicens. \| De hac Ioachimi Rota iudicium \& declaratio Paschalini Regiselmi. Vgl. Vaticinia (wie Anm. 103), f. [a4] $]^{v}$, Überschrift; [Regiselmus], De rota statim post principium in primo folio, versa facie, subiecta iudicium, \& declaratio, ebd., f. $\mathrm{L}^{\mathrm{r}-\mathrm{v}}$ : „Nos eam [= rotam] proposuimus, $\&$ Porri desiderium, \& artem laudauimus, meditentur in ea curiosi, videantque, siquid in ea occultetur, quod ipsorum palato satisfaciat. Dicimus nos, si vera sit, admiratione, stupore, \& mentis commotione digna, \& plena de futuro Pontifice expectanda, pluresque annos præsenti dandos; [...]" (ebd., f. L L $^{\mathrm{N}}$ ).

105 Wolff (wie Anm. 1), II, 940-941: „Expositio noua figuraru[m] \& literarum quarundam Rotæ Ioa- || chimicæ, ex quibus Lector \& cæterarum intellectum facilè deprehendet. || ,LVna notat veteris tenebrosa oracula pacti: || Sol facit ista nouo manifesta volumine Christi. || [...] || [...]: Aquila hinc, quæ complicat alas, || Ore crucem gerit, \& curuatam in cornua lunam, $\|$ Sed tamen in regno magna virtute leones, $\|$ Atq; Heroës erunt: quorum moderamine quædam \|| Extremum circa mundi benè tuta manebunt, \| Non sine lugubri gemitu. Quia duplice Fato \| Turca tribus telis de nobis sumet acerbas \| Pœnas: nec penitus delebit, \& ensis acutus || Tantùm cluniculas feriet, caudamq; leonis. || F. geminum signat gemini crudelia fati || Damna: quibus multùm propter peccata 
Epistola nuncupatoria zum zweiten Band der Lectiones memorabiles geäußerte Auffassung über die Lage und die Bedürfnisse des Reichs ${ }^{106}$ findet sich in diesen Versen der Ursprung. Ihnen zufolge bedeutete „der Türke“, das Tier mit den drei aus seinem Maul hervorkommenden Wurfgeschossen, den Vollzug scharfer Strafen ,an uns“, nicht aber den völligen Untergang, zumal das scharfe Schwert in den Klauen des Tieres nur das Hinterteil und den Schwanz des auf das Reich verweisenden Löwen verletzte. Das zugeordnete doppelte „F“ sollte die besondere Grausamkeit der Unterdrückung wegen Sündhaftigkeit bezeichnen. In der Epistola nuncupatoria griff Wolff dies als verstärkten Aufruf zur Buße auf und bezog das kreuzartige „T“ im Schnabel des auf der Runde des Rads dem Löwen (im Uhrzeigersinn) folgenden Adlers auf Plagen und Elend, die künftig Haupt und Glieder mit ungeheuerlichem Schmerz bedrängen und erschrecken sollten. Zudem sei „VAT“, so entnahm Wolff es anderen Quellen, als Aufruf zur Kreuznahme zum eigenen Heil zu verstehen. Damit war er bei den von ihm für nötig gehaltenen politischen Konsequenzen der militärischen Bedrohung durch das Osmanische Reich angelangt. ${ }^{107}$

Die Türken ${ }^{108}$ sind in den Lectiones memorabiles als historisch-zeitgenössische wie als unmittelbar künftige Macht vielfach präsent. Ihre Endzeitlichkeit

prememur. || [...]. || Stellæ demonstrant errorum dogmata vana, || Quæ specie pietatis habent lethale venenum. || V. Siquidem librum, \& blasphemos denotat astus. || Bellum portendit gladius. [...] || [...]. "Die rota wird in diesen Versen gegen den Uhrzeigersinn gelesen; zu einer Marginalnotiz vgl. unten Anm. 106.

106 Wolff (wie Anm. 1), II, f. )()([1] ${ }^{\mathrm{v}}$ (im Anschluss an das Zitat in Anm. 101): „[...] cùm item duplices literæ $\mathrm{F}$ [umgekehrtes]F in rota Ioachimi suprà part. 1. fol. primo sub imagine bestiæ Turcica tela euomentis innuant, nos duplici FATO ad supplicium rapi; \& per literam T. quam Aquila ore gestat, crux \& miseriæ significentur, quibus non solùm caput, sed etiam membra tam immani dolore prementur, \& terrebuntur, vt nullo modo solui ab iis ante mortem possint; cumque hoc mysterium per conuersione[m] literarum plus innotescat, quia VAT est imperantis, \& capitur pro arripe, \& hoc intellectu omnes admoneantur, vt crucem arripiant, eaque se seruent, \& illa ceu fune firmissimo sese in salutis portu retineant atque figant: (vt author est Angelus Caninius Anglariensis, Antonius Cheuallerius, Abrahamus de Balmis, \& Goropius Beccanus) his de causis [...]“ (vgl. oben Anm. 89). Der Text von „hoc mysterium [...]“ bis „[...] Goropius Beccanus“ findet sich nur geringfügig variiert auch Wolff (wie Anm. 1), II, 941, marginal zu den oben in Anm. 105 zitierten Versen, in denen er inhaltlich kein Äquivalent besitzt.

107 Vgl. oben S. 397-398 mit Anm. 89.

$108 \mathrm{Zu}$ Anschauungen, Reaktionen und Kontakten in den europäischen Ländern des späten 15. und des 16. Jahrhunderts vgl. die Beiträge in: Europa und die Türken in der Renaissance, in Hinsicht auf Wolff bes. Brecht (wie Anm. 88); zum Erbfeindsyndrom im Reich vgl. W. Schulze, Reich und Türkengefahr im späten 16. Jahrhundert. Studien zu den politischen und gesellschaftlichen Auswirkungen einer äußeren Bedrohung, München 1978, 21-66. Zu den politischen Konstellationen zur Zeit des sog. Langen Türkenkriegs vgl. J.P. Niederkorn, Die europäischen Mächte und der „Lange Türkenkrieg“ Kaiser Rudolfs II. (1593-1606) (Archiv für österreichische Geschichte, 135), Wien 1993. 
war in protestantischer Perspektive, aber nicht nur in dieser, vornehmlich in der Exegese des alttestamentlichen Buchs Daniel und damit in den Vorstellungen von der weltgeschichtlichen Abfolge der vier Reiche verankert. ${ }^{109}$ Augenfälliger präsentierte Wolff die zu erwartende Rolle der Türken durch die Übernahme längerer Abschnitte aus den Revelationes des Pseudo-Methodius nebst Passagen aus einem Traktat des Augsburger Klerikers Wolfgang Aytinger (um 1465-nach 1508), den dieser seiner Ausgabe der Revelationes von 1496 bei Johann Froschauer in Augsburg beigegeben hatte. Wolff las und exzerpierte dieses Textcorpus in dessen von Sebastian Brant mit Illustrationen versehener Ausgabe, die 1498 bei Michael Furter in Basel erschienen war. ${ }^{110}$ Aytinger hatte die Aussagen des Pseudo-Methodius dahingehend vereindeutigt, dass er die filii Ismahel als Türken identifizierte, die ein römischer König besiegen werde. ${ }^{11}$ Bei Francesco Sansovino (1521-1583) fand Wolff verschiedene Prophezeiungen, die den Untergang des Osmanischen Reichs als bald bevorstehend bezeichne-

109 Vgl. A. Seifert, Der Rückzug der biblischen Prophetie von der neueren Geschichte. Studien zur Geschichte der Reichstheologie des frühneuzeitlichen deutschen Protestantismus (Beihefte zum AKG, 31), Köln/Wien 1990, 11-27, 34-35.

$110 \mathrm{Zu}$ Aytinger, zu Brants Ausgabe und deren Inhalt vgl. W. Ludwig, Eine unbekannte Variante der Varia Carmina Sebastian Brants und die Prophezeiungen des Ps.-Methodius. Ein Beitrag zur Türkenkriegspropaganda um 1500, Daphnis 26 (1997) 263-299, hier 275-291 und 297-298. Vgl. auch Schmolinsky (wie Anm. 1), 113-115. Die in Wolff (wie Anm. 1), I, 43-45, aus Aytinger/Brant übernommenen Textpassagen der Revelationes entsprechen mit Abweichungen: Die Apokalypse des Pseudo-Methodius. Die ältesten griechischen und lateinischen Übersetzungen, hg. von W.J. Aerts/G.A.A. Kortekaas, I-II (CSCO 569/570; Subsidia 97/98), Leuven 1998; Bd. I, [11],7, S. 143,3 - [11],13, S. 147,7; [11],17, S. 155,17 - [12],2, S. 157,4; [12],2, S. 157,4 - [12],5, S. 161,7; [12],8, S. 163,1 - [13],2, S. 165,1; [13],6, S. 169,1 - S. 171,11 und [13],11, S. 175,1-7; [13],17-19, S. 181-183; [14],11-12, S. 195 und 197. Die Bilder in den Lectiones memorabiles weichen z. T. von denen der Ausgabe Brants ab. Zur Prophetie des Pseudo-Methodios vgl. H. Möhring, Der Weltkaiser der Endzeit. Entstehung, Wandel und Wirkung einer tausendjährigen Weissagung (Mittelalter-Forschungen, 3), Stuttgart 2000, 54-104; Ders., Der Arabersturm, die Endkaiser-Weissagung der Christen und die Mahdī-Erwartung der Muslime, in: Ende und Vollendung. Eschatologische Perspektiven im Mittelalter, hg. von J.A. Aertsen/M. Pickavé (Miscellanea Mediaevalia, 29), Berlin/New York 2002, 193-206, hier 193-201. Zu Aytingers Ausgabe in Hinsicht auf Gog und Magog vgl. A.C. Gow, The Red Jews. Antisemitism in an Apocalyptic Age, 1200-1600 (Studies in Medieval and Reformation Thought, 55), Leiden/New York/ Köln 1995, 132-133 mit Abb. S. 386-387.

111 Pseudo-Methodius hatte einen griechischen oder römischen König genannt; vgl. Die Apokalypse (wie Anm. 110), [13],11, S. 175,2; weiterhin ist von einem römischen König die Rede; vgl. Möhring, Weltkaiser (wie Anm. 110), 99 mit Anm. 405 und 406. Kapitelüberschrift und Text bei Aytinger differierten nun; vgl. Wolff (wie Anm. 1), I, 45: „Ibidem. Quomodo Turci post victoriam lati existentes, \& con- || uiuantes, à Romano Rege inter ebulas opprimuntur. \| [...]. Tunc subitò insurget super eos Rex Græcorum, siue Romanorum, in furore magno, [...]." $\mathrm{Zu}$ Aytingers entsprechenden Auffassungen in seinem Traktat vgl. Ludwig (wie Anm. 110), 288-291. 
ten. ${ }^{112}$ Die 1570 in Modena gedruckte Prophetiensammlung des alchimistischen Autors Giovanni Battista Nazari (2. Hälfte 16. Jahrhundert) Discorso della futura et sperata vittoria contra il Turcho. Estratto da i sacri profeti \& da altre Profetie, Prodigij, \& Pronostici: \& di nuouo dato in luce. Per Gio. Battista Nazarri Bresciano. gab Wolff in einer ins Lateinische übersetzten Fassung wieder. ${ }^{113}$ Der dort neben zahlreichen anderen Weissagungen erscheinenden türkischsprachigen Prophezeiung Patissahomoz, die der einmal errungenen osmanischen Herrschaft über die Christen ein rasches Ende prognostizierte, hatte Wolff zuvor bereits besondere Aufmerksamkeit gewidmet, indem er ihren ersten lateinischbuchstabigen, mit einer lateinischen Übersetzung und Kommentierung versehenen Druck, der 1545 von Bartolomej Georgijević (Đurđević, 1505/ 1510 -nach 1566) in Antwerpen veranstaltet worden war, in sein Werk aufgenommen hatte. ${ }^{114}$ Ein von Jacobus Francus, i.e. Conrad Lautenbach (1534-

112 Wolff (wie Anm. 1), II, 803, ad a. 1560: „Idem Sansouinus edidit libellum anno 1570. 26. Aprilis, in quo vaticinia quædam, $\&$ inter cætera de Turcico quoque Imperio, ad rem nostram maximè conducentia, recenset. Quòd nimiùm \& Turca \& Iudæi, Mahometum magum fuisse, confiteantur, ipsiusque leges non vltra mille annos duraturas, prædictum sit. Alterum vaticinium, Turcici Imperij dominum decimum quintum ei finem impositurum esse, testatur." Wolff hatte die „Origo Mahometis“ zu 623 eingeordnet; vgl. ebd., I, 186. Bei dem Büchlein dürfte es sich um Sansovinos italienische Lettera o vero discorso sopra le predittioni fatte in diversi tempi da diverse persone Le quali pronosticano la nostra futura felicità, per la guerra del Turco l'anno 1570. [...] handeln; vgl. C. Göllner, Turcica. Die europäischen Türkendrucke des XVI. Jahrhunderts, II: MDLI-MDC, Bucureşti/ Baden-Baden 1968, 206-207, Nr. 1269 (Datierung: 20. April 1570). 1560/1561 hatte Sansovino sein sehr erfolgreiches dreibändiges Sammelwerk Dell'Historia universale dell'origine et imperio de Turchi in Venedig publiziert; vgl. A. Höfert, Den Feind beschreiben. „Türkengefahr“ und europäisches Wissen über das Osmanische Reich 14501600 (Campus Historische Studien, 35), Frankfurt a. M./New York 2003, 138-141; Göllner (wie Anm. 101), 240.

113 Wolff (wie Anm. 1), II, 884-898, hier 884: „1572. DISCVRSVS DE FVTVRA ET SPERA- \| TA VICTORIA CONTRA TVRCAM: E SACRIS PRO- \| phetis, alijsq; vaticinijs, prodigijs, \& prognosticis depromtus, ac nouiter in $\|$ lucem datus per Iohannem Baptistam Nazarum Brixiensem, || lingua Italica, typis Venetianis Sigismundi Bordognæ; || Latinè redditus per Theosophiæ studiosum || quendam virum. || Vnio conspirat sancta, incursura colubrum." Der Widmungsbrief an die Stadt Brixen ist auf den 1. Mai 1570 datiert (ebd.). Vgl. Göllner (wie Anm. 112), II, 205, Nr. 1266; Abb. des Frontispiz ebd., 203 (mit dem bei Wolff wiedergegebenen Motto).

114 Wolff (wie Anm. 1), II, 893; 55-60, hier 55: „1513. Prognoma siue Presagium Mehemetanorum, primùm de Chri- || stianorum calamitatibus, deinde de sue gentis interitu, ex Persica lingua in Latinum || sermonem conuersum, Authore Bartholomeo Georgieuits. Vgl. Göllner (wie Anm. 112), I: MDI-MDL, Bucureşti/Berlin 1961, 401, Nr. 853; Ders. (wie Anm. 101), 341; Höfert (wie Anm. 112), 77; zu Georgijević ebd., 211-214, passim. Wolff, ebd., 60-61, lässt die Interpretation der Prophetie durch Paschalinus Regiselmus folgen, die er im Venezianischen Druck der Papstvatizinien gefunden hatte; vgl. Vaticinia (wie Anm. 103), f. L2 ${ }^{\mathrm{r}}-[\mathrm{L} 3]^{\mathrm{r}}$; Text und Übersetzung ebd., f. [H4] $]^{\mathrm{v}}-\mathrm{I}^{\mathrm{r}}$. Die Prophetie erscheint mehrfach im zweiten Band der Lectiones memorabiles im Kontext 
1595), bekannt gemachtes, angeblich in Paderborn aufgetauchtes Versvatizinium über das letzte Jahrzehnt des 16. Jahrhunderts prophezeite, wie Hilten, für 1600 das Hervorbrechen der Türken aus dem Orient und sah ihre Rückkehr in die Heimat als unwahrscheinlich an. ${ }^{115}$ Gleichermaßen inserierte Wolff auch Voraussagen, die den Zusammenbruch Roms oder der Welt auf astronomischastrologischer Basis ankündigten. Ausführlich ließ er David Herlitz zu Wort kommen, der das Ende der Türken und einen allumfassenden endzeitlichen Umsturz für 1603 errechnet hatte und daher Hiltens Prophetie für gerechtfertigt hielt. $^{116}$

So endzeitlich die zu erwartenden osmanischen Angriffe empfunden wurden und durch wie katastrophische Prophezeiungen sie festgeschrieben sein mochten, so eindeutig erschien Wolff allerdings, dass es sich bei den Türken nicht um eine Verkörperung des Antichrist handelte. Das Argument stützte sich auf den neutestamentlichen locus classicus der antichristlichen Erkennungsmerkmale, den zweiten Thessalonicherbrief $(2,4)$ : „,... Also / das er sich setzt in den tempel Gottes / als ein Gott / vnd gibt sich fur / er sey Gott. " ${ }^{\text {117 }}$ Offensichtlich

diverser Exzerptgruppen; vgl. z. B. Wolff (wie Anm. 1), II, 971-973, hier 971, bei Adam Nachenmoser ad a. 1588. Nachenmosers 1588 in Leiden (i.e. Straßburg) gedrucktes Prognosticon theologicum (vgl. VD 16, N 19) findet sich auch umfänglich und teils schematisiert exzerpiert in Crusius' Tagebuch; vgl. Diarium III, 92,21-96,16 (6. Juni 1600). Zu Nachenmoser vgl. Barnes (wie Anm. 28), 121-124, 138, 293, Anm. 57, passim.

115 Wolff (wie Anm. 1), II, 1026: „Idem. Badelbornæ in VVestphaliâ præsagi rhythmi quidam sunt inuenti, qui futura ad annum vsque 1600. protendunt; vt: ,Anno 1590. Hoc anno video; si quid præsagia possunt: || Quòd doleat magnis Austria tot a malis. \| [...] . \| Anno 1600. Tum modè de terris Turcæ gradientur Eois: \| At puto non illos posse redire domum.“ „Idem“ bezieht sich auf „Jacobus Franco“ (ebd., 1025, ad a. 1595); unter diesem Pseudonym publizierte der Frankfurter evangelische Prediger, Dichter und

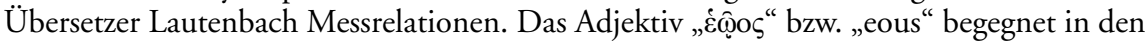
Revelationes des Pseudo-Methodius und entspricht ,orientalis'; vgl. Die Apokalypse (wie Anm. 110), 148, 186 (Wörterverzeichnisse mit Stellenangaben). Zur Thematisierung der „Türkengefahr“ sowie zur Paderborner Weissagung vgl. Kaufmann (wie Anm. 48), 92 93, 95.

116 Vgl. z. B. Wolff (wie Anm. 1), II, 637: „1552. Lucas Gauricus Mathematicus. || PRædixit, ruinam Romæ fore circa annum 1598. propter certas causas ex doctrinâ directionum Astrologicarum desumtas. Quem citat ac sequitur \& Dauid Herlitzius Mathematicus. Imp. Carolo 5. Pp. Iulio 3.“ Zu Luca Gaurico (1475-1558) vgl. F. Bacchelli, Gaurico, Luca, Dizionario Biografico degli Italiani LII (1999) 697-705. Herlitz zitiert Wolff (wie Anm. 1), II, 1042-1044, ad a. 1597. Vgl. Kaufmann (wie Anm. 48), 94-95, 99-104; Leppin (wie Anm. 12), passim. Zu Hilten vgl. oben S. 400-402. Auch Crusius nahm umfangreiche Exzerpte aus Herlitz' Schrift über den Untergang des türkischen Reichs in sein Tagebuch auf; vgl. Diarium I, 197,22-200,20 (29. September 1596); vgl. Nennung bei den Neuerscheinungen ebd., 316,31-32 (1. April 1597).

117 Biblia: das ist: || Die gantze Heilige || Schrifft: Deudsch || Auffs new zugericht. || D. Mart. Luth. || Begnadet mit Kur= \| fürstlicher zu Sachsen Freiheit. \| Gedruckt zu Wittem $=\|$ berg / Durch Hans Lufft. M.D.XLV., hg. von H. Volz unter Mitarbeit von 
saßen jedoch nicht die Türken im Tempel Gottes, sondern, für Lutheraner eine Selbstverständlichkeit, das Papsttum. ${ }^{118}$

Diese revelatio des Antichrist durch Luther, Basis und Ausgangspunkt der Lectiones memorabiles, bedeutete für Wolff, sich mit biographischen Elementen der Antichristvita nicht eingehender befassen zu müssen. Vorstellungen von einem personalen Ursprung des Antichrist aus dem Stamm Dan galten ihm als papistische Träumereien. ${ }^{119}$ Der Papstantichrist war vielmehr an wiederkehrenden, kollektivbiographisch gesetzten Merkmalen zu erkennen, wie sie das antithetisch aufgebaute Passional Christi et Antichristi Lukas Cranachs d. Ä. von 1521 bot. ${ }^{120}$ Wolff druckte es zu 1557 in der lateinischen, 18 Bildpaare um-

H. Blanke, Textredaktion F. Kur, I-III (dtv text-bibliothek), München 1974, hier III, 2387.

118 Wolff (wie Anm. 1), II, 946: „1582. Gilbertus Genebrardus. || [...] || Hic Genebrardus etiam alicubi Turcam Antichristum dicit, sed errat. Antichristus enim in templo Dei sedebit, quod ille non facit, sed Papa. 2. Thes. 2." Gilbert Génébrard (1537-1597) war Theologe und Orientalist; vgl. F. Laplanche, Génébrard, Gilbert, OSB, LThK ${ }^{3}$ IV (1995) 444-445. Vgl. Seifert (wie Anm. 109), 18. Zu Luthers Antichristdeutung vgl. Leppin (wie Anm. 12), 206-207, 214-220; zum Kriterium des Tempels, i.e. der Kirche, ebd., 218-219, 223; zur binnenkonfessionellen Publizität der Antichristidentifikation ebd., 220-243. Angesichts der uneinheitlichen, mit Einschränkungen vorgehenden luther(an)ischen Anwendung des Antichristbegriffs auf die Türken (vgl. ebd., 237-238) sind die interpretatorischen Varianten von Bedeutung, die sich insbesondere aus der Danielexegese hinsichtlich des Bestands der vierten Weltmonarchie ergaben; vgl. Seifert (wie Anm. 109), 11-20, 28-37, passim. Zu konfessionsspezifischen Deutungen der Türken vgl. M. Pohlig, Konfessionskulturelle Deutungsmuster internationaler Konflikte um 1600 - Kreuzzug, Antichrist, Tausendjähriges Reich, ARG 93 (2002) 278-316, hier 288-291. Zur Entwicklung von Luthers Antichristverständnis vgl. Richardsen-Friedrich (wie Anm. 53), 78-133; zu Verbreitung und Polemik ebd., 134241; in der zweiten Hälfte des 16. Jahrhunderts ebd., 242-261; zur Polemik dieser Zeit ebd., 261-371. Zur reformatorischen „Präteritisierung' des Antichrist“ vgl. Seifert (wie Anm. 109), 7-10.

119 Wolff (wie Anm. 1), I, 823, ad a. 1440, zum hebräischen Danielkommentar des R. Leui ben Gerson: „[...] vbi Pontificem Romanum bestiam illam à propheta descriptam vocat, eumque Pharaonem appellat. Hinc refutantur somnia papistarum dicentium, Antichristum quendam singularem oriturum de tribu Dan, [...]." Ausführlich zitiert Wolff Matthaeus Sutlivius (Matthew Sutcliffe, 1550-1629), De vera Christi Ecclesia, zum Thema Antichrist und Papstantichrist; ebd., II, 1001-1007, ad a. 1592, hier 1005: „Dicit [= Robert Bellarmin SJ, 1542-1621], Antichristum vnum tantùm hominem fore, eumque ex tribu Dan nasciturum: nondum autem venisse: sed cùm tandem venerit, Henochum \& Eliam occisurum esse: \& postquàm aliquot menses Hierolymis regnârit, interfectum iri. || Ridicula pleraq; \& falsa. [...]. || Nihil enim frequentius in sacris literis, quàm vt sub singulari numero plures eiusdem speciei comprehendantur."

120 WA 9 (1893), 677-715 (Hg. G. Kawerau), Abb. im Anhang. Vgl. Leppin (wie Anm. 12), 218, 221, 226-229. Kursorisch zu den Nachschnitten bei Wolff K. Groll, Das „Passional Christi und Antichristi“" von Lucas Cranach d. Ä. (Europäische 
fassenden Version „Antitheses. De præclaris Christi et indignis Antichristi facinoribus" des Simon Rosarius zusammen mit einer Interpretation ab, ${ }^{121}$ nachdem er bereits zum Jahr 1500 eine lateinische, aus 15 Distichen bestehende "Antithesis Christi \& Antichristi“ von Konrad Nucer eingeordnet hatte. ${ }^{122}$ Gewissermaßen als biographische Typologie ,ad malam partem'veranschaulichten die Bilder und Texte die Widerchristlichkeit der Päpste durch die Konfrontation mit der Vita Christi. Das Verfahren kulminierte im 17. Bildpaar in der Himmelfahrt bzw. einem Höllensturz und endete mit der Gegenüberstellung zweier Gesetzesübergaben: der göttlichen an Moses und einer seitens des Teufels an den päpstlichen Antichrist.

Weiterhin legte Wolff Wert darauf, seinem Lesepublikum wiederholt den Nachweis zu erbringen, dass die römische Kirche von Anfang an und durchgängig für Babylon gehalten und ihr Oberhaupt Antichrist genannt worden war. Besonders prägnant ließ sich dies mittels einer von dem Juristen und Historiker Simon Schard (1535-1573) zusammengestellten Liste von Zeugnissen zeigen, die Wolff vollständig abdruckte. ${ }^{123}$ War hier der erste

Hochschulschriften. Reihe 28, 118), Frankfurt a. M./Bern/New York/Paris 1989, $110-111$ mit 116 .

121 Wolff (wie Anm. 1), II, 711-747, [ad a. 1557], hier 711: „ANTITHESES. || DE PRÆCLARIS, CHRISTI ET || INDIGNIS ANTICHRISTI FACI- || noribus: || HOC EST, \| DESCRIPTIO VERI PASTORIS || CHRISTI, ET ECONTRA ET LVPI, \| [...] \| à $\|$ SIMONE ROSARIO CIRCA HOC \| tempus editus est hic libellus cum imagi- \| nibus sequentibus. || [...].“; mit S. 748-751: „De prestantissimis Christi, \& indignissimis Antichristi \| Moribus, viri fidelis declaratio." Als Antithesis [...] 1557 in Genf erschienen; vgl. WA 9 (1893), 695-696; Hinweis auf Wolffs Nachdruck ebd., 696.

122 Wolff (wie Anm. 1), I, 957. Vgl. WA 9 (1893), 685: Aus inhaltlichen Gründen können die Verse erst aufgrund des Passionals Cranachs von 1521 verfasst worden sein.

123 Wolff (wie Anm. 1), II, 839-844, ad a. 1565: „TESTIMONIA EX TRIGINTA MA- ॥ xime authoritatis scriptoribus, qui Romam Babylonem, \| eiusq; Episcopum Antichristum certò statuerunt: à Simone Schardio I.C. Im- \| perialis Camere assessore, in vnum collecta \& edita."; übernommen aus: HYPOMNEMA, || DE FIDE, OBSERVAN- || TIA, AC BENEVOLENTIA \| Pontificum Romanorum erga Impe- \| ratores Germanicos, collectum ex ue $\|$ ris atque fidelibus historiarum mo- $\|$ numentis, à S. S. S. [...] BASILEA, PER \| Ioannem Oporinum. [1566], 170-191, hier 170: „TESTIMONIA EX || VARIIS AVTORIBUS COL- || lecta, Romam Babylonem esse, || eiusq[ue] Episcopu[m] iure An- || tichristum dici. || QVia superiùs Romam aliquoties Babylonem, eiusque episcopum Antichristum nominaui, ne quis id me citra autoritatem fecisse existimet, testimonia aliquot ueterum scriptorum, qui itidem fecerunt, subiungere libuit: ut ex ijs elucescat, \& ab ipsis Romam pro Babylone, eiusq; præsidem pro Antichristo habitum fuisse. [Diese Einleitung fehlt bei Wolff.] 1 Initio itaq;, urbem Romam Babylonem esse, ipse angelus Dei affirmat, exponens Apocalyp. 17 Ioanni euangelist[a]e uisionem bestiæ, habentis septem capita, [...]. "Die Liste umfasst nur 29 Zeugnisse, zuletzt nach Wolff, ebd., 844: „29. VVolffgangus Aitinger, clericus Augustanus, qui prophetias Methodij commentarijs illustrauit, contendit, Antichristum non in corporea, sed mystica Babylone nasciturum. Ea verò, teste Petro, Roma est. || Hisce alia quoque similia testimonia quàm plurima adduci possent: [...]." Vgl. 
Beleg bereits in der Apokalypse des Johannes gegeben, so ließ Wolff den Beginn des antichristlichen Papsttums mit dem als erstem Papst geltenden Leo I. (440-461) einsetzen, indem er Erörterungen zu den Dekreten des Konzils von Chalkedon (451) einen Abschnitt über die betrügerischen Machenschaften der Päpste zur Erlangung des Primats folgen ließ. ${ }^{124}$ Zudem machte er der Geschichte des Papsttums unterliegende Strukturen namhaft, die sich bei Autoren historischer und prophetischer Materien, wie Onofrio Panvinio oder Theophrastus Paracelsus (1493/1494-1541), finden und auf eine grundlegende Veränderung von Kirche und Welt nach 1600 schließen ließen. ${ }^{125}$ Diese Strukturen speisten sich aus Zahlenproportionen - bei-

Wolff, ebd., 2, ad a. 1502 zu Aytinger. Zu Schard, der u. a. Rat bei Herzog Wolfgang von Zweibrücken war (vgl. oben Anm. 4), vgl. Eisenhart, Schard, ADB XXX (1890) $581-583$.

124 Vgl. Anm. 125. Wolff (wie Anm. 1), I, 144-146, ad a. 451 und 458. Vgl. R. Schieffer, Leo I. d. Gr., LexMA V (1991) 1876-1877. Zum Anfang des päpstlichen Antichristentums vgl. K. Koch, Europa, Rom und der Kaiser vor dem Hintergrund von zwei Jahrtausenden Rezeption des Buches Daniel (Berichte aus den Sitzungen der Joachim Jungius-Gesellschaft der Wissenschaften e.V., Hamburg, Jg. 15, Heft 1), Hamburg 1997, 104: In der protestantischen Auslegung des Buchs Daniel finden sich verschiedene Päpste als Beginn der Verderbnis genannt: Leo I. oder Gregor I. (590604) oder Leo III. (795-816). Wolff bemerkt zu Gregor I. (ebd., 172-176, ad a. 596), dass dieser den Kaiser von Konstantinopel als Herrn anerkannt und viele Irrtümer und Missbräuche des schon sich ausbreitenden Antichrist bekämpft habe (ebd., 172); die Zeit Leos III. und Kaiser Karls des Großen sieht er kritischer: „Hoc tempore verè illud de Ecclesia Romana dici potuit, venenum (diuitiarum) in illam infusum fuisse: [...]." (ebd., 211, ad a. 800).

125 Wolff (wie Anm. 1), II, 443: „1540. Mutatio status Ecclesiastici \& politici post annum 1600. || ex Onuphrio, Theophrasto, \& alijs. || Proportio Romanorum Pontificum in membrorum || numero, \& in nominum mysterijs talis est. || De origine noui \& vltimi Romani Imperij, videlicet || 56. Pontificibus, qui per 40. annos à Syluestro primo vsque ad Pontificem Constantinum || Syrum, qui primus sibi à Casare Iustiniano pedes osculari passus est, sub || Imperatore Constantino vixerunt. PEr hos quadringentos annos Papa solus sibi primatum quæsiuit, [...]." Statt 40 dürften 400 Jahre gemeint sein. Die Einordnung zu 1540 dürfte sich einer Weissagung des Paracelsus verdanken: „Theophrastus Paracelsus circa annum Christi 1540. antequàm noster iam Imperium tenens Rudolphus, longè clementissimus Cæsar natus esset (post 10. videlicet annos) mortuus est: \& tamen vaticinatus is est, ad hunc nostrum Imperatorem, nomine \& annis digitum intendens, dicensque: inter $\mathrm{R}$ primum \& $\mathrm{R}$ secundum, 303. annos fore. Quod ex sequentibus rationibus benè prædicere longè antè potuit. $\|$ [...]." (ebd., 445). Paracelsus war 1541 gestorben, Rudolf II. von Habsburg, Kaiser von 1576 bis 1612, 1552 geboren worden. Zu 1541 gab Wolff die weitverbreitete Prognosticatio an Ferdinand I. (1531/1556-1564) von 1536 wieder, allerdings nicht in der lateinischen Fassung des Dichters und Freunds von Paracelsus Marcus Tatius Alpinus, sondern in einer lateinischen Übersetzung des Theologen und Hofpredigers in Neuburg a.d. Donau, des „vir doctiss[imus]“ David Schram(m) (1559-1615), den er zu 1590 als „amicus singularis mihi“ bezeichnet; vgl. Wolff (wie Anm. 1), II, 484-501 sowie ebd., 979-980, Zitat S. 979. Vgl. C. Gilly (Red.), Paracelsus in der Bibliotheca Philoso- 
spielsweise den Anzahlen von Pontifikaten in analogen Zeitabschnitten und offenbarten geheimnisvolle Verbindungen bestimmter Namen mit bestimmten Wirkungen: Bonifatius, Leo und Gregorius hätten sich als Krisen indizierende Namen herausgestellt. ${ }^{126}$ Der dritte und letzte Niedergang des neuen Römischen Reichs seit Kaiser Konstantin d. Gr. (reg. 306-337) errechne sich aus den Abständen von je 75 Jahren der beiden vorangegangenen Niedergänge 1452 und 1527 für 1602 und betreffe die politische wie die kirchliche Macht. ${ }^{127}$ Zweifellos werde der gerade gewählte Gregor XIV. seinem Papstnamen entsprechend mindestens bis dahin regieren. ${ }^{128}$ Hier irrte der Redaktor - Wolff, Simon Studion oder wer immer - bzw. ließ den zeitlichen Rahmen seiner Arbeit erkennen, denn Gregor XIV. (*1535), Papst vom 5. Dezember 1590 bis 16. Oktober 1591, und sein wirklich die vatikanische Politik führender Kardinalnepot Paolo Camillo Sfondrati

phica Hermetica Amsterdam. Ausstellung zum 500. Geburtsjahr des Theophrastus Bombast von Hohenheim, Paracelsus genannt, Amsterdam 1993, 41, Nr. 20; K. Sudhoff, Bibliographia Paracelsica. Besprechung der unter Theophrast von Hohenheim's Namen 1527-1893 erschienenen Druckschriften (Versuch einer Kritik der Echtheit der Paracelsischen Schriften. I. Theil: Die unter Hohenheim's Namen erschienenen Druckschriften), Berlin 1894, 431, Nr. 250.

126 Wolff (wie Anm. 1), II, 443. Später vermerkte Wolff ähnliche, die Gegenwart betreffende, buchstaben- und zahlenmystische Verfahren eines anderen Autors; vgl. ebd., 1024: „1595. Eustachius Poyssel. || HOc tempore ædidit scripta varia Eustach. Poyssel, de claue Dauid, de fine mundi anno 1623. futuro, mutatione temporum, \& alia. Producit autem ex vocabulis \& numeris multa mystica, Vbi inter cætera vide, quænam ex Româ, VVittebergâ, Heydelberga, Luthero, Rudolpho, \& similibus nominibus cogat \& eruat. Imp. Rud. 2. Pp. Clem. 8."Zu Poyssels Schriften vgl. VD 16, P $4523-$ 4534.

127 Wolff (wie Anm. 1), II, 443: „Primum Romani Imperij decrementum seu ruina accidit, imperio græco declinato, atq; Constantinopoli, noua Roma, à Turcis occupata, anno salutis partæ 1452. || Secundum, quod sub Carolo V. in pontificatu Romano euenit, sub Leone X. initium sumsit: \& paulò pòst etiam Roma, sub Clemente VII. anno redemtionis humanæ 1527 . est occupata. \| Quòd verò tertium \& postremum decrementum circa annum Christi 1600. euenturum sit: ipsum docet tempus, inter primum \& secundum decrementum interceptum, 75. videlicet anni, qui annis 1527. additi, faciunt 1602. annos: circa quos vltimum decrementum Imperij Romani eueniet, cùm in politica, tum in Ecclesiastica potestate seu regimine." Vgl. Anm. 125.

128 Wolff (wie Anm. 1), II, 444-445: „Vt sub Gregorijs supremum potestatis culmen acquisiuit, gladioque obtinuit: [...]. $\|[\ldots]$ \&, si iam electus Papa Gregorius XIV. cognominatur patet inde, regimen ipsius cum ætate diu duraturum, \& absq; dubio vsq; ad tempus anni Christi 1600. aut etiam vltrà, protensum iri. Nam circa id tempus, $\&$ pòst, demum res finietur. Quæ autem porrò de Romano imperio, \& mundano \& Ecclesiastico, vsque ad diem nouissimum supererunt: tantùm reliquiæ eius, ac nihil aliud, quàm schismata, cùm in politico, tum in Ecclesiastico regimine erunt. Vt enim numeri potentum atque annorum, in Romanis Pontificibus, circa iam sæpius citatum tempus incipiunt: ita etiam in Romanis Imperatoribus, \& politicis monarchis, finiuntur." 
(1561-1618, Kardinal seit 19. Dezember 1590) sollten weder lange noch im Sinn des hier dem Papstnamen beigelegten Nimbus amtieren. ${ }^{129}$ Eine dergestalt abweichende Entwicklung der Papstgeschichte dürfte allerdings weder für Wolff noch für seine zeitverwandten Leser die Voraussagen über die Endzeit nach 1600 oder 1602 falsifiziert haben.

Nach bisheriger Kenntnis am deutlichsten behauptete Wolff seine Beteiligung bei der Deutung eines Vatiziniums, das er als ein dem Minoriten Johannes von Capestrano $(1386-1456)^{130}$ zugeschriebenes zu 1444 in den Lectiones memorabiles abdruckte und mit Erklärungen versah. ${ }^{131}$ Der Einleitung zufolge sollte es sich dabei um eine vorchristliche Bildprophetie handeln, deren Auslegung Johannes Carion um zehn Jahre missraten war. Erst dem frommen schlesischen Mönch „Capistranus“, einem hervorragenden Astronomen und Propheten, sei, nach anfänglichem Scheitern, im Zusammenhang mit seinen astronomischen Berechnungen eines Deutschland und dem Römischen Reich schrecklichste Übel ankündigenden Kometen

129 Vgl. G. Schwaiger, Gregor XIV, LThK ${ }^{3}$ IV (1995) 1022. Zu Gregor XIV. vgl. Wolff (wie Anm. 1), II, 998. Zu Simon Studions prognostischen Aktivitäten notierte Crusius in seinem Tagebuch (vgl. oben Anm. 30) am 6. Juli 1596: „Literas à M. Simone Studione accipio: ubi se de suis prognosticis declarat.“ (Diarium I, 127,17-18); am 13. April 1597: „M. Studionis vaticinia, nostro Principi grata sunt, qui in eum liberalis est. Filius interea pro eo docet." (ebd., 323,32-33; vgl. ebd., 415,9-10); am 20. November 1598: „Additi sunt varii numeri M. Sim. Studionis, M. [= manu] scripti, de completione prophetiarum, per Numeros, etc." (Diarium II, 135,8-9). Wolff (wie Anm. 1), I, 312, ad a. 1095, zeigte ein sich in der Klosterkirche von Alpirsbach (Württemberg) befindendes Bild, dessen Protagonisten (Lamm, Abt, Mensch, Wolf, Bär, einige Objekte) ebd., 313-320, in einem langen Gedicht von Studion ausgelegt wurden: „In huius mysticæ figuræ \& historiæ carmen $\|$ Simonis Studion.“ (ebd., 313); darin u.a.: „ANTICHRISTVS SVB IMAGINE \| Abbatis in cathedra sedens."

130 Als Überblick über Leben und Schriften vgl. E. Paratore, S. Giovanni da Capestrano, in: S. Giovanni da Capestrano nella Chiesa e nella società del suo tempo. Atti del Convegno storico internazionale Capestrano - L'Aquila 8-12 ottobre 1986, hg. von E. \& L. Pasztor (Comitato per il VI Centenario della nascita di San Giovanni da Capestrano), L'Aquila 1989, IX-XXIV; K. Elm, Die Bedeutung Johannes Kapistrans und der Franziskanerobservanz für die Kirche des 15. Jahrhunderts, ebd., 373-390.

131 Wolff (wie Anm. 1), I, 824-831, hier 824: „1444. Ioannes Capistranus, Monachus Silesius. “ 1621 wurde der Text mit Bezug auf Wolff wiederabgedruckt; vorangestellt findet sich eine deutsche Übersetzung des Einleitungsteils und der Prophetie selbst: CAPISTRANI Prophezey / || Vom Zustand des Roe= || mischen Reichs. || Seit der Offenbahrung deß Heiligen || Evangelij. || Gedruckt im Jahr 1621. [s. 1.]; vgl. VD 17, 14:3063G. Ebd., f. A $3^{\mathrm{r}}$ : „Diese Figur sampt des Capistrani außlegung / findet sich auch in Johannis VVolfij lectionibus memorabilibus, sub centnario [!] decimo quinto, ad annum Christi 1444. Tom.1. pag. 824. darzu VVolfius selber etliche notas vnd observationes setzet; vnd lauten seine eigene wort daselbst also: [...]“; ebd., f. $\mathrm{C}^{\mathrm{v}}$ : „Hactenus Wolfius.“ 
ihre Bedeutung aufgegangen. Bild und Auslegung habe er in einer Mauer dergestalt versteckt, dass sie erst nach seinem Tod gefunden werden konnten. ${ }^{132}$ Welcher Provenienz auch immer die Darstellung der Vorgeschichte sein mag, so kann doch das sprechende Ich der Consideratio „à me data" mit Wolff in Verbindung gebracht werden, da die Daten der Ereignisse, auf die angespielt wird, eines Interpreten seiner Lebenszeit bedurften. Dabei stand für ihn nicht fest, ob wirklich Capestrano der Verfasser des Vatiziniums gewesen sei. ${ }^{133}$

Inhaltlich gehört es zum weiten Kreis der politisch-zeitgeschichtlich aufgeladenen Endzeitprophetien. Nach besonders für 1547 vorhergesehenen Umwälzungen vor allem in Frankreich und der Verlegung des Papstsitzes nach Mainz sagte "Capistranus“ eine Friedenszeit auf Erden voraus, in der der gesamte Klerus wieder apostelgleich leben und niemand Papst sein wollen würde. ${ }^{134}$ Des Interpreten Erklärungen bereiten jedoch textkritische

132 Wolff (wie Anm. 1), I, 824: „Vaticinium 20. annis ante natum Christum lapidi impres$\|$ sum, \& Venetias anno 1495. ex vrbe Altina allatum, de Romani Imperii \& Anti- \| christi ruinâ: ex Capistrani reuelatione, || DIgna quædam supra modum admiratione imago, prophetiaque, lapidi insculpta annis ante Christum 20. ex aduerso Venetiarum in petra, ita, sine omni tamen explanatione, reperta fuit: Superior illius pars Regis, altera Præsulis nomen legentium oculis proponebat. Nemo autem, quid sibi vellet, expedire audebat. Vnicus M Ioannes Carion, illâ hominum aliquot interitum, miserasque fortunæ acerbitates significari, haruspicabatur. Verùm non rectè assecutus est. Anni etenim decem, certum erroris ipsius indicium fecêre. Vixit autem nostra tempestate pius quidam in monasterio apud Silesios monachus, Capistranus nomine, excellens, \& in præstantissimis Astronomiæ cultoribus eminens, vates in multis probatus: [...], Germaniæ vniuersæ Imperioque Romano damnum miseriasq; ineuitabiles apportaturum coniecit: \& cum interpretamento suo picturam, pergamento capsulæque traditam, in tutiori muri parte collocauit: signis tamen adiectis, vt, ipso vitæ huius miseriis per mortem erepto, posset inueniri: vt \& factum est 1548. anno." Wolff, ebd., 825, präzisiert im Titel der sich anschließenden Consideratio \& explicatio prophetice Capistrani, Monachi || Silesij, [...]: 1547 sei die Prophetie ans Licht gekommen und 1548 gedruckt worden.

133 Wolff (wie Anm. 1), I, 829: „Prophetia. || HAc interpretatione à me data, prophetia latinis literis scripta, in figuram suprà positam confecta, absque imagine mihi offertur. An verò Capistranus sit autor, nécne? mihi non constat. Ab illa tamen Capistrani expositione non admodum abhorret: quam hîc positam cum Capistrani scriptis conferemus. Sic autem habet, vt sequitur: [...]“. Es folgt ein Vergleich mit des „Capistranus" Auslegung einer verwandten, 1444 in Ungarn entdeckten und 1460 anlässlich eines Kometen von ihm gedeuteten Bildprophetie (ebd., 830-831). Die Bilder ebd., 824, bzw. zu Beginn des Drucks von 1621 (siehe Anm. 131), f. Av, vereinen Elemente beider figurae.

134 Wolff (wie Anm. 1), I, 825: „EGo Capistranus, sanctis Dei ministeriis addictus, per certissimam Dei reuelationem, veram huius imaginis explanationem, \& factâ à me huius Cometæ inquisitione, magnam regnorum mutationem, inprimis verò anno 1547. præuidi. || [...]. Sedes verò Romana Moguntiam transferetur. Quin munus eorum deferetur ad alios: qui id cum maiori Dei timore, sumtibusque non ita profusis 
Schwierigkeiten, da die ihnen jeweils vorangestellten prophetischen Passagen vom zuvor gegebenen Text abweichen. Wolff hielt die Kriegsprognose für $1547 \mathrm{im}$ Krieg der Protestanten in den Jahren 1547, 1548 und 1549 für erfüllt und identifizierte die französischen Könige Karl IX. (reg. 1560-1574) und Heinrich III. (reg. 1574-1589) sowie wiederholt Geschehnisse in Frankreich, Belgien und Deutschland. Nun - nach 1589 sehe man sich „in secundi impetus fine, tertii autem initio“. Gegen dessen Ende werde ein friedvoller Herrscher auftreten. ${ }^{135}$ Wohl 1613, einer anderen Rechnung zufolge 1605-1615, würden das Römische Reich und der dritte Ansturm enden. Die nach dem Buch Daniel und der Apokalypse zwischen diesem Untergang der letzten Herrschaft des Antichrist und dem Weltende eingeschobene Frist von 45 Jahren hinzugezählt, werde 1650 oder 1660 die Welt untergehen. ${ }^{136}$ Künftig, zur Zeit der letzten Anstrengung des Papsttums, bedürfe es der Einigkeit „unserer" protestantischen Fürsten und eines tragfähigen Bündnisses zwischen Franzosen, Deutschen und den Völkern am Rhein. ${ }^{137}$ Wolff beabsichtigte, sich andernorts deutlicher über seine aus

administrabunt. [...]. || Quin etiam, qui tunc viuent, cogitabunt, Deum, antiquamq; pacem sitam esse in terrâ: idque ad tempus duntaxat. Eo tempore Papa, Cardinales, Archiepiscopi, cuncti ex clero, vi \& malo ad priscam Apostolorum viuendi rationem compellentur. Nec quisquam tunc, qui Papa velit esse, inuenietur. [...].“

135 Wolff (wie Anm. 1), I, 826: „Explicatio. || ACta sunt hæc in tristi illo Protestantium bello, annis 1547. 48. 49. [...]. Declaratio. \| HÆc satis superque in prioribus Galliæ regibus, Carolo huius nominis nono, fratreque Henrico, ætas superior fuit experta. Atque hinc, in secundi impetus fine, tertii autem initio constitutos nos, videmus." Ebd., 827: „Prophetia. || CAdente autem impetu tertio Leone, homo mira animi magnitudine constantiaque F. quidam Aquisgrani in locum eius euehetur. || Explanatio. || HVius superiùs quoq; facta est mentio. An autem is F. nomen habiturus sit, aut potiùs pacifici (quò aliorum etiam respectant vaticinia) aliis diiudicandum relinquo. Tempus certè, omnia reuelans, satis declarabit.“ Im Weiteren wird der künftige König nur „N.“ benannt (ebd.; vgl. ebd., 828).

136 Wolff (wie Anm. 1), I, 827: „Interpretatio. || IPsum Imperii Romani, tertiique incursus finem (anno ni fallor 1613. futurum, vt sequetur) ex prophetia Danielis \& Apocal. 45. anni suggerunt: quorum non libellus modò, sub Sibyllarum nomine dispersus, verùm Hieronymus quoque in suo ad vltimum Danielis caput commentario meminit: aitq; tot à finali vltimaque regni Antichristi ruina ad mundi finem annos relictos. Hic igitur anno 1650. vel 1660. est futurus: quod tempus multæ computationes \& vaticinia plurima haud malè proponunt." Vgl. R.E. Lerner, Refreshment of the Saints: The Time after Antichrist as a Station for Earthly Progress in Medieval Thought, Traditio 32 (1976) 97-144. Wolff, ebd., 828: „Designatio. || [...]. Tribus itaque incursionibus constitutis, singulisque annis 30. adiunctis, circa annum à Christo nato 1610 . aut fortè citiùs, 1605. aut tardiùs, 1615. complentur. Circa quos equidem, ex omnibus vaticiniorum coniecturis, Antichristi ruinam, regni Christi amplificationem, \& si quæ alia Capistrani sunt iudicia, reperio esse futura.“

137 Wolff (wie Anm. 1), I, 827: „Explicatio. || HÆc fieri in Rege N. incipient. Et notandum diligenter, pios in hoc tertio impetu, væque tertio, hoc est, conatu Papæ vltimo, alium, præter illum, defensorem habituros neminem. Quin, nisi principes 
Schriften von Propheten gewonnenen Erkenntnisse über die Zukunft zu äußern, aber auch dieser Plan verging im individualeschatologischen Ende. ${ }^{138}$

Endzeit, wie sie im christlichen Horizont weltgeschichtlich zu erwarten ist, zeigt sich historisch als eine Frage nach Endzeiten, nach Daten und Zeiträumen, die Bedeutung erlangen, sofern Geschichtsmodelle kanonisch gesetzt sind, die eine rechenbare Dauer der Welt, wie etwa 6000 Jahre, vorsehen. Zu Wolffs Zeiten verdichteten sich für die Zeitgenossen insbesondere lutherischer Konfession ${ }^{139}$ die seit Jahrzehnten oder Jahrhunderten vertrauten Diskurse von Verderbtheit, Strafandrohung und Buße, die in solchen der Umkehr und der Reform konvergierten. In den Lectiones memorabiles waren sie kompendienhaft in der Sprache der Gelehrsamkeit zu besichtigen. ${ }^{140}$ Auch sie belegen, dass Sinnformationen der longue durée reformatorische Inhalte in ihren eigensten Argumenten überwölbten, ${ }^{141}$ obwohl die Enthüllung des Papstantichrist als eine der Bruchfiguren gelesen wurde. Noch war die Endzeit chronologisierbar, und noch war sie im Spiel, wenn Handlungsoptionen und Handlungsaufforderungen für eine politica

nostri, veram Euangelii doctrinam profitentes, viribus animisque fuerint coniuncti, sua non obtinebunt. Atque omninò stabile concorsq; inter Gallos, Germanos, Rheniq; populos foedus (neq; enim alio modo Pontificiorum consilia \& conatus infringemus) necessarium erit." Höchstens drei Päpste seien nach dem letzten Herrscher zu erwarten; ebd.: „Significatio. || [...]: ita hîc quoque certis ex coniecturis (quarum rationes, causæq; alibi) Pontificatum cathedramq; Romanam planè sub Pontifice post N. N. perituram: neq; plures post hunc, quàm tres, ad tertii impetus finem secuturos, affirmamus. Et hic tertius etiam, vltimusq; Romani Imperii, vbi Roma miserè deuastata excindetur, casus est." Der geweissagten Verlegung des Papstsitzes nach Mainz wusste Wolff allerdings keinen Sinn abzugewinnen; vgl. ebd.

138 Wolff (wie Anm. 1), I, 828: „Verum de his, ex Prophetis à me confirmatis, alibi dilucidiùs. Hîc autem prophetiam, ipsam quoque obscurè procedentem, breuiter attingere placuit. Qui verò pleniorem \& prolixiorem huius rei desiderat historiam, in practicis Theologicis, anno 1589. luci donatis videto: in quibus certas eiusdem rationes, ex Prophetis satis luculenter, licet meliùs fieri potuisset, extructas \& adductas cognoscet." (vgl. auch oben Anm. 74).

139 Zur konfessionellen Formierung astrologischer und apokalyptischer Prognostik in der zweiten Hälfte des 16. Jahrhunderts vgl. Smolinsky (wie Anm. 12).

140 Die Lectiones memorabiles lassen sich zu Teilen auch als Reservoir von Argumenten für das ohnehin Gewusste verstehen, wie Leppin (wie Anm. 12), 220-222, dies als „konfessionelle[...] Binnenfunktion" der repetitiven deutschsprachigen Antichristpublizistik beschreibt (ebd., 221; vgl. 37-38; zur lutherisch-konfessionellen Orientierung durch apokalyptische Publizistik vgl. ebd., 283-285, auch 278-279). Im Blick auf sein intendiertes Publikum war und musste Wolffs Anspruch ein weiter reichender sein, indem er Zeugnisse diverser europäischer Provenienzen, gegebenenfalls übersetzt, präsentierte.

141 Vgl. B. Jussen/C. Koslofsky, `Kulturelle Reformation` und der Blick auf die Sinnformationen. Einleitung, in: Kulturelle Reformation. Sinnformationen im Umbruch 1400-1600, hg. von Dens. (Veröffentlichungen des Max-Planck-Instituts für Geschichte, 145), Göttingen 1999, 13-27, hier 15-16, 22-24 (B. Jussen). 
christiana in Kirche und Welt $\mathrm{zu}$ diskutieren und $\mathrm{zu}$ kommunizieren waren. ${ }^{142}$

142 Verwendete Abkürzungen: ARG = Archiv für Reformationsgeschichte; $C R=$ Philippi Melanthonis Opera quae supersunt omnia, hg. von K.G. Bretschneider/H.E. Bindseil (Corpus Reformatorum, Bd. 1-28), Halle, [ab Bd. 19, 1853:] Braunschweig 18341860, repr. New York and London/Frankfurt a. M. 1963; Diarium = Diarium Martini Crusii, [Bd. I]: 1596-1597, hg. von W. Göz/E. Conrad, Tübingen 1927; [Bd. II]: 1598-1599, hg. von Dens., Tübingen 1931; [Bd. III]: 1600-1605, unter Mitwirkung von R. Rau/H. Widmann hg. von R. Stahlecker/Eu. Staiger, Tübingen 1958; [Bd. IV]: Gesamtregister, bearb. von Eu. Staiger, Tübingen 1961; MBW = Melanchthons Briefwechsel. Kritische und kommentierte Gesamtausgabe, hg. von H. Scheible, Bd. 1 ff., Stuttgart-Bad Cannstatt 1977 ff.; Bd. 6: Regesten 5708-6690 (1550-1552), bearb. von H. Scheible/W. Thüringer, 1988; Bd. 7: Regesten 66918071 (1553-1556), bearb. von Dens., 1993; Bd. 8: Regesten 8072-9301 (15571560), bearb. von Dens., 1995; VD 16 = Verzeichnis der im deutschen Sprachbereich erschienenen Drucke des XVI. Jahrhunderts - VD 16 -, hg. von der Bayerischen Staatsbibliothek in München in Verbindung mit der Herzog August Bibliothek in Wolfenbüttel, I. Abt.: Verfasser - Körperschaften - Anonyma, 22 Bde., Stuttgart 1983-1995; VD 17: Verzeichnis der im deutschen Sprachraum erschienenen Drucke des 17. Jahrhunderts, ULR: http://www.vd17.de; ${ }^{2}$ VL: Die deutsche Literatur des Mittelalters. Verfasserlexikon, 2. Aufl., hg. von K. Ruh/G. Keil/W. Schröder/B. Wachinger/F.J. Worstbrock, 10 Bde., Bd. 11: Nachträge und Korrekturen, Berlin/New York 1978-2004; WA = D. Martin Luthers Werke. Kritische Gesammtausgabe, Bd. 1 ff., Weimar 1883 ff. 
